\title{
WestVirginiaUniversity
}

THE RESEARCH REPOSITORY @ WVU

Graduate Theses, Dissertations, and Problem Reports

2007

\section{Characterization of a series hydraulic hybrid diesel vehicle}

Joshua W. Flaugher

West Virginia University

Follow this and additional works at: https://researchrepository.wvu.edu/etd

\section{Recommended Citation}

Flaugher, Joshua W., "Characterization of a series hydraulic hybrid diesel vehicle" (2007). Graduate Theses, Dissertations, and Problem Reports. 4300.

https://researchrepository.wvu.edu/etd/4300

This Thesis is protected by copyright and/or related rights. It has been brought to you by the The Research Repository @ WVU with permission from the rights-holder(s). You are free to use this Thesis in any way that is permitted by the copyright and related rights legislation that applies to your use. For other uses you must obtain permission from the rights-holder(s) directly, unless additional rights are indicated by a Creative Commons license in the record and/ or on the work itself. This Thesis has been accepted for inclusion in WVU Graduate Theses, Dissertations, and Problem Reports collection by an authorized administrator of The Research Repository @ WVU. For more information, please contact researchrepository@mail.wvu.edu. 
Characterization of a Series Hydraulic Hybrid Diesel Vehicle.

Joshua W. Flaugher

Thesis submitted to the College of Engineering and Mineral Resources

at West Virginia University in partial fulfillment of the requirements

for the degree of

\author{
Master of Science \\ in \\ Mechanical Engineering \\ Mridul Gautam, Ph.D., chair \\ W. Scott Wayne, Ph.D. \\ Benjamin C. Shade, Ph.D.
}

Department of Mechanical and Aerospace Engineering

Morgantown, West Virginia

2007 


\title{
Characterization of a Series Hydraulic Hybrid Diesel Vehicle.
}

\author{
Joshua W. Flaugher
}

\begin{abstract}
The objective of this study was to evaluate the performance and emissions profiles of a prototype Series Hydraulic Hybrid Diesel Vehicle (SHHDV). The test vehicle was a collaborative effort between Parker-Hannifin and Autocar. The outcome of which was an extensive set of data and a compilation of "lessons learned," which were to be applied for further development of these vehicles. Research is needed in this area for developing a better understanding of the benefits from hydraulic hybrids. The vehicle platform used in this study was that of Autocar's Xpeditor model, a diesel powered cabover refuse truck. The hydraulic hybrid and a baseline vehicle were evaluated on the West Virginia University (WVU) Transportable Heavy-Duty Vehicle Emissions Testing Laboratory with two test cycles that were developed using in-use data provided by Parker-Hannifin and Autocar from a refuse vehicle route. The first cycle, labeled Saginaw Pick-Up (SPU), mimicked the stop-and-go driving typical of a vehicle's operation during real-world refuse collection. The second cycle, labeled Saginaw Transport Cycle (STC), mimicked the high speed transport seen during the vehicle's operation to and from the point of origin. The testing gave insight to the potential of this technology with valuable information for further refinement. The hybrid vehicle was successful in following the low speed stop-and-go test cycles; however it was unable to fully attain the designed high speed transport cycle. In the end, the hybrid test vehicle failed to achieve its primary goals of overall emissions reduction and improved fuel economy. The hybrid produced an average of $23.4 \%$ more carbon dioxide $\left(\mathrm{CO}_{2}\right), 11.8 \%$ lower oxides of nitrogen (NOx) and 21.9\% lower fuel economy during the low speed SPU test cycles. For the high speed STC tests, the hybrid vehicle only followed the test cycle adequately during one of the tests (STC 2). During STC 2 the hybrid vehicle produced $8.27 \%$ more $\mathrm{CO}_{2}, 5.85 \%$ lower NOx and $19.4 \%$ lower fuel economy.
\end{abstract}




\section{ACKNOWLEDGEMENTS}

I would like to start off by thanking Dr. Mridul Gautam for being my advisor and providing funding throughout graduate school and research. Thank you for your help and guidance that has led me through school and into my career. I thank Dr. Scott Wayne for his expertise and advice when it came to issues pertaining to my project. I also have to thank Dr. Benjamin Shade for assistance during testing of not only my project but other projects I was working on at the university. Ben became a good friend and someone instrumental to the completion of my masters degree.

I also need to give special thanks to Thomas Spencer, Dave McKain, Dan Carder and staff. Tom gave me the opportunity to work as an hourly at the ERC which provided valuable experience and a stepping stone to my graduate career. I want to thank Dave McKain for helping me develop the test cycles used for this experiment and Dan Carder who was a blast to work with and was a wealth of knowledge. I also wish to thank the entire Westover staff for their hard work during the long hours of testing on this project.

While obtaining my masters I worked very closely on a variety of projects with Thomas McConnell, Petr Sindler and Robin Ames and numerous other wonderful coworkers. I learned a lot while working with these guys and they helped make school a lot of fun and I feel lucky to have worked with such a talented group of individuals.

To my friends (you know who you are) and family, you provided me with invaluable support and friendship along the way. My parents' guidance simply made all of this possible and I have to thank my friends being there for me. I apologize for leaving people out but I do thank everyone who helped make this a reality. 


\section{TABLE OF CONTENTS}

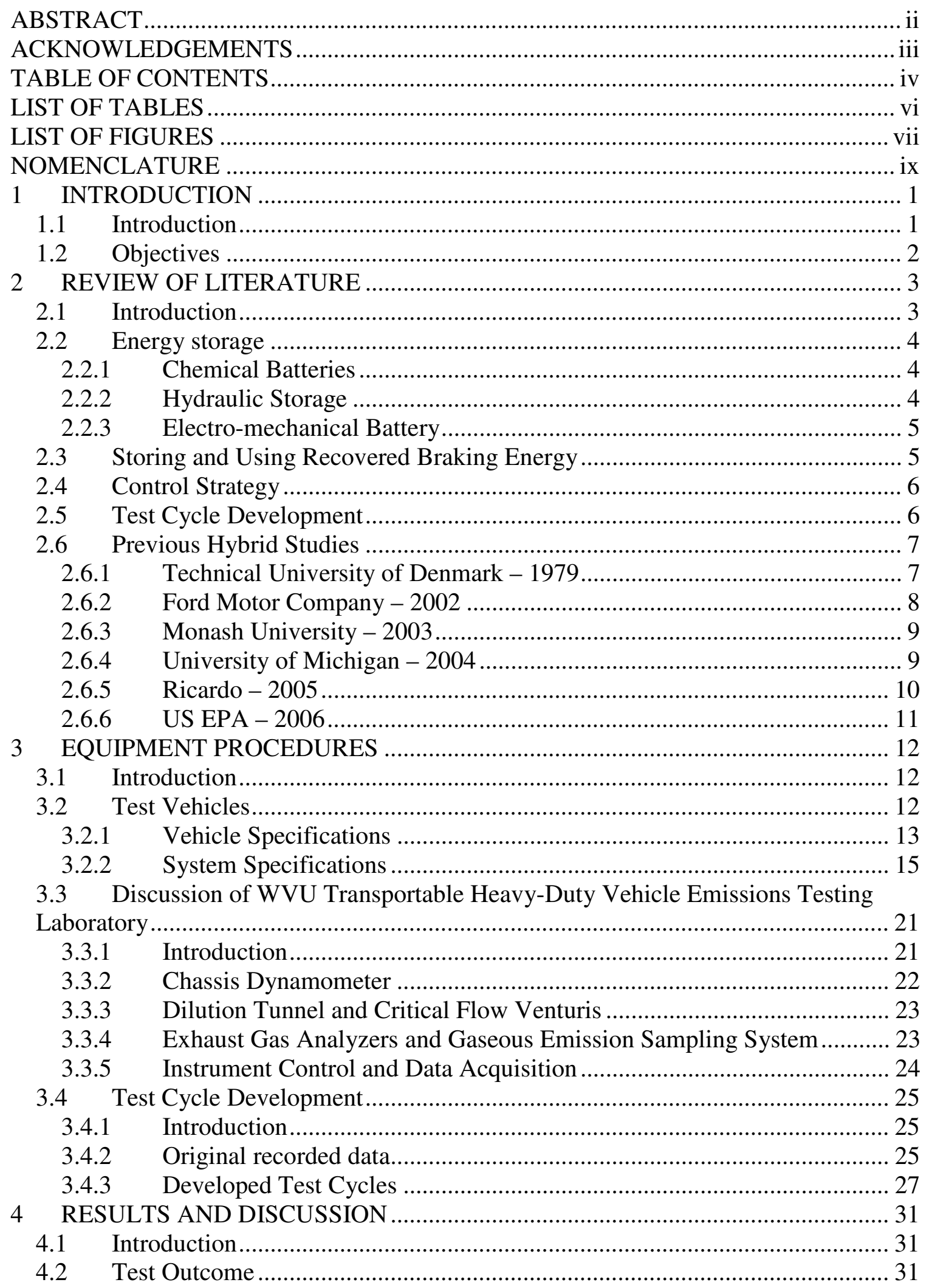




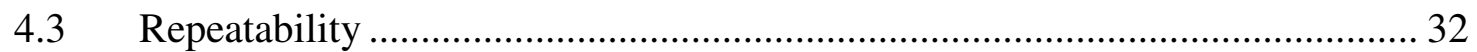

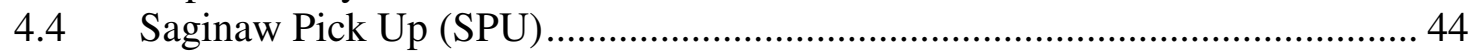

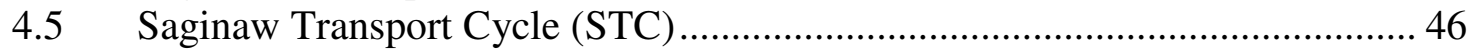

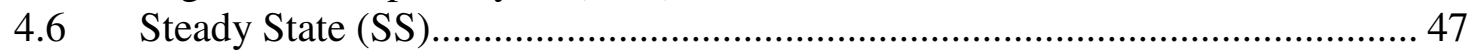

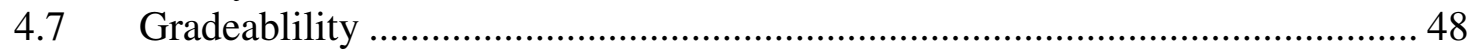

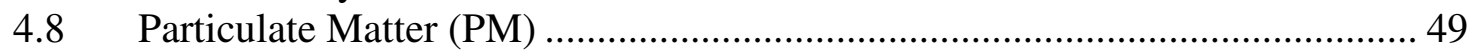

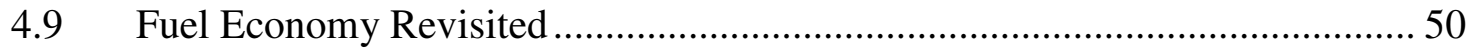

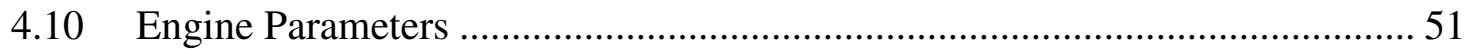

5 CONCLUSIONS AND RECOMMENDATIONS ……….................................... 56

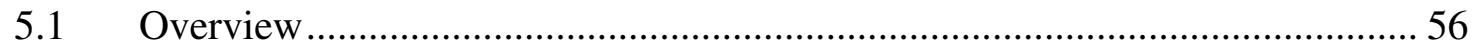

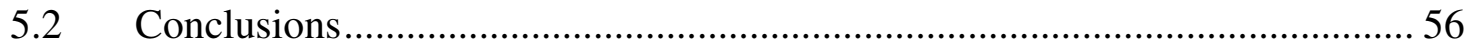

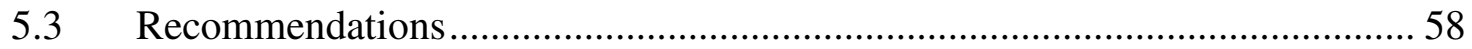

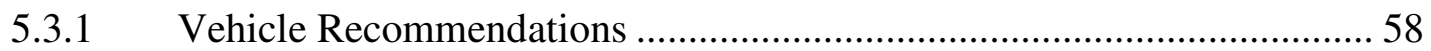

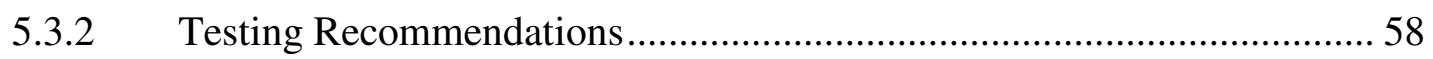

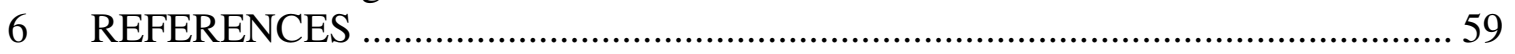

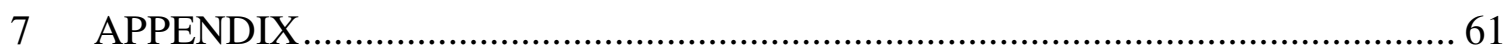

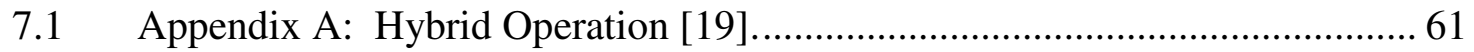

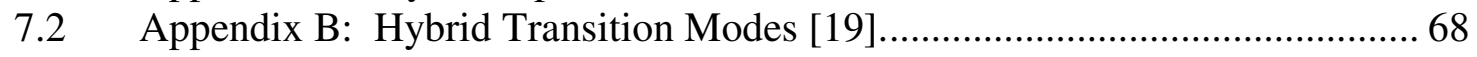

7.3 Appendix C: Original Cycle ………………................................................ 73

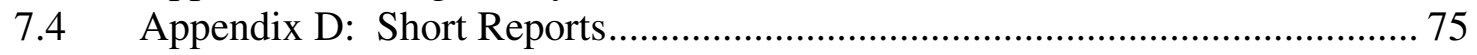




\section{LIST OF TABLES}

Table 3.1: Baseline Vehicle Specifications. ............................................................. 13

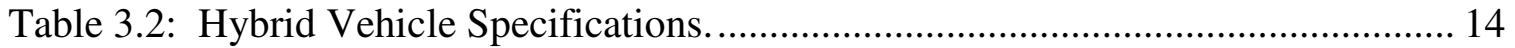

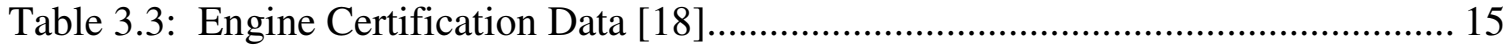

Table 3.4: Comparison of Recorded Cycle to Developed Test Cycles............................ 30

Table 4.1: Comparison of Baseline Mileage to the Developed Test Cycles. ................... 37

Table 4.2: Comparison of Hybrid Vehicle Mileage to the Developed Test Cycles. ....... 43

Table 4.3: Mileage Comparison Between Baseline Tests. ........................................... 43

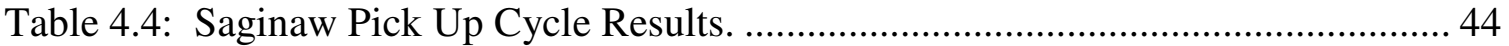

Table 4.5: SPU Comparison of Hybrid to Baseline Vehicle. .......................................... 46

Table 4.6: Saginaw Transport Cycle Results.............................................................. 47

Table 4.7: STC Comparison of Hybrid to Baseline Vehicle. ......................................... 47

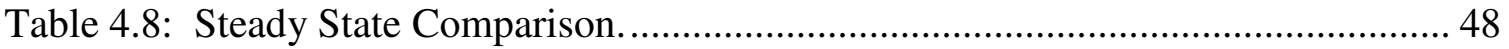

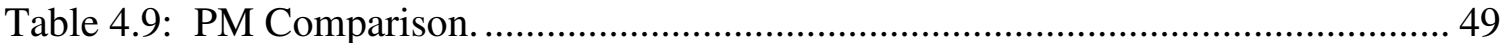

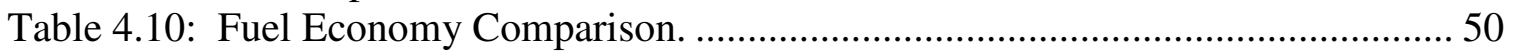

Table 7.1: Test Numbers Correlated to Test Cycles................................................ 75 


\section{LIST OF FIGURES}

Figure 3.1: Modified Autocar Xpeditor.................................................................. 13

Figure 3.2: Parker Hannifin PV270 Axial Piston Pump [19] .......................................... 16

Figure 3.3: Muncie Power Products Inc. Horizontal Split Shaft Unit [19]..................... 17

Figure 3.4: C22-195 [19] .................................................................................. 18

Figure 3.5: Eaton-Fuller Two Speed Auxiliary Transmission [19]................................ 18

Figure 3.6: High Pressure Accumulator................................................................... 19

Figure 3.7: Low Pressure Accumulator. ................................................................ 19

Figure 3.8: Entire Hybrid System Layout [19] ........................................................... 20

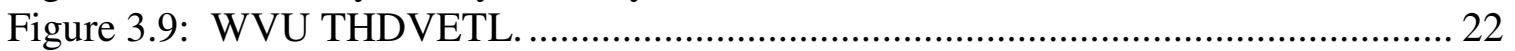

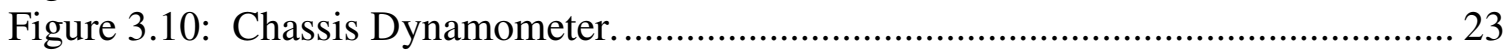

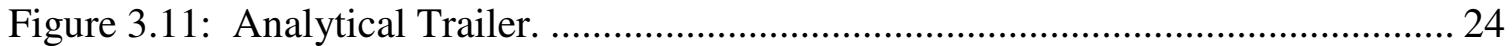

Figure 3.12: Recorded Saginaw Cycle $\left(1^{\text {st }}\right.$ Half $)$........................................................ 26

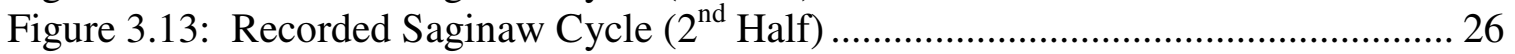

Figure 3.14: Developed Saginaw Transport Cycle (STC) …………………………...... 27

Figure 3.15: Developed Saginaw Pick Up Cycle (SPU) ................................................ 28

Figure 3.16: Developed Test Cycle (whole)............................................................ 29

Figure 4.1: SPU Baseline Repeatability Comparison.................................................... 33

Figure 4.2: STC Baseline Repeatability Comparison........................................................ 33

Figure 4.3: Baseline SPU 1 Comparison to Developed Test Cycle.................................. 34

Figure 4.4: Baseline Repeatability for SPU Tests. ........................................................ 35

Figure 4.5: Baseline STC 1 Comparison to Developed Test Cycle................................. 35

Figure 4.6: Baseline Repeatability for STC runs......................................................... 36

Figure 4.7: Hybrid Vehicle Speed Compared to Developed SPU Test Cycle.................. 38

Figure 4.8: Hybrid Vehicle Speed Compared to Developed STC Test Cycle.................. 38

Figure 4.9: Hybrid SPU 1 Run to Developed Test Cycle............................................... 39

Figure 4.10: Hybrid SPU Repeatability...................................................................... 40

Figure 4.11: Hybrid STC 2 Run Compared to Developed Test Cycle. ............................ 41

Figure 4.12: Hybrid STC 1 Run Compared to Developed Test Cycle. ……………......... 41

Figure 4.13: Hybrid STC 3 Run Compared to Developed Test Cycle. ........................... 42

Figure 4.14: Average SPU CO $\mathrm{C}_{2}$ Comparison......................................................... 45

Figure 4.15: Average SPU NOx Comparison........................................................... 45

Figure 4.16: Hybrid Gradeability Test................................................................... 49

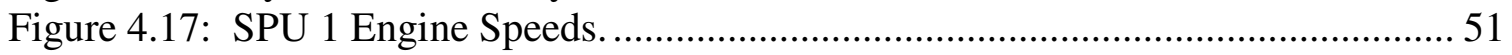

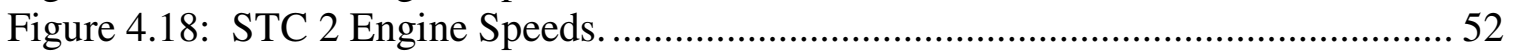

Figure 4.19: Baseline SPU Engine Efficiency ……………..................................... 53

Figure 4.20: Hybrid SPU Engine Efficiency. ........................................................... 53

Figure 4.21: Baseline STC 2 Engine Efficiency.......................................................... 54

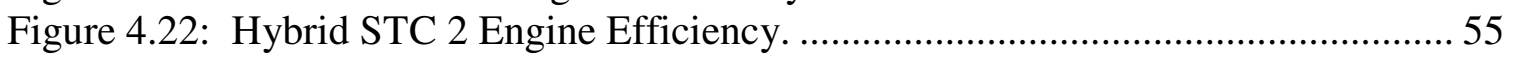

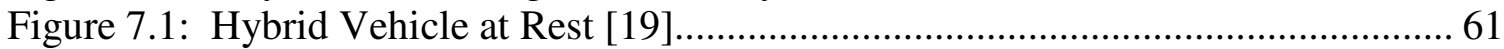

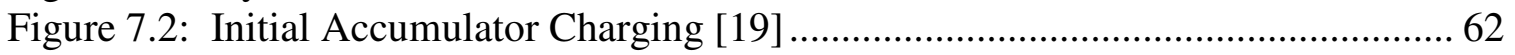

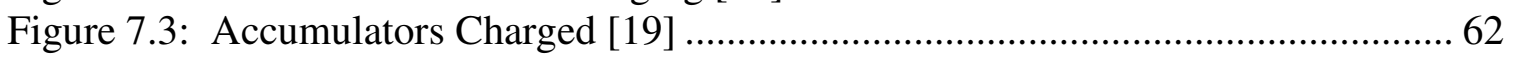

Figure 7.4: Accumulators Charged, Waiting For Command [19] ................................... 63 
Figure 7.5: Acceleration Command Received, C23-195s Provide Propulsion [19] ........ 63

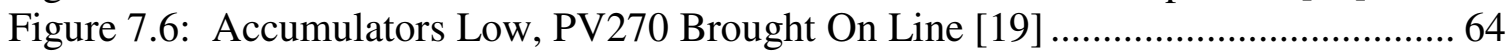

Figure 7.7: Accumulator Low, PV270 Providing Primary Propulsion [19] ....................... 64

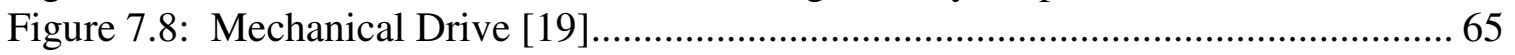

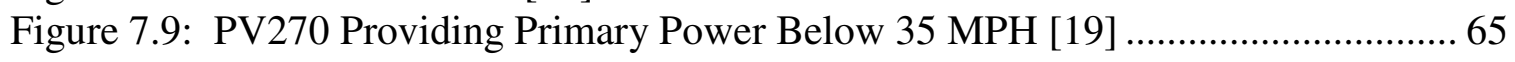

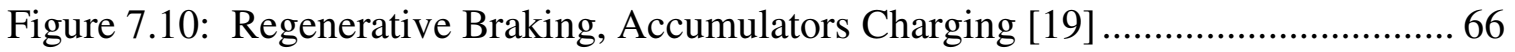

Figure 7.11: Regenerative Braking, Friction Brakes On Command [19] ....................... 66

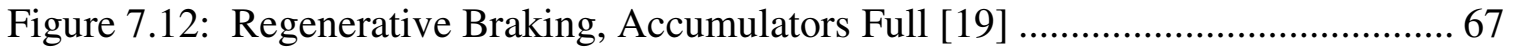

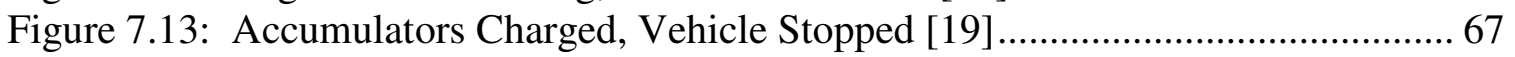

Figure 7.14: Original Recorded Saginaw Data (High Speed 1) ................................... 73

Figure 7.15: Original Recorded Saginaw Data (High Speed 2) .................................... 73

Figure 7.16: Original Recorded Saginaw Data (Low Speed) ..................................... 74 


\section{NOMENCLATURE}

\begin{tabular}{|c|c|}
\hline ADVISOR & Advanced Vehicle Simulator \\
\hline bar & Barometric Pressure \\
\hline CAN & Controller Area Network \\
\hline CARB & California Air Research Board \\
\hline $\mathrm{cc}$ & Cubic Centimeter \\
\hline CBD & Central Business District \\
\hline CFR & Code of Federal Regulations \\
\hline $\mathrm{CO}$ & Carbon Monoxide \\
\hline $\mathrm{CO}_{2}$ & Carbon Dioxide \\
\hline $\mathrm{CV}$ & Coefficient of Variance \\
\hline DC & Direct Current \\
\hline ECU & Electronic Control Unit \\
\hline EPA & Environmental Protection Agency \\
\hline GPS & Global Positioning System \\
\hline g/bHP-hr & Grams per Brake Horsepower-Hour \\
\hline $\mathrm{HC}$ & Hydrocarbons \\
\hline HEPM & High Efficiency Pump/Motor \\
\hline $\mathrm{HEV}$ & Hybrid Electric Vehicle \\
\hline HFID & Heated Flame Ionization Detector \\
\hline HHDDT & Heavy-Heavy Duty Diesel Truck \\
\hline IC & Internal Combustion \\
\hline $\mathrm{kg}$ & Kilogram \\
\hline $\mathrm{kW}$ & Kilowatt \\
\hline $\mathrm{L}$ & Liter \\
\hline LEPM & Low Efficiency Pump/Motor \\
\hline lpm & Liters Per Minute \\
\hline MPG & Miles per Gallon \\
\hline
\end{tabular}




$\begin{array}{ll}\text { mph } & \text { Miles per Hour } \\ \text { NDIR } & \text { Non-dispersive Infrared } \\ \text { NREL } & \text { National Renewable Energy Laboratory } \\ \text { NOx } & \text { Oxides of Nitrogen } \\ \text { PM } & \text { Particulate Matter } \\ \text { ppm } & \text { Parts Per Million } \\ \text { psi } & \text { Pounds per Square Inch } \\ \text { PTO } & \text { Power Take Off } \\ \text { scfm } & \text { Standard Cubic Feet Per Minute } \\ \text { rev } & \text { Revolution } \\ \text { RPM } & \text { Revolutions Per Minute } \\ \text { SAE } & \text { Society of Automotive Engineers } \\ \text { SHHDV } & \text { Series Hydraulic Hybrid Diesel Vehicle } \\ \text { SPU } & \text { Saginaw Pick-Up } \\ \text { SS } & \text { Steady State } \\ \text { STC } & \text { Saginaw Transport Cycle } \\ \text { THDVETL } & \text { Transportable Heavy-Duty Vehicle Emissions Testing Laboratory } \\ \text { UDDS } & \text { Urban Dynamometer Driving Schedule } \\ \text { UPS } & \text { United Parcel Service } \\ \text { US } & \text { United States } \\ \text { WVU } & \text { West Virginia University } \\ & \end{array}$




\section{INTRODUCTION}

\subsection{Introduction}

Today's industrial expansion coupled with the serious threat of ever increasing fuel prices have lead to an imperative need to improve fuel economy. Further increasing concerns over environmental issues are mounting considerable pressure on engineers and scientists to reduce harmful emissions from fossil fuel burning vehicles. The Clean Air Act, established in 1963 and revised in later years, sets a basis for emissions reduction and air quality that increasingly brings pressure on the manufacturers and fleet operators to do their part in emissions reduction [1].

Until alternative energy sources are discovered, refined and made readily available, the gap will have to be bridged with a blend of traditional and radical ideas. Hybrid vehicle technology offers hope in the immediate future. These vehicles are being developed and continually improved and practical uses of several hybrid vehicle models are visible today, mostly in the small personal car and sport utility market.

Hybrid technology has its roots in nearly all aspects of transportation and can be found in many forms. The current prevalent hybrid vehicles are mechanical-electric systems which use mechanical energy (from the engine), as well as recovered mechanical energy from braking to charge a battery or series of batteries for aid in propulsion. The batteries required for these vehicles are quite expensive and very heavy. Hydraulic hybrids on the other hand are suited for heavy-duty applications in part due to the higher power density potential. It was predicted these hydraulic hybrids have the potential to increase fuel economy by $50 \%$ in urban driving [2].

When a new hybrid vehicle is developed there is a need for proper evaluation so that the designers can analyze project goal achievement and other data used in vehicle redesign and refinement. It is important to determine the design's performance and endurance and this is where proper testing facilities can help to characterize these new vehicles.

Traditionally, testing and evaluation of diesel engines is performed by each engine manufacturer in an engine test cell where only the engine is tested. In recent years chassis dynamometers were developed for testing of an entire system, which will also 
include many additional drivetrain inefficiencies. These chassis dynamometers, which were developed to test vehicles in their final configuration, can also test vehicles out in the field after a certain amount of use or aging. The laboratories are instrumental in the evaluation of a hybrid vehicle since a hybrid vehicle incorporates a variety of components that typically encompass the whole vehicle.

The West Virginia University (WVU) Transportable Heavy-Duty Vehicle Emissions Testing Laboratory (THDVETL) is comprised of several trailers that can be brought on site to measure vehicle emissions simulating repeatable in-use conditions. The chassis dynamometer is housed on a large flatbed trailer, with the instruments and computer control housed in a second trailer. The facility has the capability of running an entire vehicle through rigorous tests.

\subsection{Objectives}

The scope of this project was to evaluate a prototype Series Hydraulic Hybrid Diesel Vehicle (SHHDV) and compare it to that of a similar baseline diesel refuse vehicle. The prototype, version 'Alpha', was a collaborative effort by Parker-Hannifin and Autocar. Both vehicles were tested on WVU's THDVETL. The performance of the hydraulic hybrid prototype vehicle was compared to the baseline vehicle to evaluate the functionality, controls, emissions and fuel economy.

A realistic test cycle was created and implemented to mimic the rigors of a refuse truck more appropriately than any of the existing chassis duty cycles. The test cycle was designed for realistic high speed transport, along with the stop-and-go driving typical of the vehicle's curb-side pick up. The development process incorporated data recorded from an actual refuse truck route in Saginaw, MI that was instrumental for test cycle development.

The WVU THDVETL recorded emission and performance parameters. In addition, data from the electronic control unit (ECU) were recorded via SAE J1939/CAN for use in Parker-Hannifin/Autocar evaluations. The ECU data broadcast conforms to standardized industry formats, SAE J1708/J1587 and J1939 protocols [3]. Controller Area Network (CAN) was developed in 1994 and has a higher transfer rate than J1708 [3]. 


\section{REVIEW OF LITERATURE}

\subsection{Introduction}

Hybrid vehicles are not a new concept but it was only in the recent years that environmental, social and financial concern coupled with more efficient and practical technology of today, provide achievable results. Amongst the several variations of hybrids, the hybrid electric configuration is usually preferred for smaller applications due to its compactness and noise reduction capabilities. The hydraulic hybrid is preferred in many medium and heavy-duty situations since the hydraulic power train combines a higher power density while enabling rapid charging/discharging better than that of current hybrid electric vehicles [4]. Vehicles with a large chassis also are capable of physically housing the hydraulic systems which are currently in production. Larger vehicles that see frequent stop-and-go driving, which force an IC engine to perform inefficiently, can draw the greatest benefit from this technology. Hybrid technology presents a good stepping stone for future technology since it can now be implemented with current vehicle systems; a significant advantage over more exotic technologies, such as hydrogen fueled engines. These developmental technologies still require many more years of research and development.

The key feature of hybrid vehicles lies in regenerative braking. The concept involves conserving energy that is typically lost in today's basic machines. The energy stored in a vehicle in motion is lost as heat during mechanical braking. Heat is generated by the force applied to the brakes and is then dissipated to the atmosphere. Ideally regenerative braking recovers as much of the energy, stored as momentum, as possible for later use during acceleration or propulsion instead of converting momentum into heat energy. The hybrid system engages pumps which use the rotating energy to pressurize tanks (accumulators). The energy required to pressurize the tanks slows the vehicle and this stored energy can be later used in acceleration, thus reducing the amount of loading seen by the engine. 


\subsection{Energy storage}

There are several methods available for energy storage in future hybrid vehicles. Some of these include: chemical batteries, hydrogen fuel cells, hydraulic accumulators and electro-mechanical batteries. The technologies that are readily available, or will be in the immediate future, are the electric and hydraulic hybrids due to the accessibility of the required components. Even if proven not to be the most effective, it is acknowledged that hybrids will at least serve to bridge the gap until progress in future technologies is made.

\subsubsection{Chemical Batteries}

The standard electric hybrid vehicles are available with either series or parallel transmission systems. The parallel setup enables both the electric motor and the IC engine to directly propel the vehicle. The series configuration uses the engine purely as a source of energy for the electric system, which in turn is directly connected to the drive wheels.

A 2003 hybrid electric study by Chu et al. used the series transmission setup in a transit bus [5]. An electrical motor provided energy to propel vehicle or acted as an electric generator during braking to charge the batteries. In this setup there was no direct link between the IC engine and the drive wheels. This setup improved acceleration and fuel economy. Some of the noted drawbacks of chemical electric battery systems include but are not limited to the following: cost, size, weight, life span, slow cyclic energy capture and release [4].

\subsubsection{Hydraulic Storage}

Hydraulic storage is simply the use of hydraulics to store and deliver energy. The energy that is typically lost during braking is stored in a high-pressure accumulator and then released for acceleration. Hydraulic hybrids have a high power density and therefore, release large amounts of stored energy [4]. Power density refers to the ability to store power compared to the weight of the storage device involved. This technology may be available for immediate implementation. Jackey et al. mentioned one drawback 
being that this application needs plenty of room and therefore is best applicable to rear wheel drive applications where it can be positioned and integrated into the drivetrain [4].

\subsubsection{Electro-mechanical Battery}

Jackey et al. describes how electro-mechanical batteries use hydro-pneumatic storage and are best suited for use in front wheel drive designs [4]. This system was composed of a hydraulic cylinder, rotary pump and storage cylinder which are packaged together with an electric motor/generator. This setup is smaller and more compact, and uses the stored pneumatic energy to generate electric energy.

\subsection{Storing and Using Recovered Braking Energy}

Andic et al. [6] published a study on the storage of lost brake energy. The objective of the study was to check the feasibility of a regenerative braking system. The system developed by the authors contained the necessary components, such as accumulators for energy storage, a pump/motor and a low pressure reservoir.

The paper described the operation where the oil is pumped into the accumulator (during braking), thereby compressing the nitrogen gas inside. This stored energy can then be used to accelerate the vehicle by reversing the process and using the pump as a motor for vehicle propulsion.

The study considered several factors for the operation of the system, namely: inert gas charge pressure, maximum/minimum operating pressures, instantaneous oil pressure, initial accumulator volume, instantaneous oil volume, spring constants, net force on the valve, braking/accelerator force applied by operator and instantaneous line pressure.

Static and dynamic models were created in this study where the dynamic model consisted of block diagrams that represented the system and the static model enabled them to size components for later use in the dynamic model testing. In the end, the

proposed models were determined by the authors to be a good basis for use in determining system parameters in a preliminary design process. 


\subsection{Control Strategy}

A paper by Matheson et al. [7] describes control strategy and its integral part of any hybrid vehicle. Here, an Australian company developed a hydraulic regenerative system for heavy vehicles. The controller directed the vehicles functions to meet the demand and increased fuel economy. The model of this system was made in Matlab/Simulink and the National Renewable Energy Laboratory's (NREL) Advance Vehicle Simulator (ADVISOR) to give estimates of potential fuel economy benefits under a variety of scenarios. Fuzzy logic, a logic system that simplifies two-valued logic for reasoning, was used to carry out the control strategy due to its ability to control nonlinear, time-varying systems [7]. The discovered shortcomings of this setup were the inability to have user or driver input; hence this model could not be directly implemented.

\subsection{Test Cycle Development}

In order to evaluate vehicles on a chassis dynamometer, it may be necessary to develop a test cycle or route that is representative of the vehicle's duty cycle. This was accomplished by fitting similar vehicles with data loggers to track the vehicle's speed while performing some usual function. WVU has developed several cycles in the attempt to meet the requirements of the vehicle being tested $[8,9]$. It was discovered that standard tests, such as the Central Business District (CBD), were not always practical or appropriate. The CBD cycle was sometimes used in the testing of trucks, but heavy vehicles fail to follow its demanding accelerations and decelerations [8]. WVU was able to develop cycles that were repeatable and acceptable for vehicle evaluation by creating cycles from recorded real world data and then creating a representative cycle for use on chassis dynamometers $[8,9,10]$. Developing a driving schedule was done by logging data (vehicle speed) from a range of vehicles in the field and modifying the tests to produce repeatable test cycles.

Gautam et al. [10] present details on the development of a test cycle for heavyheavy duty diesel truck (HHDDT) testing. This study was done in collaboration with the California Air Resources Board (CARB) and details the need to develop a more appropriate cycle than the one already in place, the urban dynamometer driving schedule 
(UDDS). CARB wanted to develop a test cycle that was representative of HHDDT behavior. The previously used UDDS test cycle was developed using a Monte Carlo simulation. Real-world data were collected by CARB using dataloggers, including a Global Positioning System (GPS). Some of parameters examined were: time, trip length, trip duration, and average maximum speed. These were some of the parameters used when comparing the developed filtered and unfiltered cycles which made it possible for the HHDDT to follow the cycle. The data were then divided into the above listed modes for individual test creation modeling those specific modes. The paper shows the use of duration, distance, average speed, maximum speed, acceleration, deceleration, total kinetic energy, and percent idle for comparison between cycles. Following the preliminary testing, a series of test protocols were developed.

\subsection{Previous Hybrid Studies}

\subsubsection{Technical University of Denmark - 1979}

A theoretical and experimental study was performed by the Technical University of Denmark in an attempt improve fuel economy of a city bus [11]. The city bus was chosen due to the vehicle's favorable driving conditions consisting of frequent braking and acceleration. The goal was to evaluate possible fuel saving characteristics with a hybrid powertrain. A parallel hybrid system was chosen because it consisted of fewer energy conversions. This project acknowledged other hybrid systems but selected the hydraulic hybrid due to its ability to be implemented with current technology. Several control strategies were used including on-off, best-efficiency, and constant IC engine torque control. The computer simulations allowed for sizing of the hydraulic pump/motor and accumulator as well as determining most efficient control strategy. Fuel savings were found to be in the $30 \%$ range for all strategies with the on-off being the simplest to implement. The study involved an experiment where a Ford Escort Van, equipped with the hydraulic system, was tested on a chassis dynamometer with the on-off control strategy. This setup yielded actual fuel savings of $14 \%$ with the computer simulation for this vehicle suggested savings of 16\% [11]. This study led to the 
implementation of a Leyland bus and was sponsored by the Danish Ministry of Commerce.

\subsubsection{Ford Motor Company - 2002}

The Ford Motor Company worked along side the United States (US) Environmental Protection Agency (EPA) on a cooperative project to design and evaluate a hydraulic hybrid system [12]. The project set out to demonstrate the control strategy of the hydraulic hybrid system as well as reducing fuel consumption on the EPA metrohighway cycle. For this project, a full size sport utility vehicle was chosen and fitted with a hydraulic drivetrain. The vehicle was tested on the US EPA chassis dynamometer in Ann Arbor, MI. The typical engine employed in this vehicle is a $5.4 \mathrm{~L}$ while the engine in the study was downsized to 4.0L. The accumulators on this particular system consisted of carbon fiber shells with an elastomer foam which allowed for the accumulator to be sized using the ideal isothermal gas equation due to the resulting reduction of heat loss. The accumulator had a bladder that contained nitrogen gas which could be compressed by hydraulic fluid and incorporated a low pressure accumulator to reduce cavitation and to hold the fluid at the end of acceleration. It also incorporated a bent axis variable displacement pump/motor with a displacement of $150 \mathrm{cc} / \mathrm{rev}$. A pulse suppressor was installed in-line to aid in the reduction of pulsations within the system. A computer controller allowed software development and data acquisition. The standard brake pedal was fitted so that the pedal does not initially engage the friction brakes and a potentiometer was electronically sensed by the controller and used the desired braking torque to control the solenoid. Further braking force could be obtained by depressing the pedal further to activate the friction brakes.

It was predicted that this setup would yield a fuel economy improvement of $24 \%$ and it was determined that $56 \%$ of the vehicle kinetic energy or $75 \%$ of the vehicle velocity could be recovered. Testing revealed a $23.6 \%$ increase in fuel economy, $19 \%$ reduction in carbon dioxide $\left(\mathrm{CO}_{2}\right), 30 \%$ reduction in Oxides of Nitrogen (NOx), $21 \%$ reduction in hydrocarbons $(\mathrm{HC})$, and $32 \%$ reduction in carbon monoxide $(\mathrm{CO})$ during the standard EPA City Cycle (hot) and improvement over the baseline of $35.5 \%$ in fuel economy and reduction of $26 \%, 40 \%, 14 \%, 43 \%$ of $\mathrm{CO}_{2}, \mathrm{NOx}, \mathrm{HC}$ and $\mathrm{CO}$ respectively. 
The study also compared the vehicle's acceleration from 0-30 $\mathrm{mph}$ where the hybrid system accelerated in 3.5 seconds compared to 5.4 seconds and 4.8 seconds with the $4.0 \mathrm{~L}$ (non-hybrid) and $5.4 \mathrm{~L}$ respectively.

\subsubsection{Monash University - 2003}

Matheson et al. studied the Permo-Drive Regenerative Energy Management System (PDREMS) [13]. This study used the Matlab and Simulink for later implementation into the NREL's ADVISOR. The study implemented an army tactical vehicle with a hydraulic system. ADVISOR combines forward and backward simulation methods. It also contained a series of driveline models but none for a hydraulic hybrid vehicle. Therefore, this study set out to develop the modeling of the hydraulic hybrid in four parts: hydraulic pump/motor, accumulators, control and baseline vehicle modeling. Fuel trials were conducted adhering to SAE fuel consumption test criteria. Test procedures of the test vehicle were matched to class 6 trucks. A reduction in fuel consumption of $26.77 \%$ with repeatability within $2 \%$ was measured over a series of runs. The authors concluded that the hybrid technology would be good for applications in busses, refuse trucks and delivery trucks. More validation tests were suggested along with optimization and component sizing during the ongoing testing.

\subsubsection{University of Michigan - 2004}

This study, conducted by B. Wu et al. at the University of Michigan, considered several control strategies required for hybrid propulsion [14]. The paper discussed the development of power management that works best with a hydraulic powertrain, in this case a parallel hydraulic powertrain. The simulation was based on a medium-duty delivery truck and modeling was performed in Matlab/Simulink along with a dynamic algorithm, used to achieve gear shifting and power splitting strategies during a test cycle. They developed a rule-based strategy that mimicked that of a previously developed hybrid electric vehicle (HEV). The engine map was divided into three sections which were used to determine control strategies.

A simple driving cycle was then developed that represented an acceleration/deceleration event. The strategies developed were different from typical 
HEV strategies and focused on the complete depletion of the accumulator to prepare it for the next charging cycle. It was found that hybridization improved the truck's fuel economy by $32.3 \%$ and $15.6 \%$ for High Efficiency Pump/Motor (HEPM) and Low Efficiency Pump/Motor (LEPM) respectively when compared to a baseline vehicle. The new power splitting helped push the benefits up to $47.4 \%$ (HEPM) and $27.8 \%$ (LEPM) [14].

\subsubsection{Ricardo -2005}

Anderson et al. conducted a study using a parallel hydraulic hybrid, a parallel electric hybrid and a series electric hybrid [15]. The goal was to improve the fuel economy of a refuse truck. A duty cycle was developed by logging actual vehicle data. Calculations were made regarding the possible downsizing of engines due to the addition of the hybrid powertrain. It was acknowledged that vehicle performance will vary highly due to the location and requirements of the vehicle at hand (city size, number of stops, traffic, and road grade) and strongly effects fuel economy. The study evaluated vehicle performance as well as the wheel energy and power used over the driving cycle. The latter can be used to help determine expected benefits from the hybrid vehicle and their regenerative braking capabilities. They developed a short driving cycle from a recorded 8 hour cycle and ensured that the short cycle had similar characteristics to that of the recorded cycle. It had similar average speed, length of stops, accelerations and decelerations. This study utilized EASY5, a graphically driven model building environment. The hydraulic hybrid was seen as a good way to capture high power density and as a good way to capture large portions of regenerative braking capabilities. They concluded that the reduction in emissions could be significant; however, it was beyond the scope of the study. The series electric powertrain provided the best improvement over any single driving cycle, but the parallel hydraulic hybrid demonstrated the best average fuel economy [15]. 


\subsubsection{US EPA - 2006}

The US EPA unveiled the first series hydraulic hybrid delivery van $[16,17]$. The US EPA, along with its partners in industry, developed this technology in a United Parcel Service (UPS) delivery van. This vehicle achieved 60\%-70\% better fuel economy (in laboratory tests), $40 \%$ or more reduction in $\mathrm{CO}_{2}$ and they claimed the ability to recover additional costs for this hydraulic hybrid in less than 3 years. This vehicle implemented a full hydraulic hybrid and eliminated the use of a conventional transmission. Other claims made were that the fleet owner would save approximately 1,000 gallons of fuel each year and would save approximately $\$ 50,000$ over a 20 year lifespan $[16,17]$. 


\section{EQUIPMENT PROCEDURES}

\subsection{Introduction}

This section describes the experimental equipment and procedures involved in characterizing the experimental prototype developed jointly by Parker-Hannifin and Autocar. The developed prototype was delivered to WVU's THDVETL for evaluation, which involved the testing of the baseline refuse vehicle and the hybrid through a previously developed test cycle which mimicked the daily operation of a refuse vehicle. Type 2 diesel fuel was used in both vehicles for the test.

\subsection{Test Vehicles}

The two vehicles tested in this study were Autocar Xpeditor refuse trucks which were powered by similar Cummins diesel engines. The baseline vehicle was outfitted with a Cummins ISL engine while the hybrid was outfitted with a smaller Cummins ISC engine. The vehicles did not have the refuse hauling and compression equipment installed during testing. Vehicle weights and load were simulated by WVU THDVETL. The engine and vehicle specifications are listed in Table 3.1 and Table 3.2 below. Rated horsepower and torque listed were the values obtained by using Cummins INSITE, a tool that allows reading parameters stored on the vehicle's ECU. 


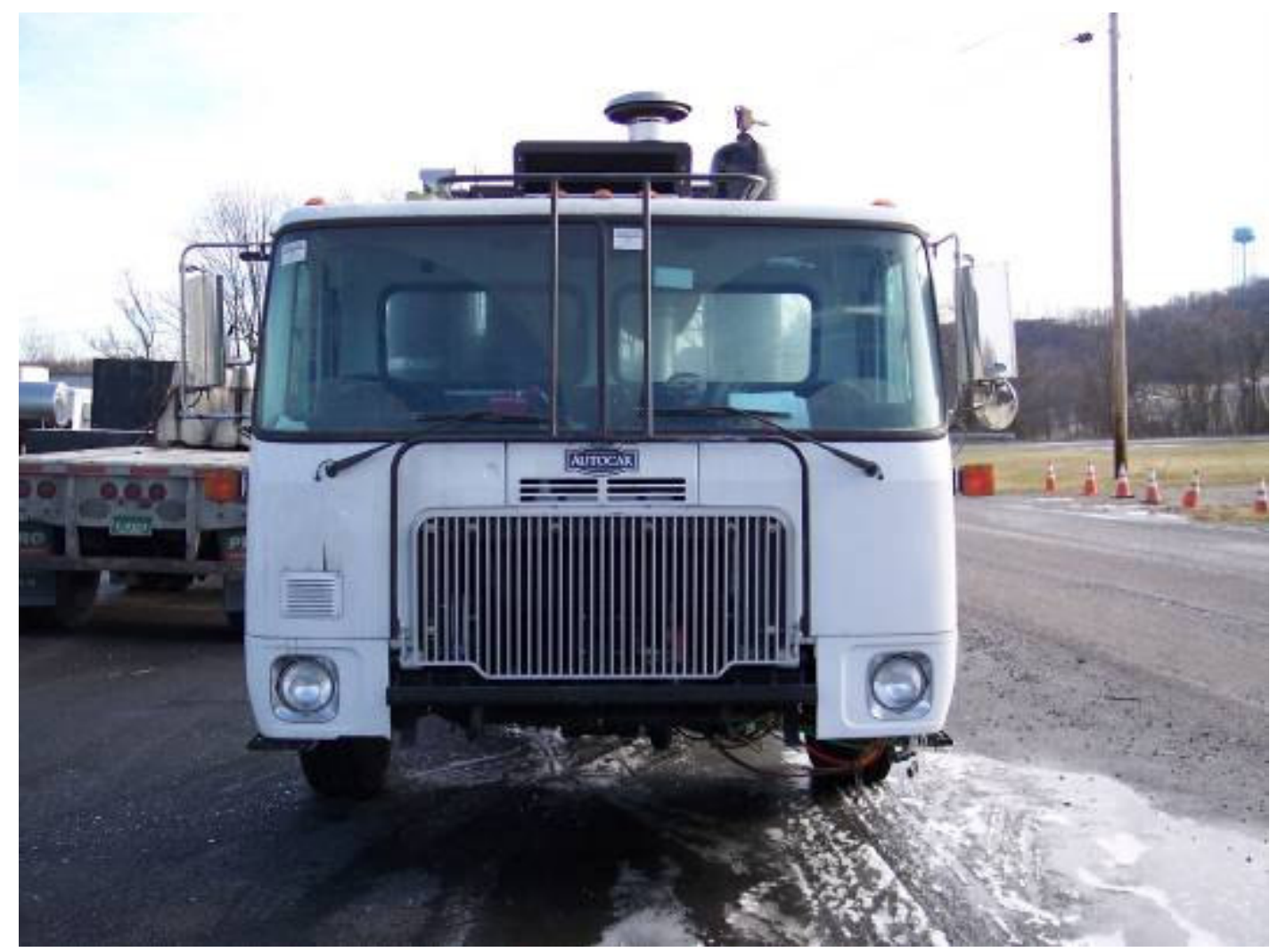

Figure 3.1: Modified Autocar Xpeditor.

\subsubsection{Vehicle Specifications}

Table 3.1: Baseline Vehicle Specifications.

\begin{tabular}{|l|c|}
\hline \multicolumn{2}{|c|}{ Vehicle } \\
\hline Manufacturer & Autocar \\
\hline VIN Number & 5VCHC6MF96H202523 \\
\hline Model Year & 2006 \\
\hline GVWR & $70,000 \mathrm{lbs}^{*}$ \\
\hline Test Weight & 40,000 Ibs \\
\hline Transmissions Type & 5-Speed Automatic \\
\hline Transmissions Manufacturer & Allison \\
\hline Transmission Model & Cummins \\
\hline \multicolumn{2}{|c|}{ Engine } \\
\hline Manufacturer & ISL \\
\hline Model & Inline 6 Cylinder \\
\hline Configuration & 2005 \\
\hline Model Year & 330 hp @ 2100 rpm \\
\hline Peak Power & $1150 \mathrm{ft}-\mathrm{lb}$ \\
\hline Peak Torque &
\end{tabular}

*Manufacturer's specification for complete vehicle 
Table 3.2: Hybrid Vehicle Specifications.

\begin{tabular}{|l|c|}
\hline \multicolumn{2}{|c|}{ Vehicle } \\
\hline Manufacturer & Autocar \\
\hline Model Number & Q0000945 \\
\hline Model Year & 2006 \\
\hline GVWR & $70,000 \mathrm{lbs}^{*}$ \\
\hline Test Weight & $40,000 \mathrm{lbs}$ \\
\hline \multicolumn{2}{|c|}{ Engine } \\
\hline Manufacturer & Cummins \\
\hline Model & ISC \\
\hline Configuration & Inline 6 Cylinder \\
\hline Model Year & 2005 \\
\hline Peak Power & $315 \mathrm{hp} \mathrm{@} \mathrm{2000} \mathrm{rpm}$ \\
\hline Peak Torque & $950 \mathrm{ft}-\mathrm{lb}$ \\
\hline
\end{tabular}

*Manufacturer's specification for complete vehicle

It should be noted that the vehicles in question may not offer a very accurate comparison due to having different sized engines. Some doubt was also cast upon the actual horsepower that these engines had and were certified to, making conclusions from results more difficult. The engine tag on the baseline vehicle indicated it to be an ISL 350 and in the certification family 5CEXH040LAI, indicating a rating of 350 horsepower. However, Cummins INSITE revealed the rated horsepower to be 330. If the ECU has been flashed (electronically altered) it would be impossible to be certain of the actual certification values the engine would now fall under. For reference, a similar ISL that matched horsepower rating given by Cummins INSITE is listed in column 2 of Table 3.3 for insight to ramifications that this discrepancy might have. Cummins INSITE reported the horsepower rating of 315 for the hybrid vehicle while the closest match in the certification tables indicates a horsepower rating of 208 (Note: No engine tag was found on the hybrid vehicle). The certification values for the baseline and hybrid vehicles can be found in columns 1 and 3 respectively in Table 3.3 below [18]. 
Table 3.3: Engine Certification Data [18].

\begin{tabular}{|c|c|c|c|c|}
\hline & & & \\
\hline & & 1 & 2 & 3 \\
\hline & Manufacturer & Cummins Inc. & Cummins Inc. & Cummins Inc. \\
\hline & $\begin{array}{l}\text { Engine } \\
\text { Family \# }\end{array}$ & 5CEXH0540LAI & 5CEXH0540LAG & 5CEXH0505CAX \\
\hline & Units & g/bHp-hr & g/bHp-hr & g/bHp-hr \\
\hline \multirow{4}{*}{$\begin{array}{l}\text { Certification } \\
\text { Levels }\end{array}$} & $\mathrm{HC}+\mathrm{NOx}$ & 2.7 & 3.1 & 2.7 \\
\hline & $\mathrm{CO}$ & 2.6 & 0 & 1 \\
\hline & PM & 0.1 & 0.01 & 0.08 \\
\hline & $\mathrm{CO}_{2}$ & 646 & 572 & 611 \\
\hline & Test Model & ISL 350 & ISL 330 & ISC 315 \\
\hline & Displacement & 540 cid & 540 cid & 505 cid \\
\hline & Rated HP & $350 @ 2100$ RPM & $330 @ 2000$ RPM & $208 @ 2100$ RPM \\
\hline & Torque & $1250 @ 1400$ RPM & $1100 @ 1300$ RPM & $950 @ 1300$ RPM \\
\hline
\end{tabular}

Table 3.3 is important in understanding how the differing engine setups may effect the emissions and performance of the vehicles being evaluated. Comparing columns 1 and 3 it is seen that the HC+ NOx values are exactly the same, PM within 0.02 $\mathrm{g} / \mathrm{bHp}-\mathrm{hr}$ and $\mathrm{CO}_{2}$ values are within $35 \mathrm{~g} / \mathrm{bHp}-\mathrm{hr}$.

\subsubsection{System Specifications}

The hydraulic system was connected in series with the original vehicle's drivetrain. The hybrid portion consisted of an axial piston pump that was located behind the engine and served the function of both building pressure in the accumulators and/or directly pumping through the manufacturer $\mathrm{C} 23-195$ pumps for propulsion. The next component was the horizontal split shaft unit which connected the driveshaft with the C23-195 hydraulic pumps. These pumps transfer the energy from the high pressure accumulators to the low pressure accumulator, transferring energy into the drivetrain and propelling the vehicle via these pumps. These pumps also capture the drivetrain's energy compressing the nitrogen gas within the accumulator and providing resistance (braking) while additional braking is supplied by traditional friction brakes if needed. The last modification comes in the form of an auxiliary transmission which allowed the hybrid vehicle to take better advantage of its hybrid powertrain at low speeds and switch to a 1:1 ratio for higher speeds. 


\subsubsection{Components}

Individual components that made up the hybrid system are described below for review. These systems work along side the original drivetrain to embody the hybrid system. The basic components are: axial piston pump, horizontal split shaft unit, C23195 pumps, 2-speed auxiliary transmission and high and low pressure accumulators. The PV270 pump was used to charge the accumulators as well as provide hydrostatic propulsion via the C23-195 pumps. The split shaft power take-off provided a mechanical connection between the C23-195 pumps and the drive wheels. The high pressure accumulators allowed storage of braking energy while the low pressure reservoir stores fluid after being used for acceleration and stored until pumped back into the high pressure accumulators. A two speed auxiliary transmission allowed for better gear ratios to better implement the hydraulic powertrain. The following lists the basic specifications available for the previously mentioned components.

\section{- Parker Hannifin PV270 Axial Piston Pump [19]}

○ Maximum displacement: $270 \mathrm{~cm}^{3} / \mathrm{rev}$

○ Output flow at $1500 \mathrm{~min}^{-1}: 405 \mathrm{lpm}$

○ Input power at $1500 \mathrm{~min}^{-1}$ and 350 bar: $263 \mathrm{kw}$

○ Weight: $172 \mathrm{~kg}$

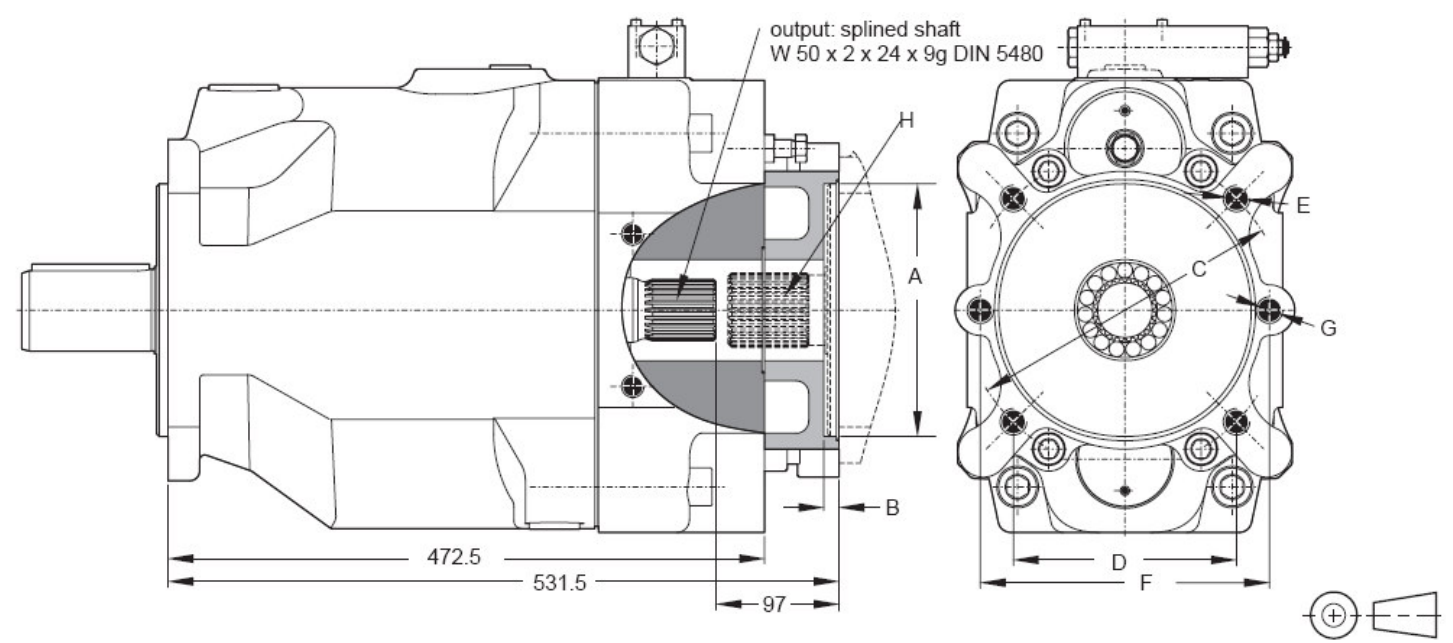

Figure 3.2: Parker Hannifin PV270 Axial Piston Pump [19]. 
- Muncie Power Products, Inc. SSH2 Horizontal Split-Shaft Unit [19]

- PTO torque capability of $940 \mathrm{lb}$. ft. max combined for each output shaft at 1500 RPM

○ Up to four outputs, independently shiftable PTO's for hydraulic pumps

- Drive connection to rear axle independent of PTO operation

○ PTO output ratio:1.28:1

- Max Output Shaft Speed: 2500 RPM

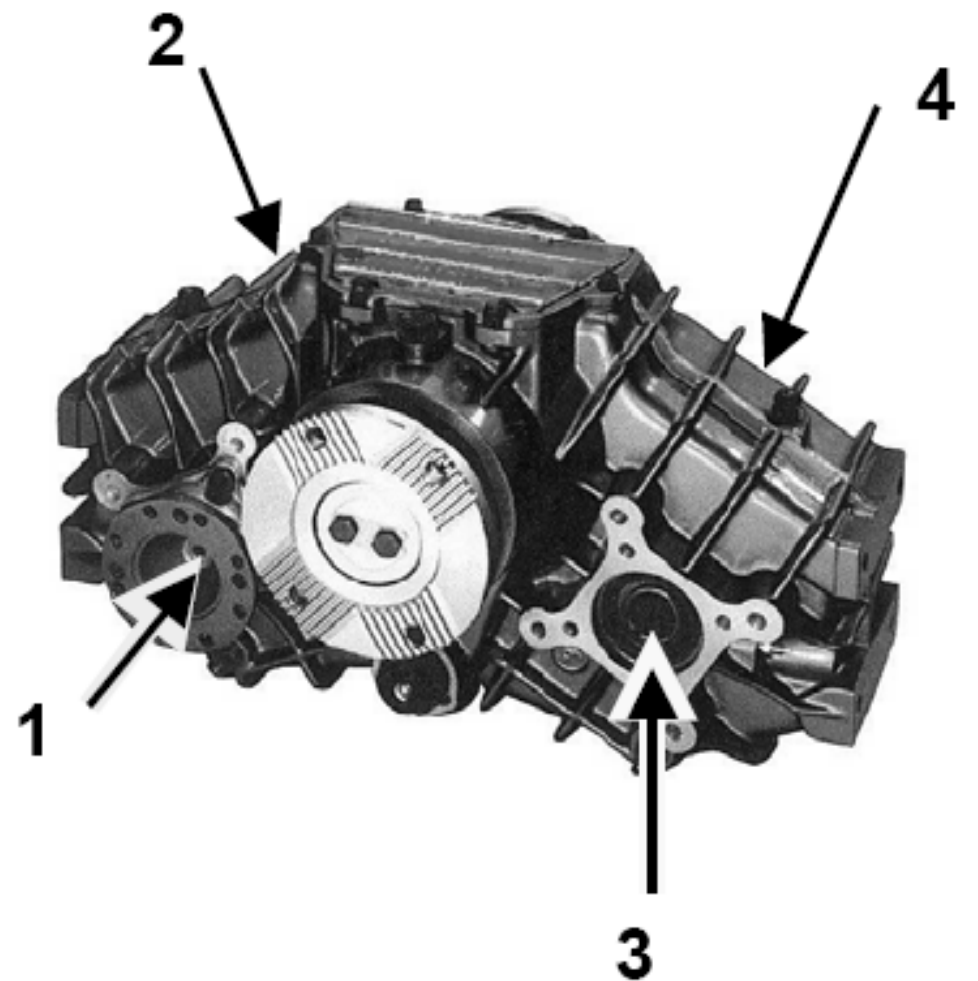

Figure 3.3: Muncie Power Products Inc. Horizontal Split Shaft Unit [19]. 
- $\mathrm{C23-195}[19]^{*}$

*Picture given of similar C22-195

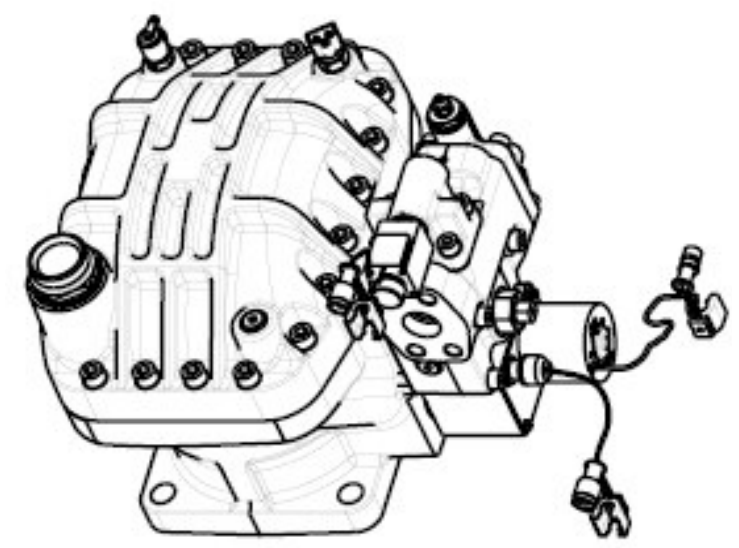

Figure 3.4: C22-195 [19].

- Eaton-Fuller Two Speed Auxiliary Transmission [19]

○ 2.30 low ratio, 1.00 high ratio.

- 2-A-92 auxiliary is rated to $13,150 \mathrm{Nm}(9700 \mathrm{lbs}$. $\mathrm{ft}$.) torque input and output

- Single shift bar control on right side of transmission case.

- Speedometer drive provision in rear bearing cover.

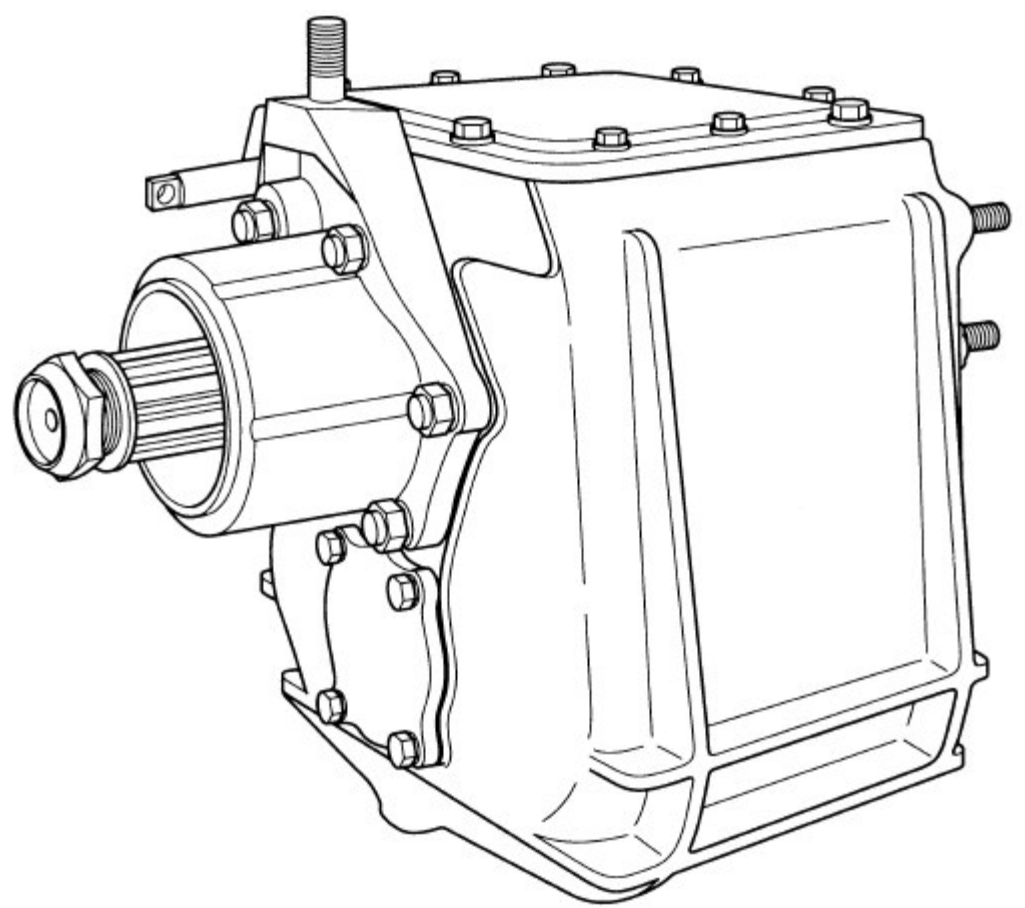

Figure 3.5: Eaton-Fuller Two Speed Auxiliary Transmission [19]. 
- High Pressure Accumulators [19]

- Capacity: 22 Gallon, 5500 PSI
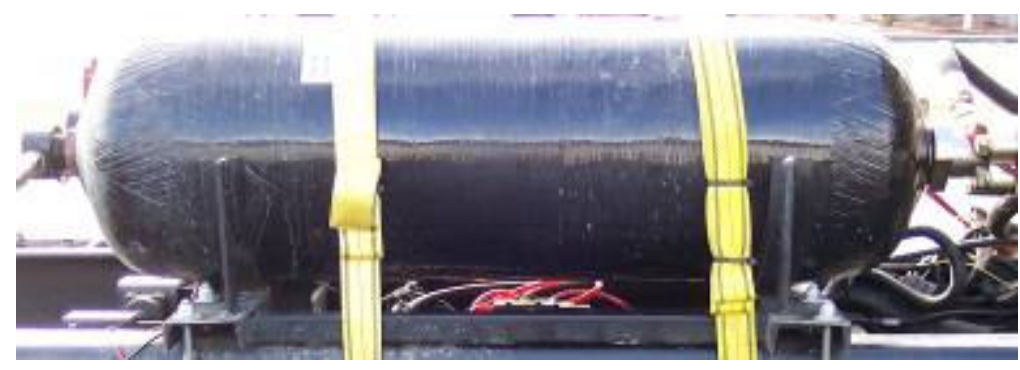

Figure 3.6: High Pressure Accumulator.

- Low Pressure Reservoir [19]

○ Capacity: 32 Gallon, 75 PSI

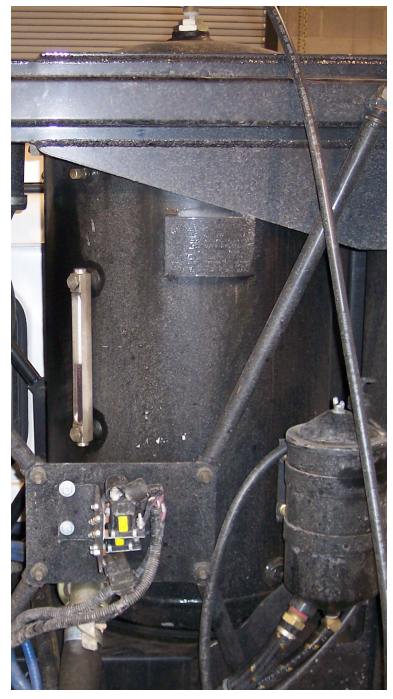

Figure 3.7: Low Pressure Accumulator. 


\section{- Entire Hybrid System Layout [19]}

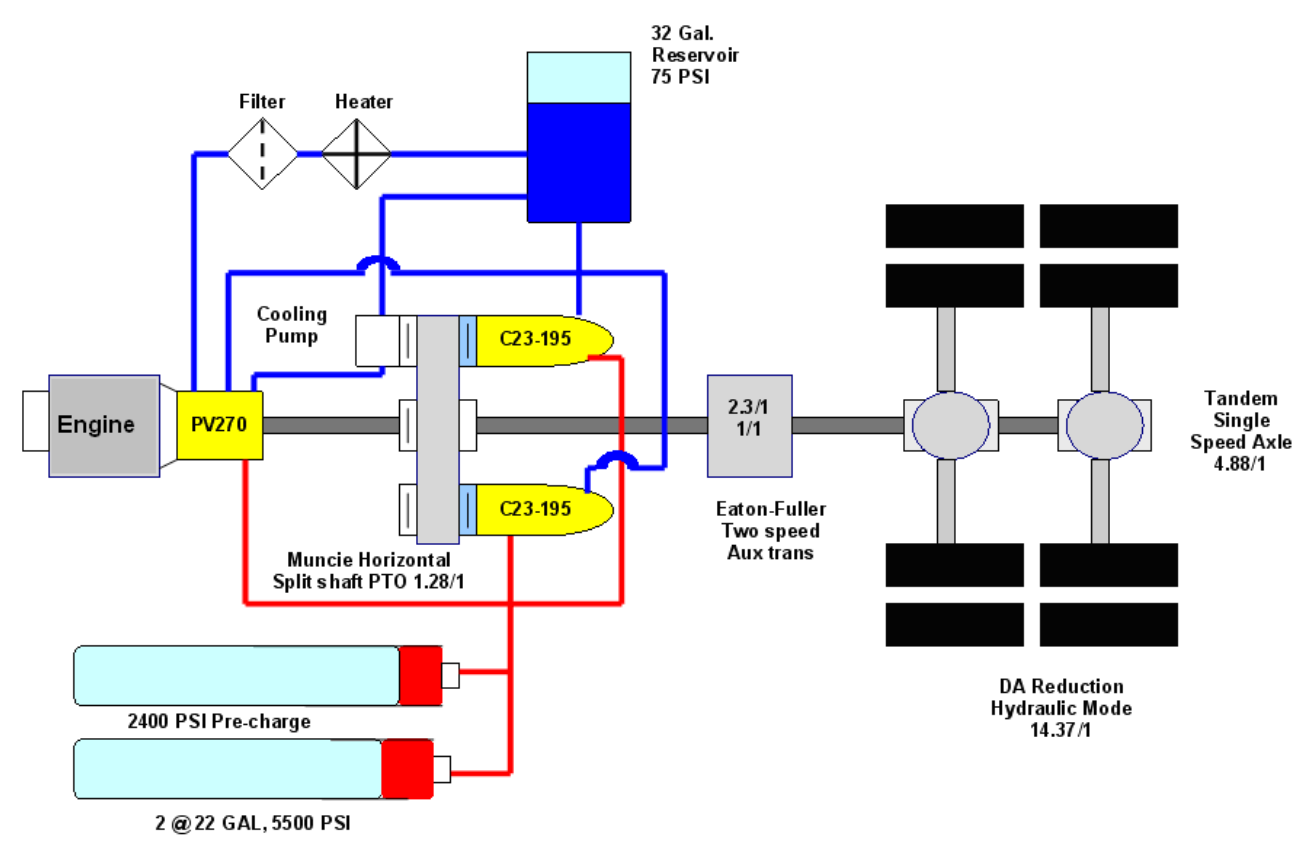

Figure 3.8: Entire Hybrid System Layout [19].

Figure 3.8 depicts the entire hybrid system. Here it can be seen how each component works together in the system. The PV270 pump is in line with the accumulators and the C23-195 pumps which are in tern can engage the main drivetrain. The red lines in the figure depict the high pressure side while blue indicates lower pressure. (See Appendix A for additional diagrams).

\subsubsection{Control strategy and transition modes [19].}

Parker-Hannifin/Autocar [19] provided brief documentation describing some engine control strategy as well as some insight into how they perform transition between modes. Additional information can be found in Appendix A and B.

In development of the hybrid vehicle a series of control strategies had to be developed to enable the systems to respond to demand. Target pressure curves, which dictate the target pressure in the accumulator as well as the hydrostatic pressure in relation to vehicle speed, were developed. The PV270 was designed to absorb the engine power and engine optimization was developed for the ISC 315 for the system to follow to 
ensure optimized efficiency. The PV270 had its displacement regulated to ensure the proper torque was acquired. The state of charge or amount of pressure stored in the accumulators is an important factor in the hybrid drivetrain and the manufactures monitored this data so that it could be used to determine modes of operation (see Appendix A for hybrid operation). The planned strategies developed by the manufacturers involved methods to charge the accumulators and pressure management.

Parker Hannifin's/Autocar's Revision 11 of the X-truck Alpha Transition Modes (Appendix B) consists of several scenarios: transition from low to high range, transition from high range to direct drive, transition from accumulator mode to hydrostatic mode, transition from direct drive to high range hydrostatic mode, transition from direct drive to accumulator mode, transition from high range to low range, and transition from hydrostatic mode to accumulator mode. Refer to Appendix A for diagrams depicting each stage of hybrid operation.

\subsection{Discussion of WVU Transportable Heavy-Duty Vehicle Emissions Testing Laboratory}

\subsubsection{Introduction}

The first Transportable Heavy-Duty Vehicle Emissions Testing Laboratory was developed by West Virginia University in the early 1990s. The lab is currently housed in Westover, WV and was developed out of growing concern about energy consumption and emissions of vehicles in the field and the growing need to evaluate them. The laboratory allows trucks to be tested in the field with this fully self contained, mobile testing facility. The facility is housed on two trailers, the chassis dynamometer and analytical trailer. The chassis dynamometer houses the mechanical means of testing the vehicle while the analytical trailer houses the analyzers, control computers and data acquisition. The entire test facility was designed in compliance of CFR 40, Part 86, Subpart N where applicable to chassis dynamometer testing. Additional insight into guidelines followed and developed in part by WVU can be found in SAE J2711 [23]. A brief background and description of the WVU Transportable Heavy-Duty Vehicle 
Emissions Testing Laboratory $[20,21,22]$ is found below. Figure 3.9 shows the WVU Laboratory's setup for testing and evaluation.

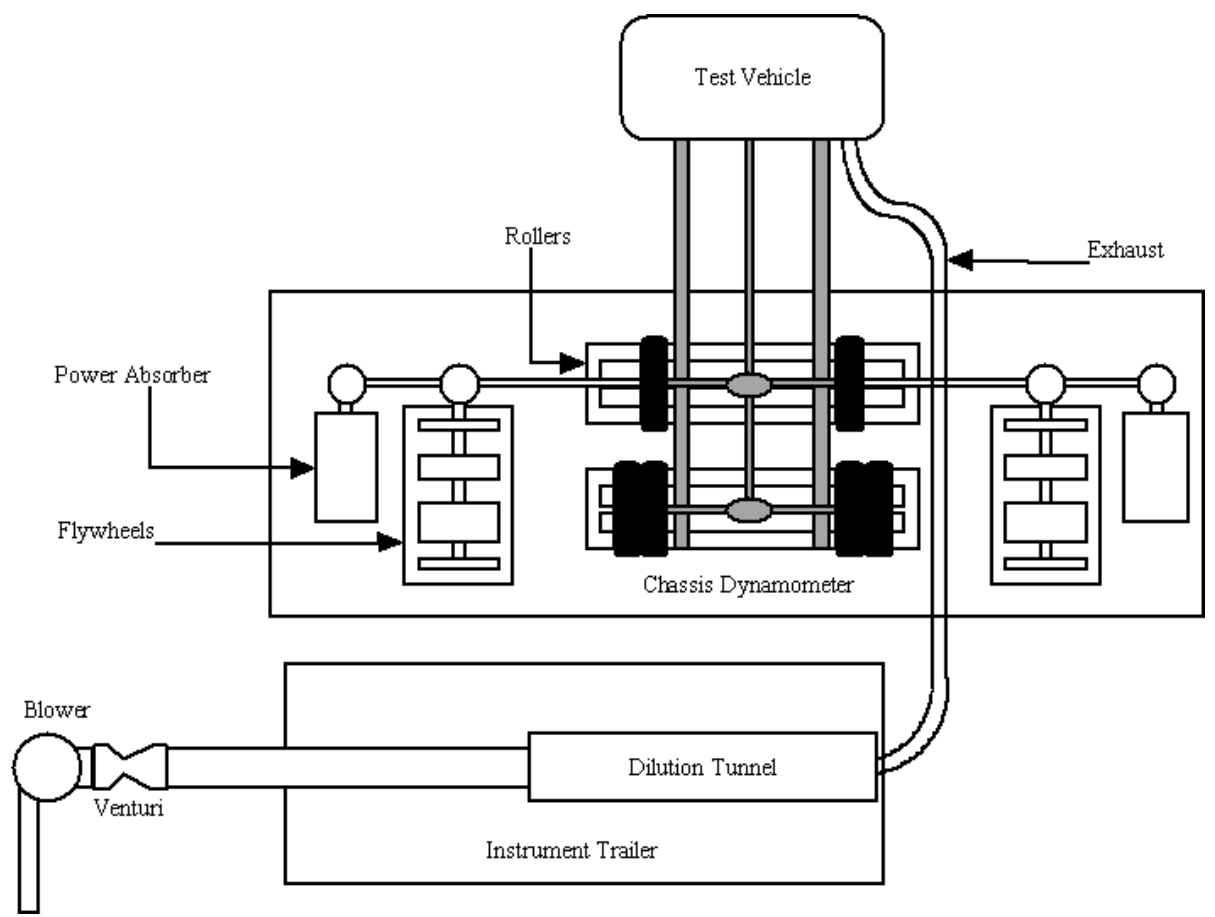

Figure 3.9: WVU THDVETL.

\subsubsection{Chassis Dynamometer}

The chassis dynamometer is housed on a large modified flatbed trailer. The trailer includes a removable tandem axle as well as hydraulic jacks to enable the flatbed to be lowered to ground level. The flatbed houses free-rotating rollers for the drive wheels to ride on, flywheels to simulate vehicle inertia, and power absorbers to simulate road load. The test vehicle pulls onto the trailer and is hooked up to the dynamometer via drive shafts connected directly to the vehicle's hubs. Torque is transferred to the flywheels and power absorbers through a drive shaft. The setup on the flatbed is symmetrical with respect to the rollers in the center. The flywheels can simulate a vehicle or test load ranging up to $66,150 \mathrm{lb}$. in increments of $250 \mathrm{lb}$. The power absorption is achieved by two eddy current absorbers. The absorbers are controlled by varying the supplied DC current and energy is dissipated as heat. 


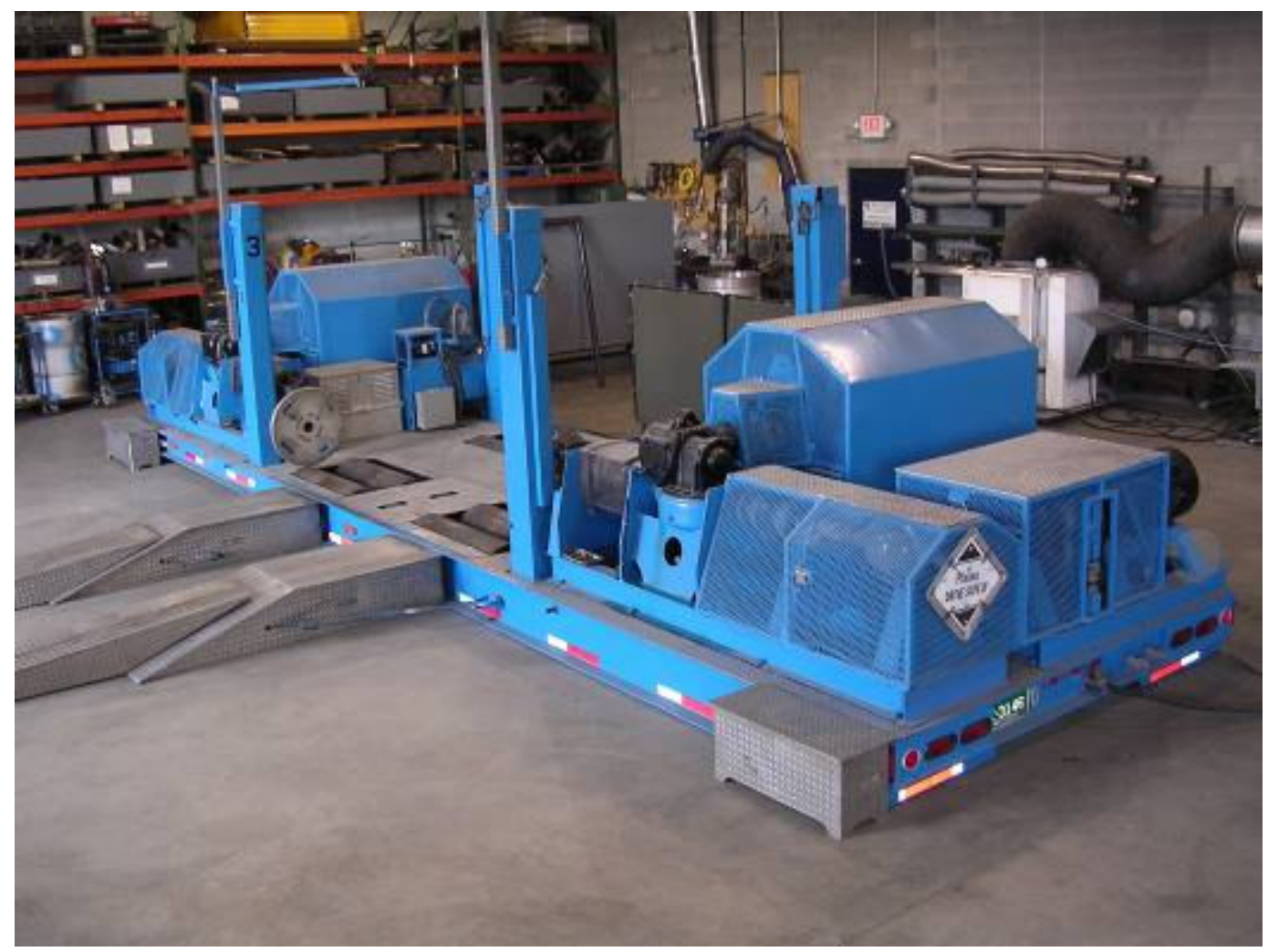

Figure 3.10: Chassis Dynamometer.

\subsubsection{Dilution Tunnel and Critical Flow Venturis}

A stainless steel dilution tunnel is utilized for exhaust gas analysis while a blower draws exhaust as well as filtered dilution air into the tunnel. Sampling probes draw off diluted exhaust gas to be routed through the analyzers. A secondary dilution tunnel leads to a filter on which PM is collected and analyzed gravimetrically post test. The air flow rate of the primary tunnel is controlled by a critical flow venturi.

\subsubsection{Exhaust Gas Analyzers and Gaseous Emission Sampling System}

Exhaust gas is drawn from probes imbedded in the dilution tunnel through heated lines to individual analyzers that are located in the climate-controlled analytical trailer. The facility has the capability to measure PM, CO, $\mathrm{CO}_{2}, \mathrm{NOx}$ and $\mathrm{HC}$ as well as formaldehyde, methanol, and methane. There are non-dispersive infra-red (NDIR) analyzers for measuring $\mathrm{CO}$ and $\mathrm{CO}_{2}$, a heated flame ionization detector (HFID) for measuring $\mathrm{HC}$, and two chemiluminescent analyzers for NOx. The systems are 
calibrated and the facility goes through a series of checks before testing to ensure the system is working properly. PM is collected by drawing a sample from the secondary dilution tunnel over a 70mm fluorocarbon coated fiberglass filter and later weighed. Finally, background air and dilute exhaust are collected in bags. The dilute exhaust is used as quality assurance/quality control (QA/QC) while the background is used to correct the test results for emissions that may be in the testing vicinity.

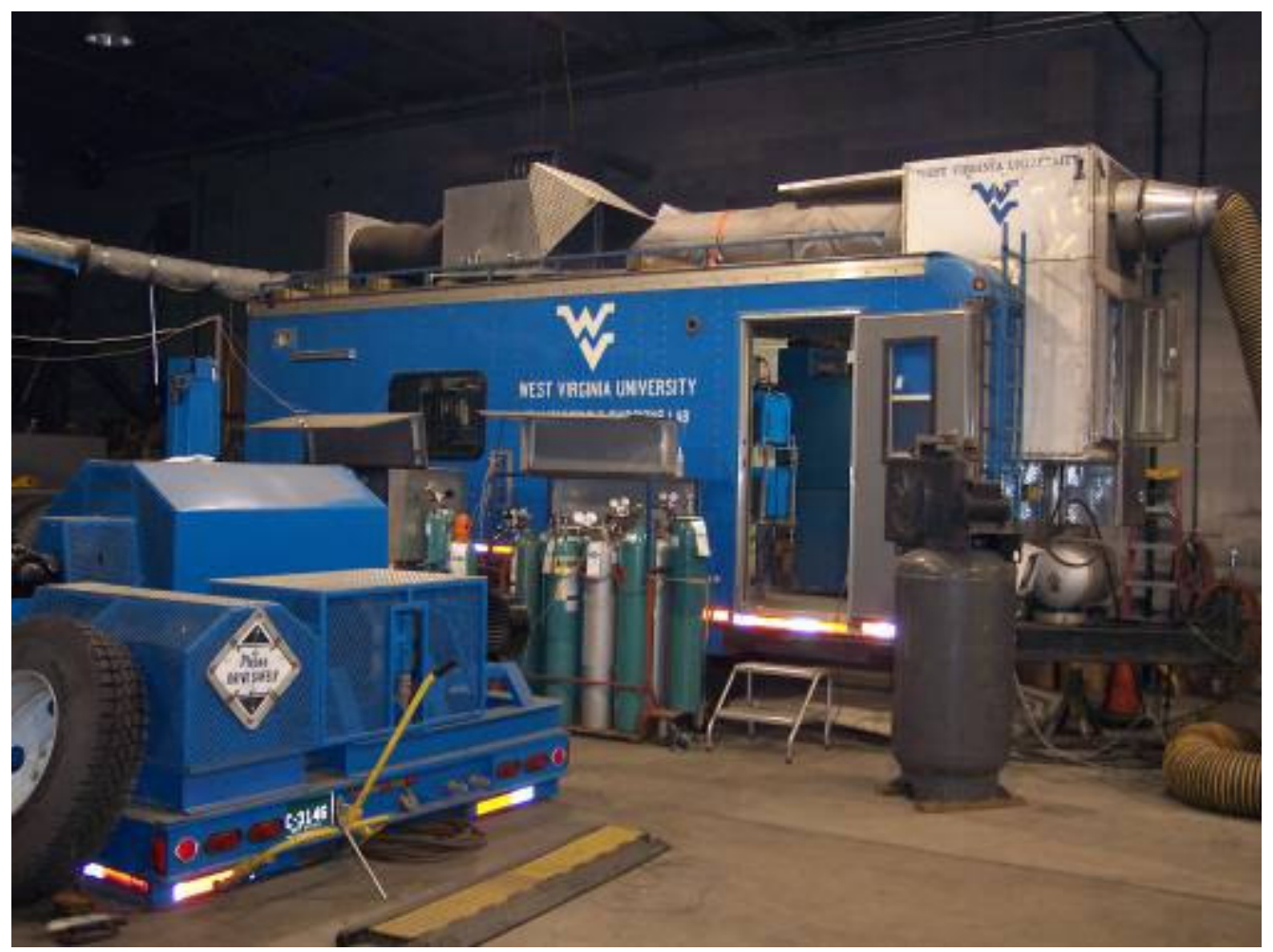

Figure 3.11: Analytical Trailer.

\subsubsection{Instrument Control and Data Acquisition}

The analytical trailer houses the control computer. The computer is used for controlling the test as well as data acquisition. The speed and torque are controlled as a function of time during a test sequence as well as the software for calibration and reduction. The test vehicle is outfitted with a monitor that displays the test cycle that the driver must follow. 


\subsection{Test Cycle Development}

\subsubsection{Introduction}

A raw file of data recorded from a refuse truck, performing its usual duties, was sent to WVU for the purpose of developing an appropriate test cycle to be used on the THDVETL. The vehicle's speed during its daily route was analyzed for use in the test development process. The developed test cycles were to be an appropriate representation of the original cycle and yet be short enough for practical testing and allow for good repeatability of tests.

\subsubsection{Original recorded data}

The original recorded cycle was roughly 6 hours in length and contained clear sections of low speed trash pick-up (stop-and-go) as well as high speed (transport). The transport sections at the beginning and end of the cycle were labeled High Speed 1 and High Speed 2 respectively while the central portion was labeled the Low Speed section. The recorded parameters can be seen in Figure 3.12 and Figure 3.13 below. The graph shows the extensive amount of time that the refuse truck spends in the transient pick up mode, where hydraulic assistance is most effective. The developed tests were to be repeated 3 times each to catch any anomalies and to ensure repeatability. 


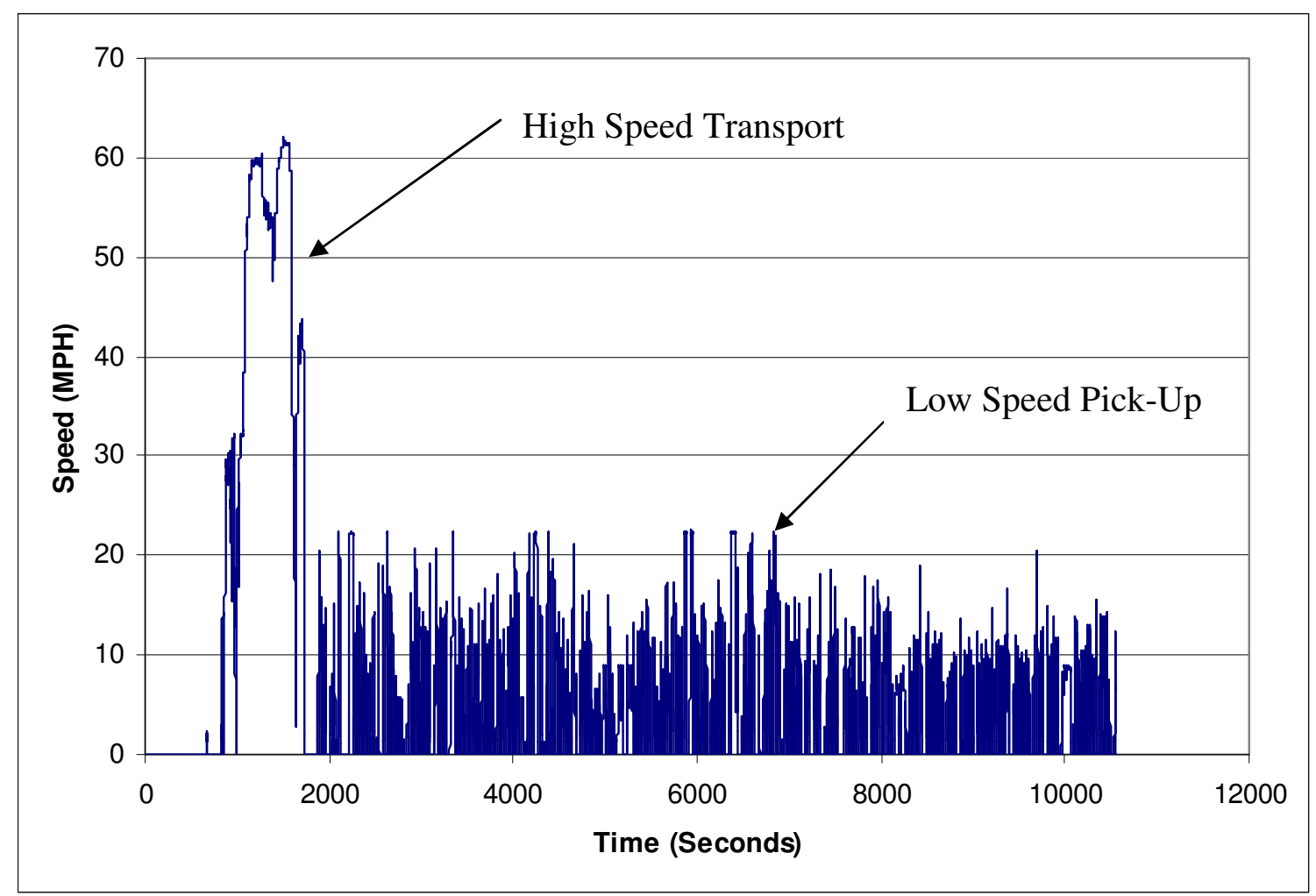

Figure 3.12: Recorded Saginaw Cycle $\left(1^{\text {st }}\right.$ Half $)$

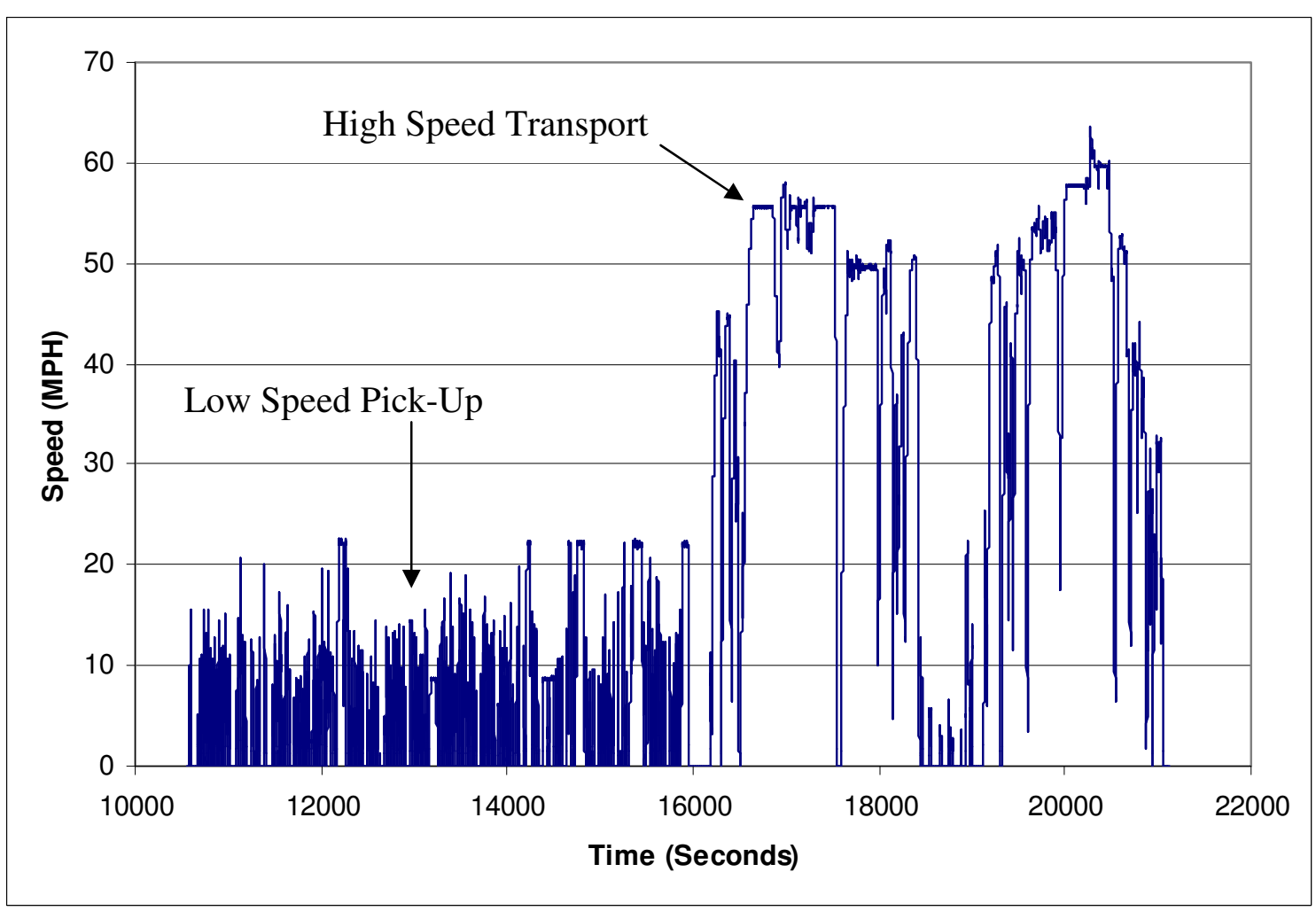

Figure 3.13: Recorded Saginaw Cycle $\left(2^{\text {nd }}\right.$ Half $)$ 


\subsubsection{Developed Test Cycles}

Development of the test cycles initially attempted to take an actual section from the original cycle that was representative of the whole. Standard practice recommended to keep cycle length roughly 30 minutes in length [23] but it was soon decided to split the high and low speed portions to better evaluate the individual driving conditions. By splitting the original data up into its high speed transport and its low speed pick-up portions, it was easier to find a section of the original data that could be used to represent the entirety of the transport section. An algorithm, developed and implemented at WVU, selected different peaks from the low speed section and found a combination that mimicked the averages from the low speed section (original data used to develop the test cycles can be viewed in Appendix C). When this was completed the result was a separate transport and pick-up cycle that represented the original cycle. An appropriate amount of idle time was also included for emissions delay which occurs due to the distance between the sampling probe and the analyzers. The final developed cycles were labeled Saginaw Transport Cycle (STC), the Saginaw Pick-Up (SPU) cycle and steady state (SS). The developed representative cycles are shown in Figure 3.14, 3.15, and 3.16. Cycle statistics are presented in Table 3.4.

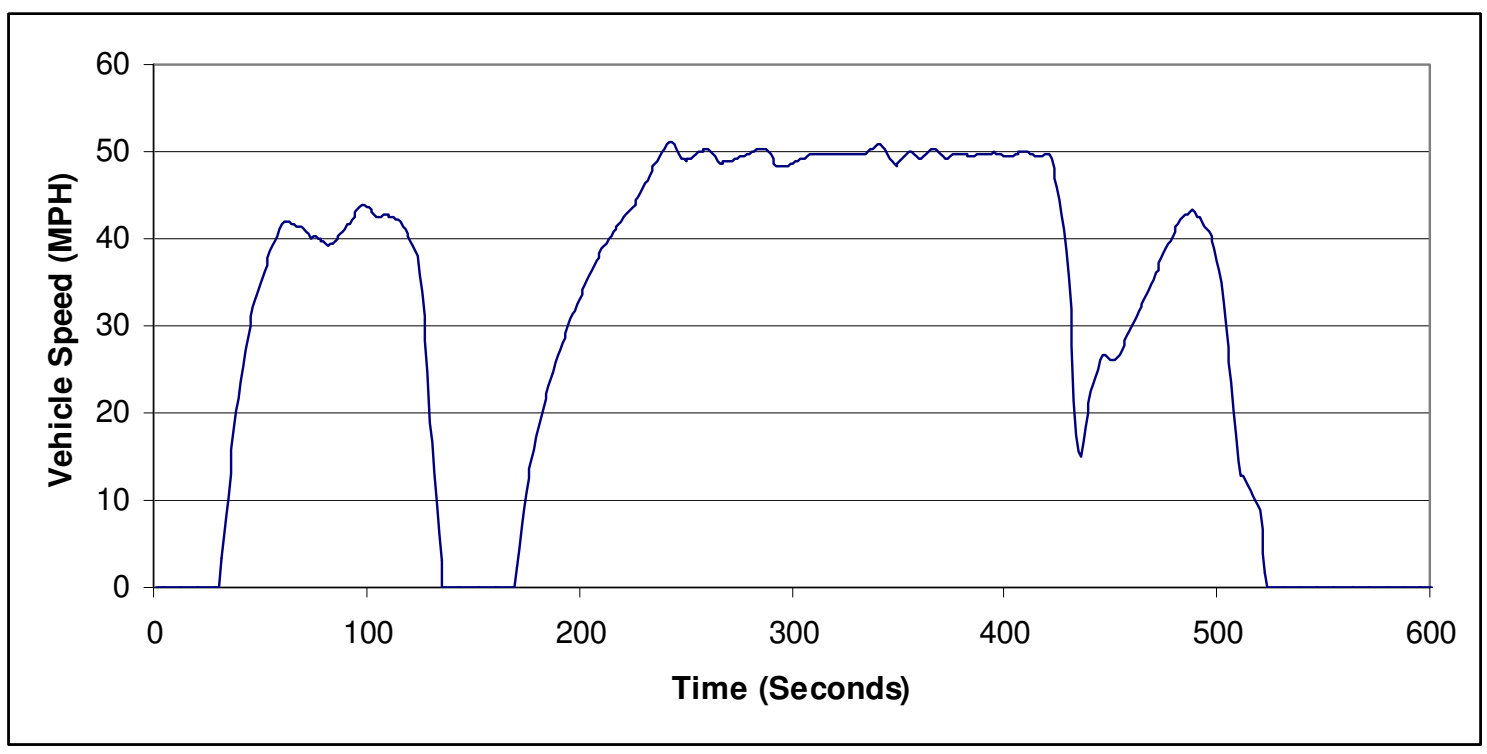

Figure 3.14: Developed Saginaw Transport Cycle (STC) 


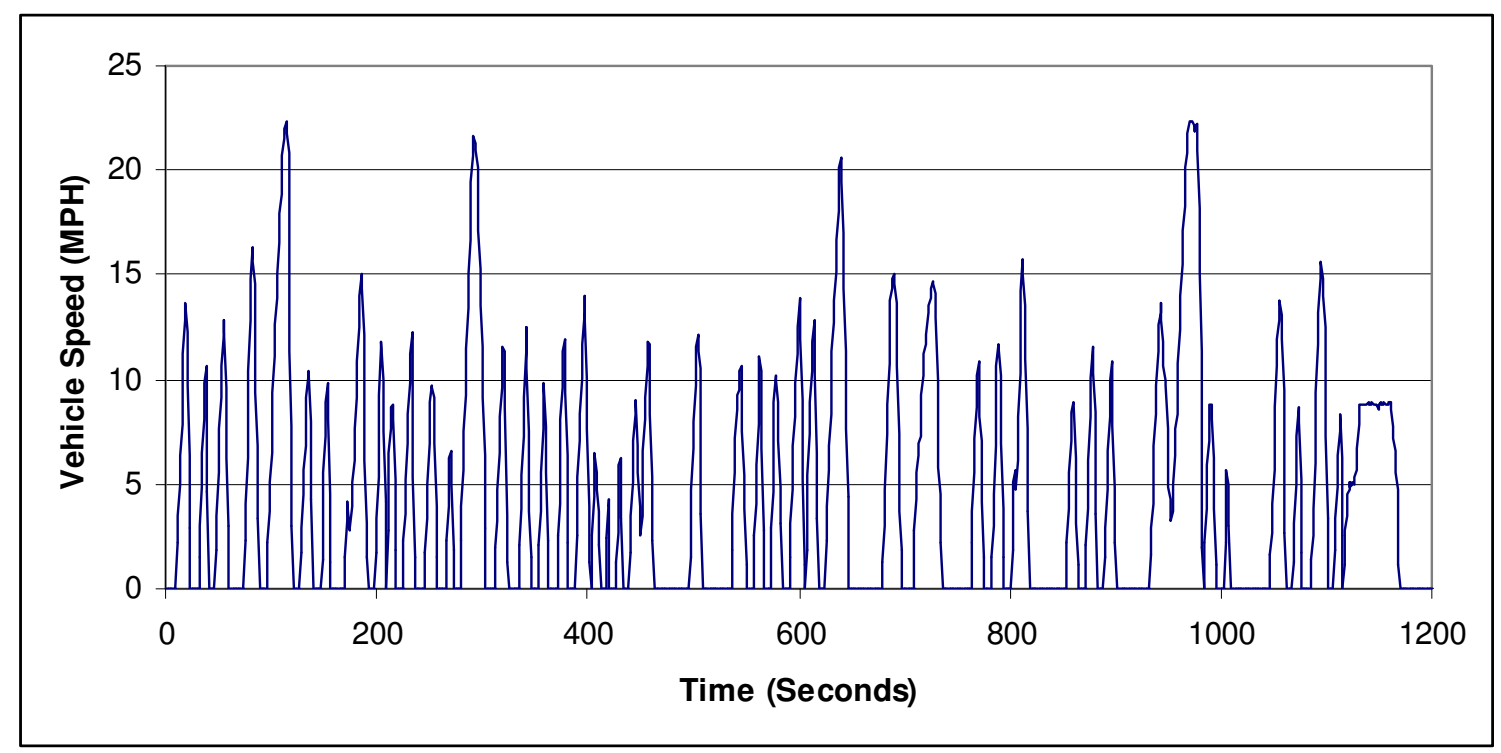

Figure 3.15: Developed Saginaw Pick Up Cycle (SPU)

The separate developed sections were pieced together to show their approximation of the original cycle and this whole developed test cycle can be seen in the Figure 3.16. For testing purposes the two developed cycles were kept separate to conform with standard engine testing procedures of test durations being between 10 and 30 minutes which also made it easier to directly compare high speed and low speed performance. 


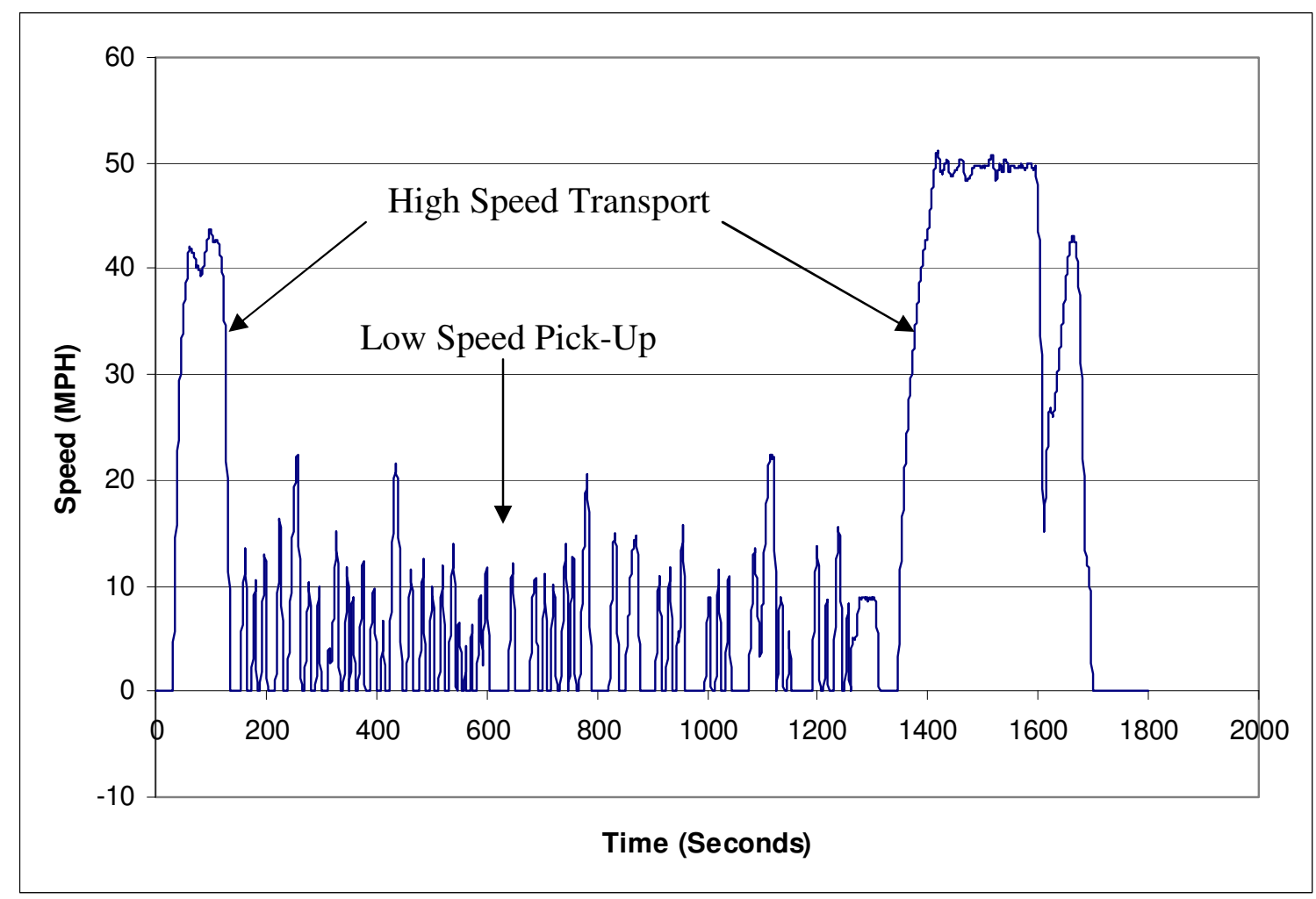

Figure 3.16: Developed Test Cycle (whole).

In the end, the developed cycles mimicked that of the original cycle well and the baseline vehicle had no trouble validating the cycle (see section 4.3). In SAE J2711 the major parameters listed when comparing test cycles were: average speed, standard deviation of speed, maximum speed, maximum acceleration, maximum deceleration, and idle [23]. The statistics of the original cycle were calculated and used to ensure the developed cycles were similar in behavior to the original (see Table 3.4). 
Table 3.4: Comparison of Recorded Cycle to Developed Test Cycles.

\begin{tabular}{|c|c|c|c|c|c|c|c|}
\hline & 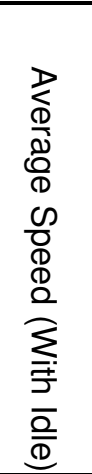 & 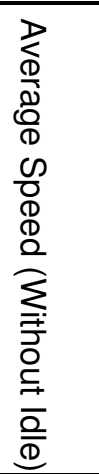 & 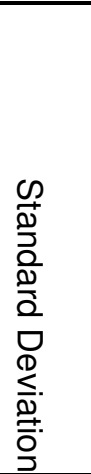 & 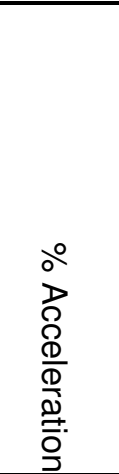 & 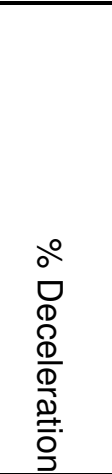 & 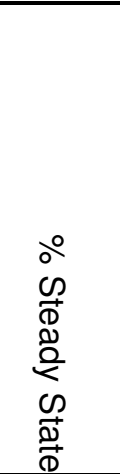 & $\frac{\circ^{\circ}}{\frac{\bar{\alpha}}{\mathrm{D}}}$ \\
\hline Original Recorded Data (Whole) & 13.7 & 22.7 & 19.2 & $24.0 \%$ & $16.5 \%$ & $19.9 \%$ & $39.5 \%$ \\
\hline Original Data (High Speed 1) & 23.0 & 43.7 & 25.2 & $8.23 \%$ & $37.6 \%$ & $37.6 \%$ & $54.2 \%$ \\
\hline Original Data (High Speed 2) & 36.0 & 42.6 & 21.2 & $21.5 \%$ & $14.6 \%$ & $48.3 \%$ & $15.7 \%$ \\
\hline Original Data (High Speed avg.) & 29.5 & 43.2 & 23.2 & $14.9 \%$ & $26.1 \%$ & $42.9 \%$ & $42.9 \%$ \\
\hline Original Data (Low Speed) & 4.66 & 8.81 & 5.98 & $28.1 \%$ & $19.5 \%$ & $5.24 \%$ & $47.1 \%$ \\
\hline Developed Cycle (Whole) & 13.0 & 21.0 & 17.2 & $32.2 \%$ & $20.9 \%$ & $8.72 \%$ & $38.2 \%$ \\
\hline Developed Cycle (High Speed (STC)) & 30.0 & 39.5 & 19.9 & $28.2 \%$ & $16.3 \%$ & $31.5 \%$ & $24.0 \%$ \\
\hline Developed Cycle (Low Speed (SPU)) & 4.50 & 8.22 & 5.43 & $34.2 \%$ & $23.3 \%$ & $34.8 \%$ & $7.70 \%$ \\
\hline
\end{tabular}




\section{RESULTS AND DISCUSSION}

\subsection{Introduction}

The scope of this project was to implement a proper procedure to evaluate a hybrid vehicle and characterize exhaust emissions from the vehicle. The THDVETL was identified as an appropriate venue for testing such a hybrid vehicle, thus it was sought out for use in this evaluation which took place on December $12^{\text {th }} 2005$. Test validation was performed by the baseline vehicle (see Section 4.3). The evaluation of emissions, gradeablilty, fuel economy and engine behavior are presented in sections 4.4-4.10. The prototype was developed under the premise of being equal to its baseline counterpart in performance while superior in emissions and fuel consumption. The two similar vehicles were subjected to the cycle (see Section 3.4) developed specifically for this study which was derived from a sample of raw data. The test consisted of two separate transient cycles (SPU, STC) as well as a series of steady state tests and a gradeabilty test.

Integrated results, reduced by Equation 4.1, were used for comparing the hybrid and baseline vehicles. The calculation for percent difference used in this study for comparison of the two test vehicles is given by Equation 4.2, where the measured value in this case is the hybrid vehicle and the reference value is taken to be the baseline vehicle or developed test cycle data. Results presented in $\mathrm{g} / \mathrm{mile}$ are presented in Appendix D.

$$
\begin{gathered}
I=\sum_{i=1}^{N} x_{i}\left(t_{i}-t_{i-1}\right) \\
\% \text { Difference }=\left(\frac{\text { measuredvalue }- \text { referencevalue }}{\text { reverencevalue }}\right)(100)
\end{gathered}
$$

Equation 4.1

Equation 4.2

\subsection{Test Outcome}

The baseline vehicle was tested first at 56,000 lbs and it faithfully followed the test cycles developed for this study. The hybrid vehicle was then tested but had difficulty following the prescribed test cycle. The test weight was reduced to $40,000 \mathrm{lb}$, and testing 
resumed for the hybrid. Technical difficulties, consisting of mechanical driveline failures and apparently ineffective control strategy, were encountered during this test continuation. Even with the reduced weights, the hydraulic hybrid test vehicle failed to fully follow the STC cycle. Following the test completion of the hybrid vehicle, the baseline vehicle was tested again, but this time at the reduced load $(40,000 \mathrm{lb})$. WVU generated short reports, containing each test run and warm up, trial runs, are found in Appendix D.

\subsection{Repeatability}

The tests performed on the baseline vehicle were used to validate the developed test cycles. The repeatability for the SPU and STC tests was found by comparing the test runs $(40,000 \mathrm{lb}$ baseline tests) to the developed test cycles. The evaluation validated the test cycles and the evaluation proved that the developed cycle was attainable by the baseline vehicle. Figure 4.1 and Figure 4.2 map the baseline's vehicle speed over the developed test cycles and it can be seen that the traces overlap. 


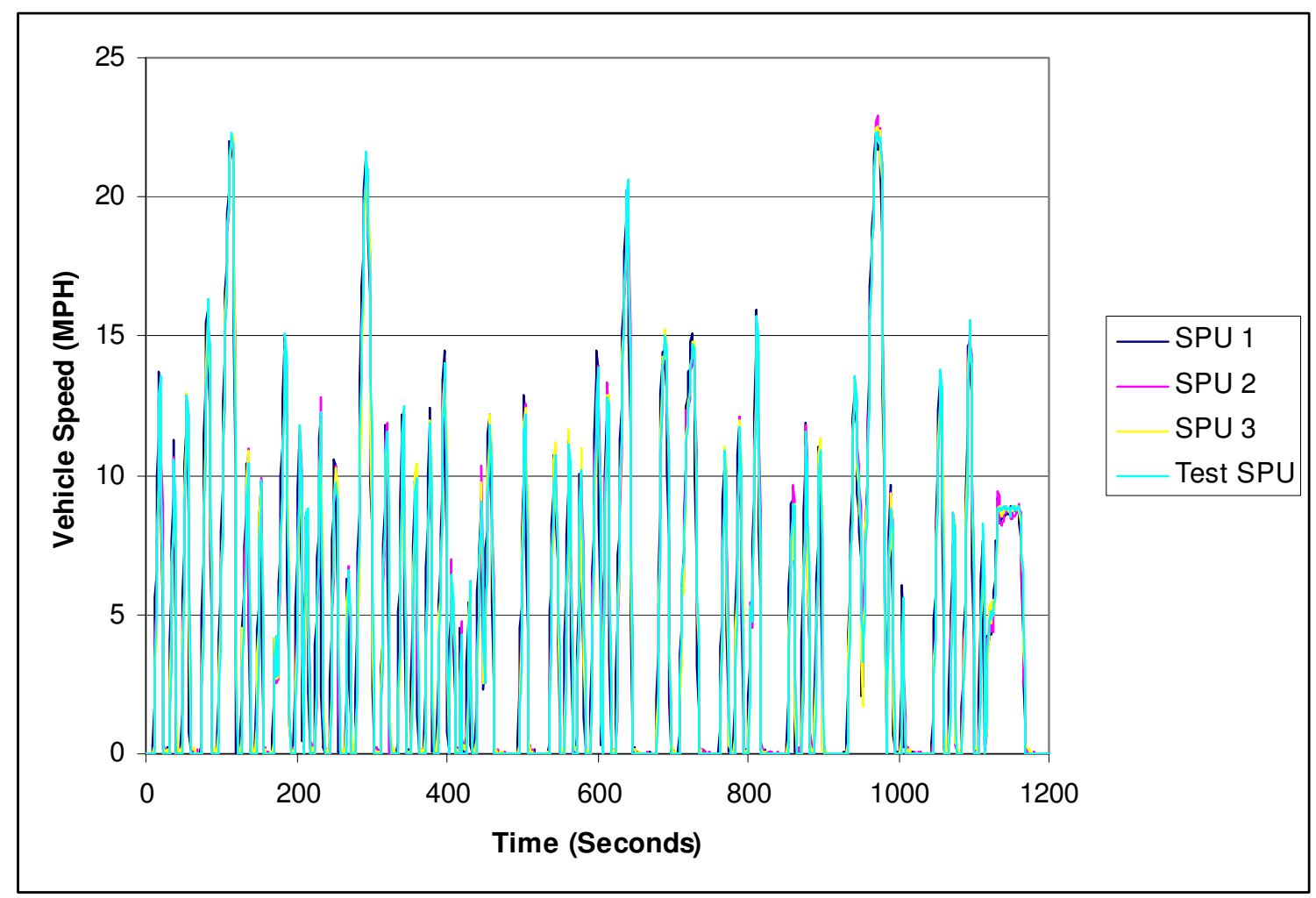

Figure 4.1: SPU Baseline Repeatability Comparison.

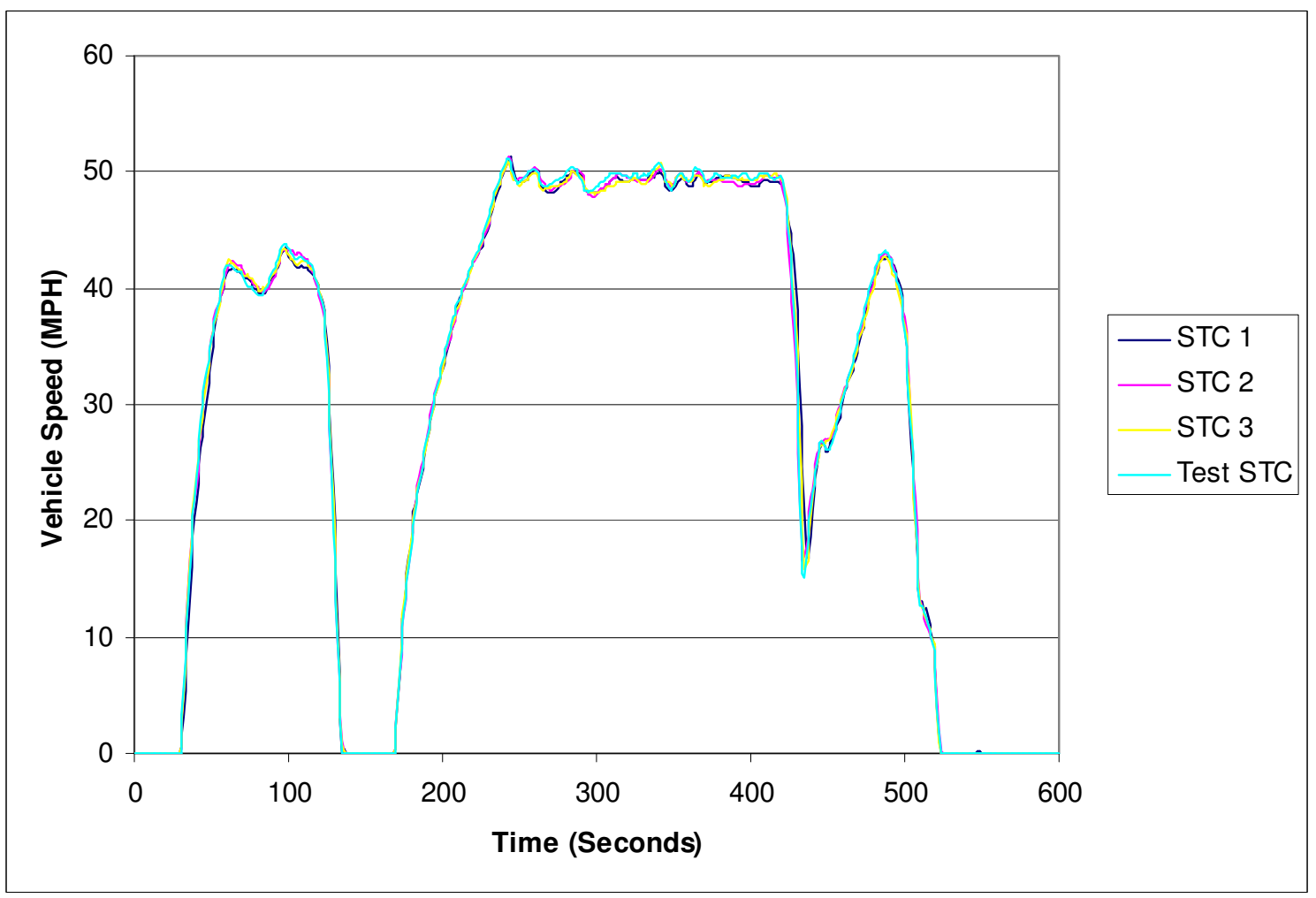

Figure 4.2: STC Baseline Repeatability Comparison. 
The baseline performance was compared to the test cycle as well as the subsequent runs and can be seen the Figures 4.1-4.6. The plots are fitted with a linear regression that best fits the data. A perfectly repeatable run would be represented by the equation $\mathrm{y}=1 \mathrm{x}$ and have an $\mathrm{R}^{2}$, how well the linear regression represents the graphed data, equal to 1 . Suggested values of $\mathrm{R}^{2}$ for hybrid vehicles, is a value of at least 0.8 or it is recommended that the tests be repeated [23]. There was good repeatability for the baseline with an $\mathrm{R}^{2}$ equal to 0.988 and 0.997 for SPU 1 and STC 1 respectively with the developed test cycles. Figure 4.4 below shows the good correlation between SPU1 and SPU $2\left(\mathrm{R}^{2}=0.988\right)$. These values are very consistent considering the human error involved with someone physically driving the test cycle. In Figure 4.5 and Figure 4.6 comparisons were made of STC 1 to the developed test cycles and between STC 1 and STC 2 respectively. The $\mathrm{R}^{2}$ value was over 0.99 between the STC 1 and the developed cycle and between STC 1 and STC 2. The remainder of SPU and STC tests followed this same trend.

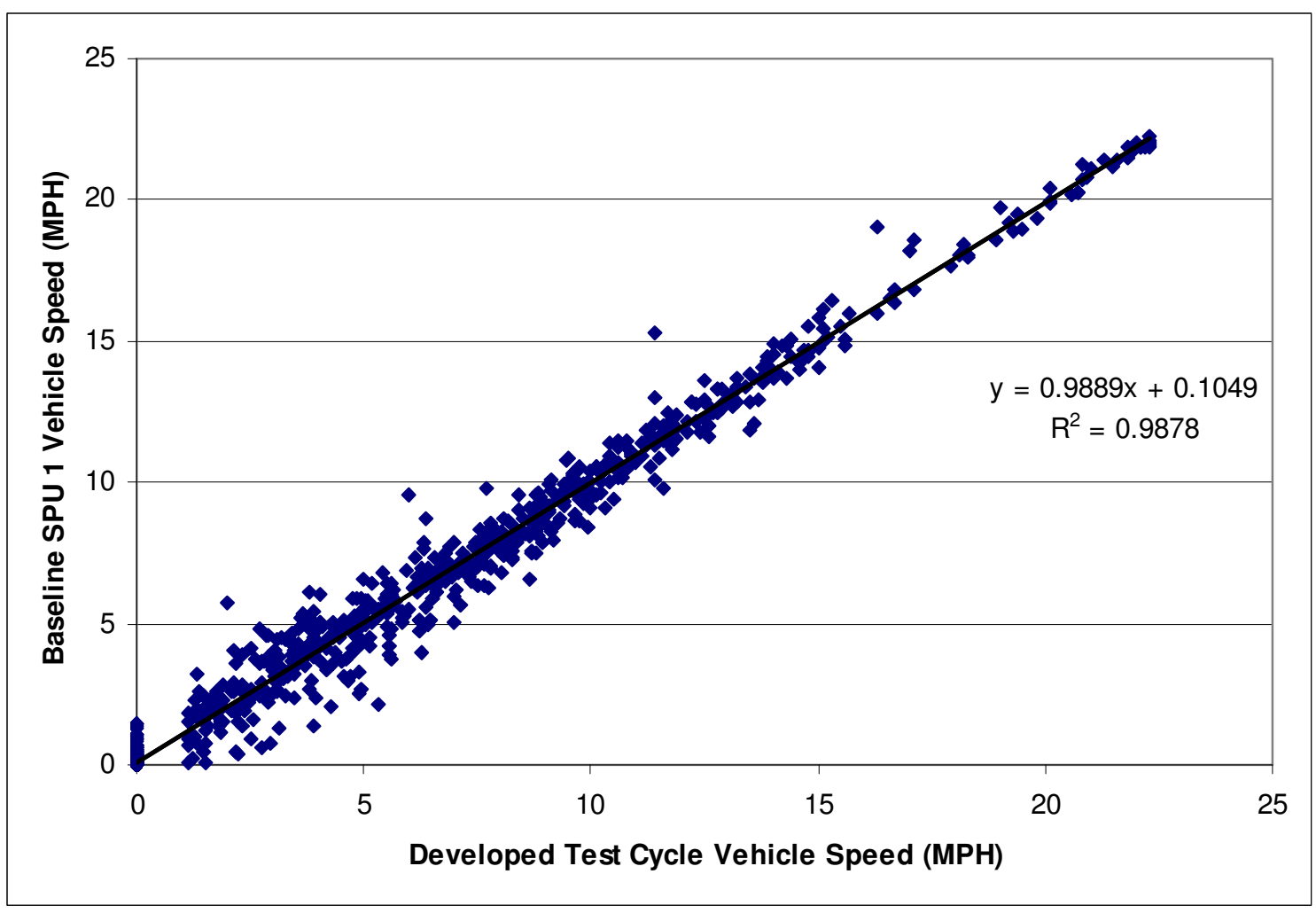

Figure 4.3: Baseline SPU 1 Comparison to Developed Test Cycle. 


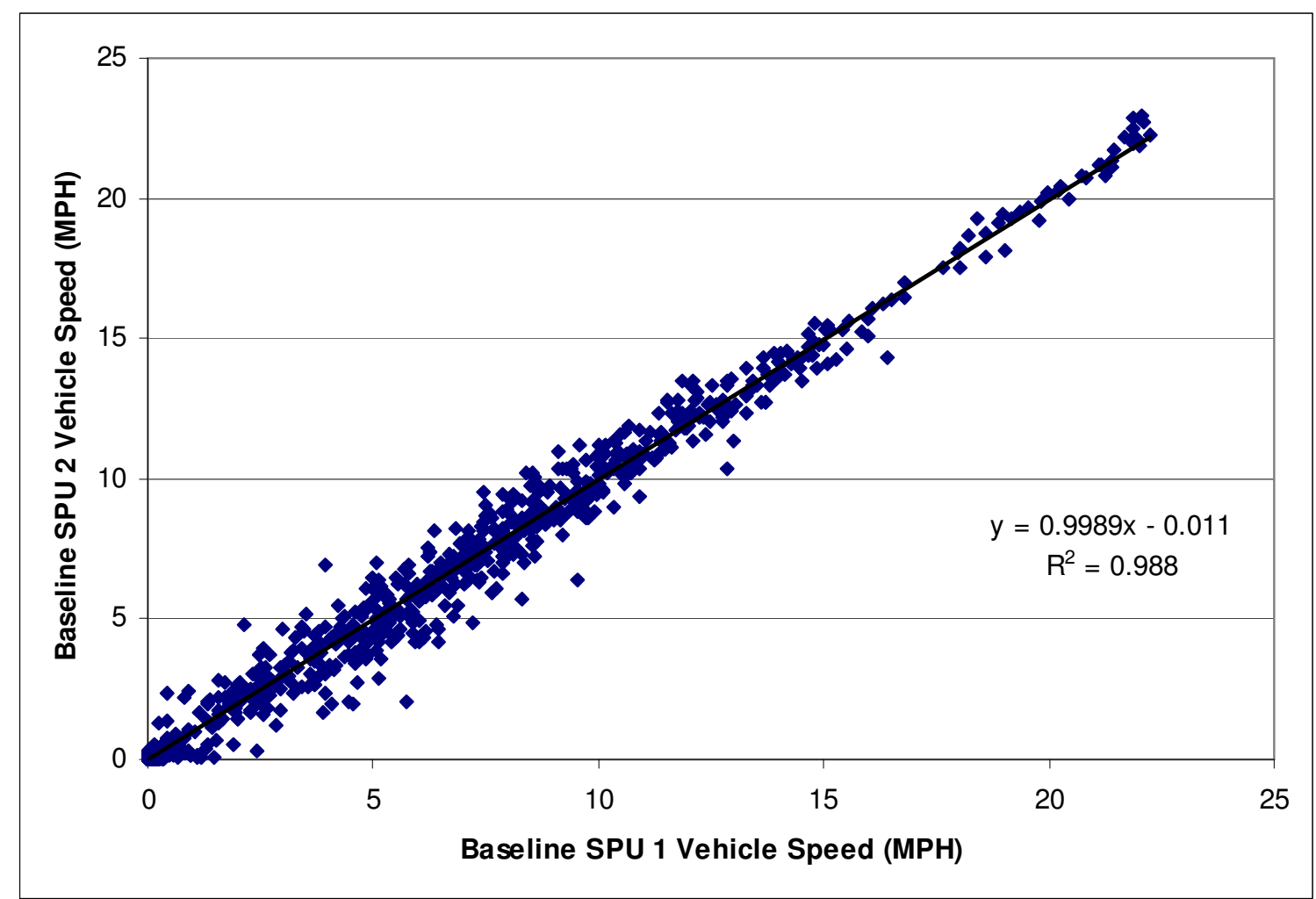

Figure 4.4: Baseline Repeatability for SPU Tests.

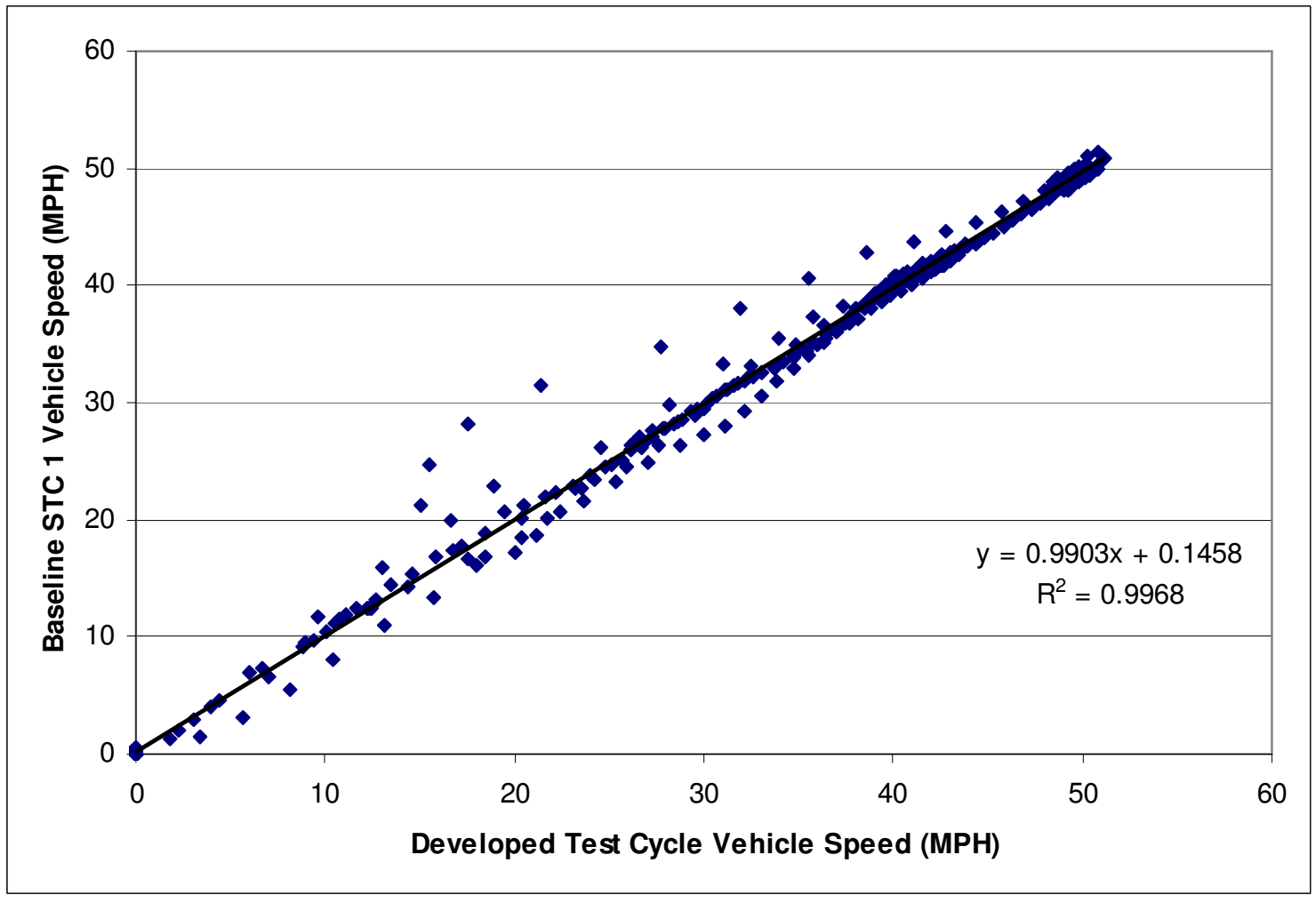

Figure 4.5: Baseline STC 1 Comparison to Developed Test Cycle. 


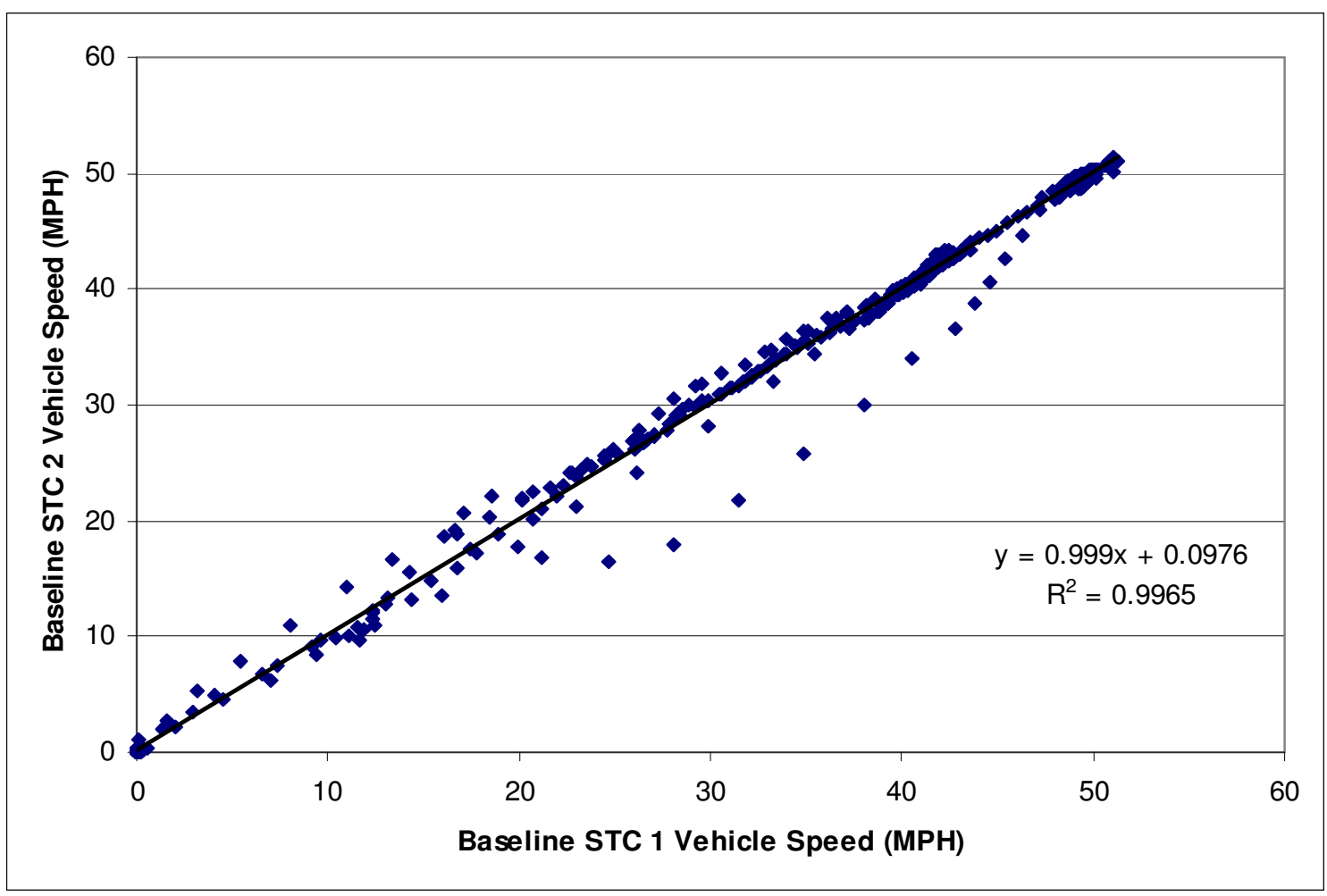

Figure 4.6: Baseline Repeatability for STC runs.

Additional comparisons between the baseline and the developed test cycles were completed by performing a mileage comparison. This is useful when using the distance based testing on the THDVETL and the vehicle should travel the same distance prescribed by the developed cycle. Table 4.1 compares the individual baseline test runs mileage to the calculated mileage of the developed test cycles. The result is a difference of the mileage between the individual tests and the developed cycle which gives additional insight into repeatability. Here there was seen less on average less than $1 \%$ difference in miles traveled for SPU and $0.07 \%$ for STC runs. 
Table 4.1: Comparison of Baseline Mileage to the Developed Test Cycles.

\begin{tabular}{|c|c|c|c|}
\hline & Model & Baseline & \\
\hline & Test Weight & $40,000 \mathrm{lb}$ & $\%$ Difference \\
\hline & Developed SPU Test Mileage: & 1.50 & \\
\hline \multirow{13}{*}{ 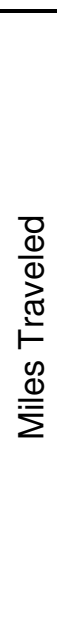 } & SPU 1 & 1.52 & 1.37 \\
\hline & SPU 2 & 1.51 & 0.71 \\
\hline & SPU 3 & 1.51 & 0.71 \\
\hline & Avg. SPU & 1.51 & 0.93 \\
\hline & Std. Dev. & 0.006 & \\
\hline & CV & 0.4 & \\
\hline & Developed STC Test Mileage: & 5.0 & \\
\hline & STC 1 & 4.99 & -0.20 \\
\hline & STC 2 & 5 & 0 \\
\hline & STC 3 & 5 & 0 \\
\hline & Avg. STC & 5 & -0.07 \\
\hline & Std. Dev. & 0.006 & \\
\hline & $\mathrm{CV}$ & 0.1 & \\
\hline
\end{tabular}

Figure 4.7 and Figure 4.8 below indicate the hybrid vehicle's adherence to the developed cycles. The hybrid was much better suited for the low speed pick up cycles than the high speed cycles. Figure 4.8 exemplifies the fact that the hybrid vehicle was not successful in following the vehicle speed traces. 


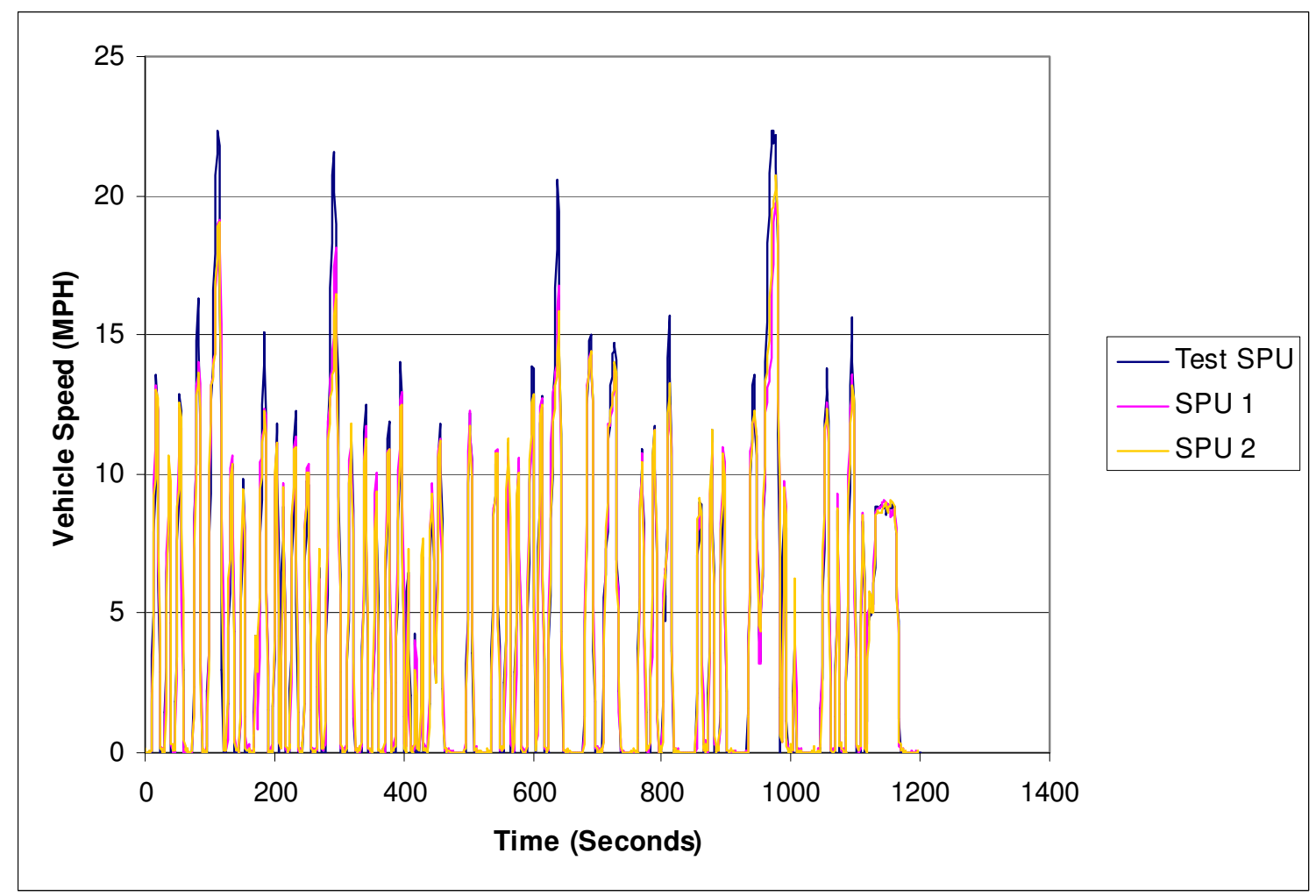

Figure 4.7: Hybrid Vehicle Speed Compared to Developed SPU Test Cycle.

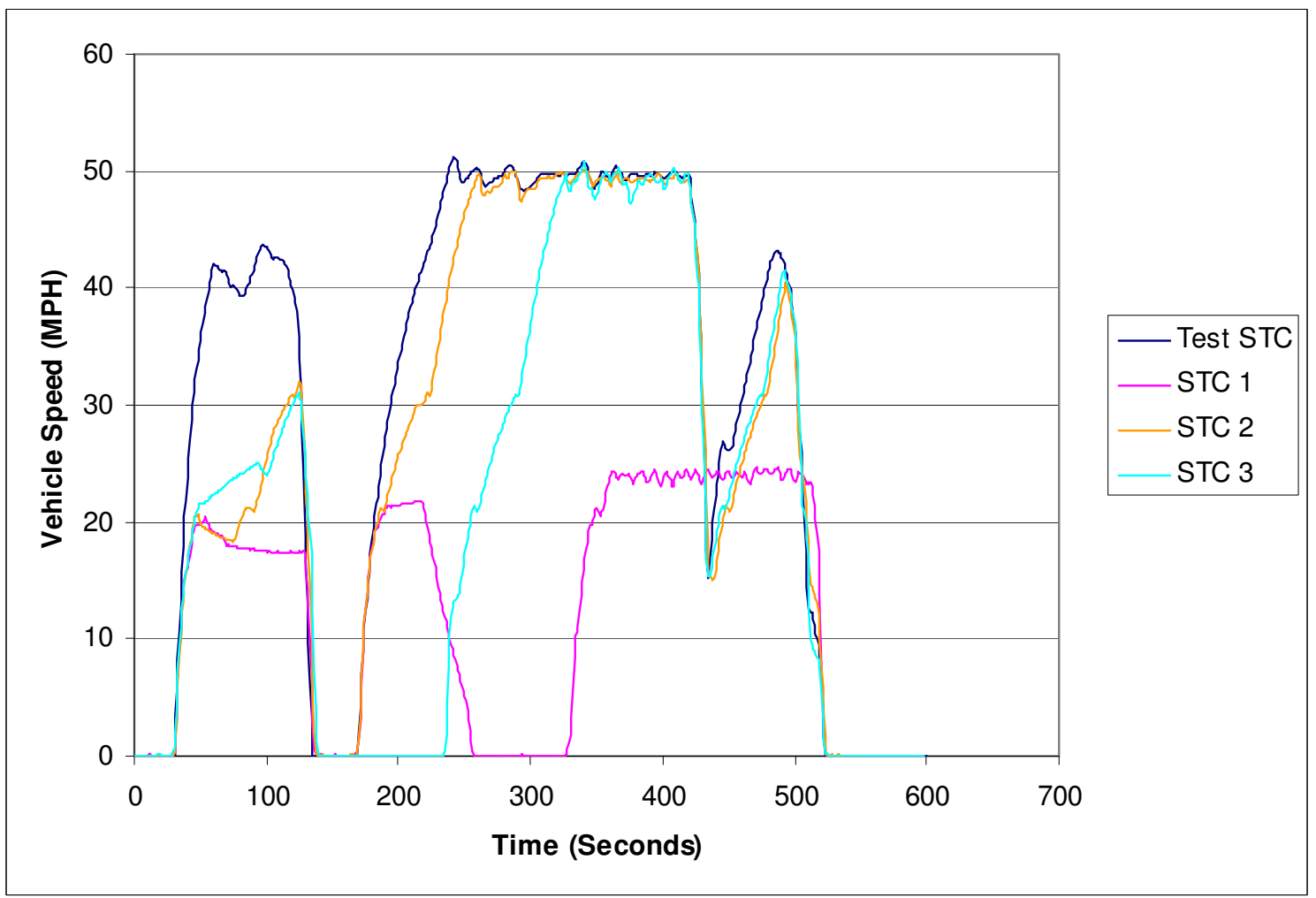

Figure 4.8: Hybrid Vehicle Speed Compared to Developed STC Test Cycle. 
Further investigation into the hybrid's performance revealed a value of 0.95 for $\mathrm{R}^{2}$ for SPU 1. Figure 4.9 and Figure 4.10 below show the hybrids SPU 1 run compared with the developed test cycle as well as the repeatability of the first two runs.

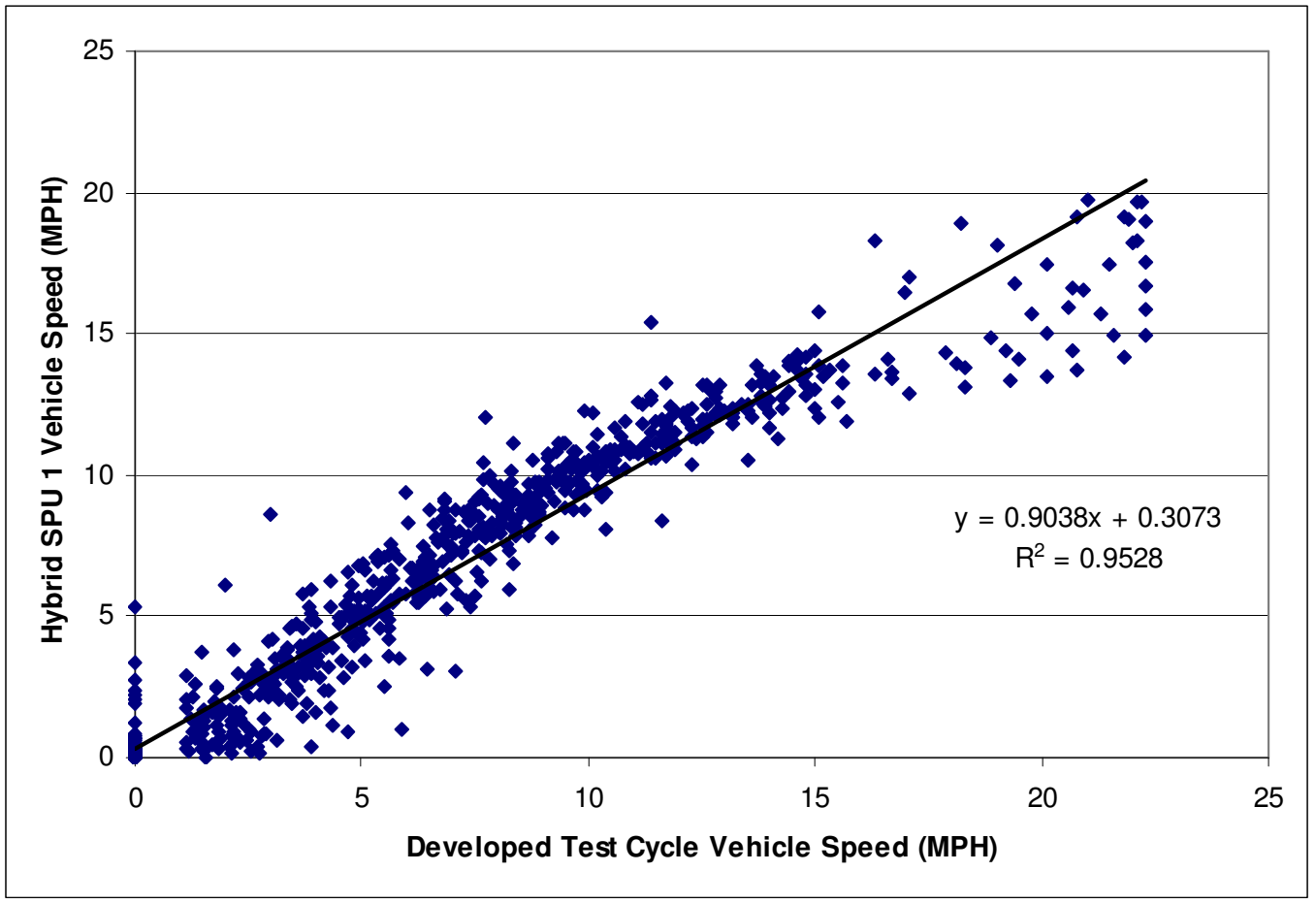

Figure 4.9: Hybrid SPU 1 Run to Developed Test Cycle. 


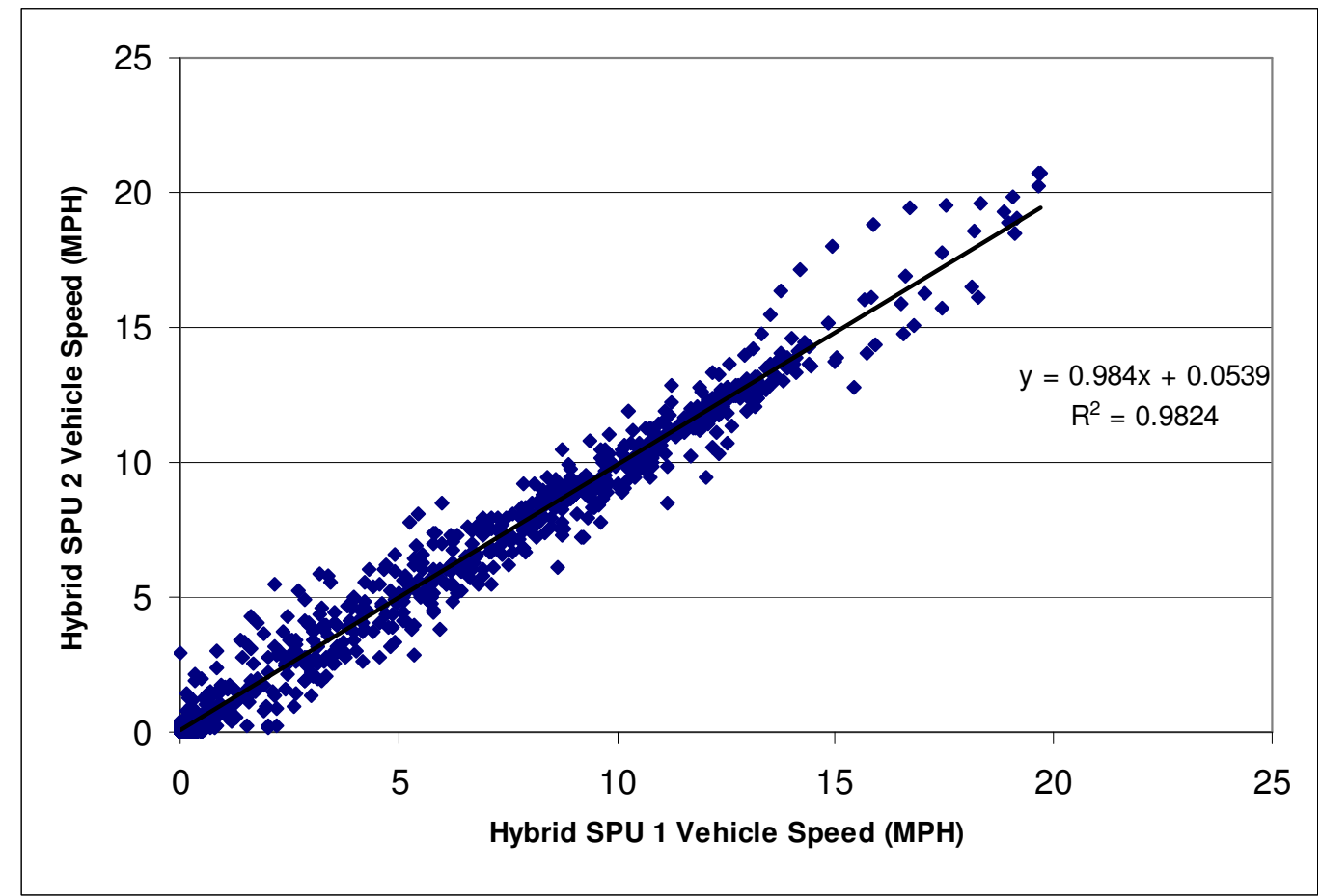

Figure 4.10: Hybrid SPU Repeatability.

Figure 4.10 depicts the repeatability of the hybrid between SPU 1 and SPU $2\left(\mathrm{R}^{2}=\right.$ 0.98). Figure 4.11 shows how STC 2 compared to the developed test cycle. There was no repeatability achieved among STC tests (see Table 4.3 for comparison of mileage traveled). 


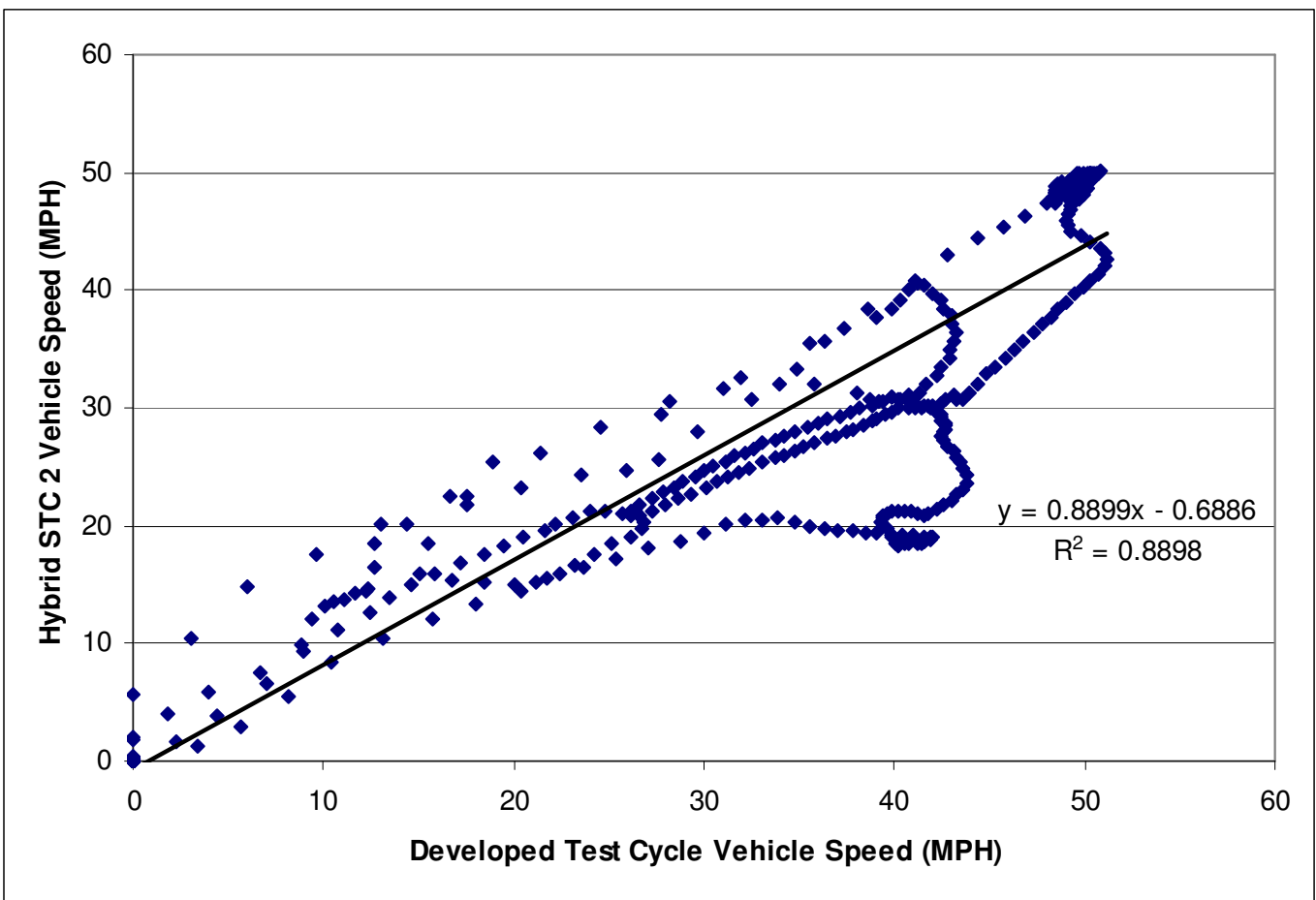

Figure 4.11: Hybrid STC 2 Run Compared to Developed Test Cycle.

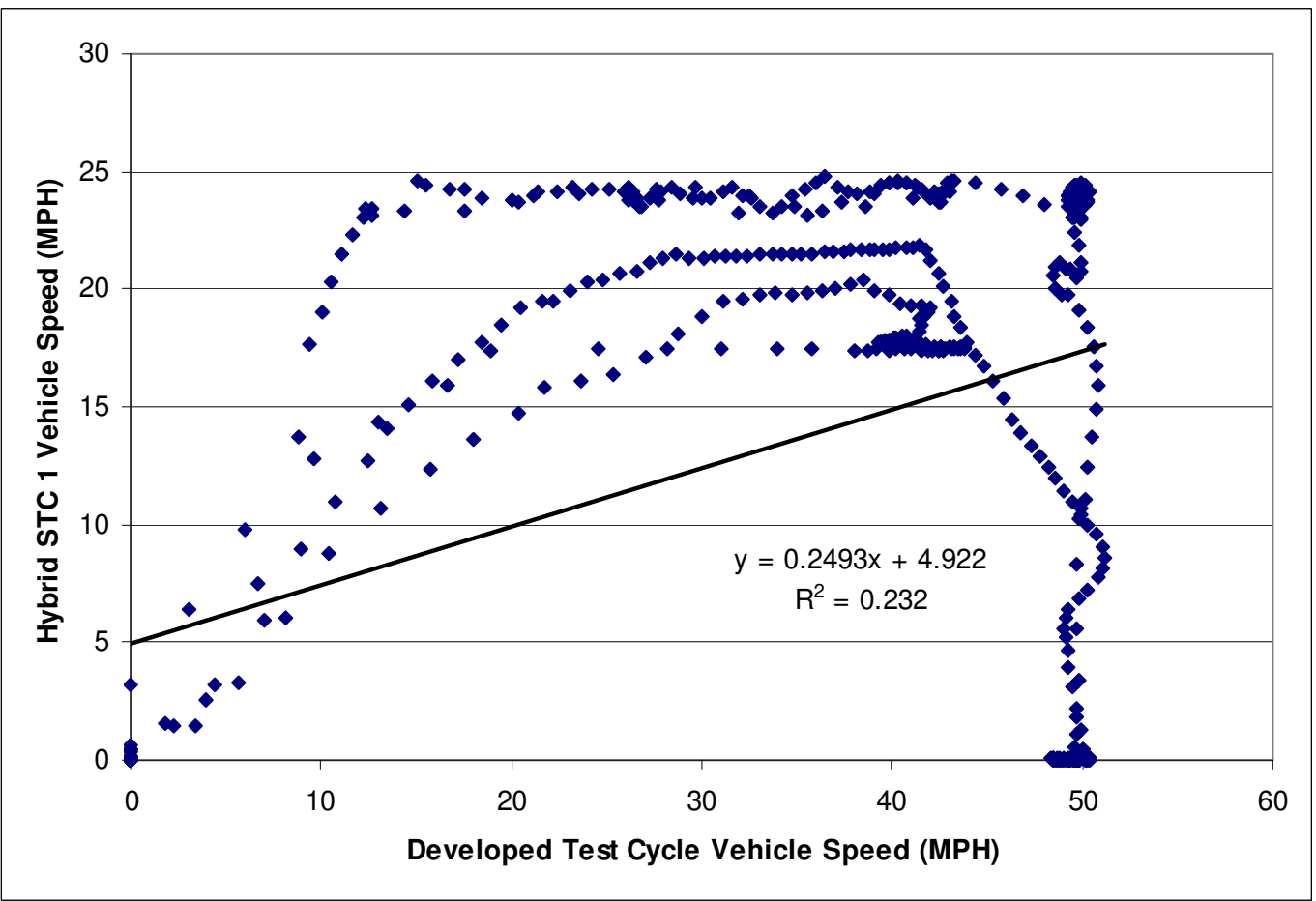

Figure 4.12: Hybrid STC 1 Run Compared to Developed Test Cycle. 


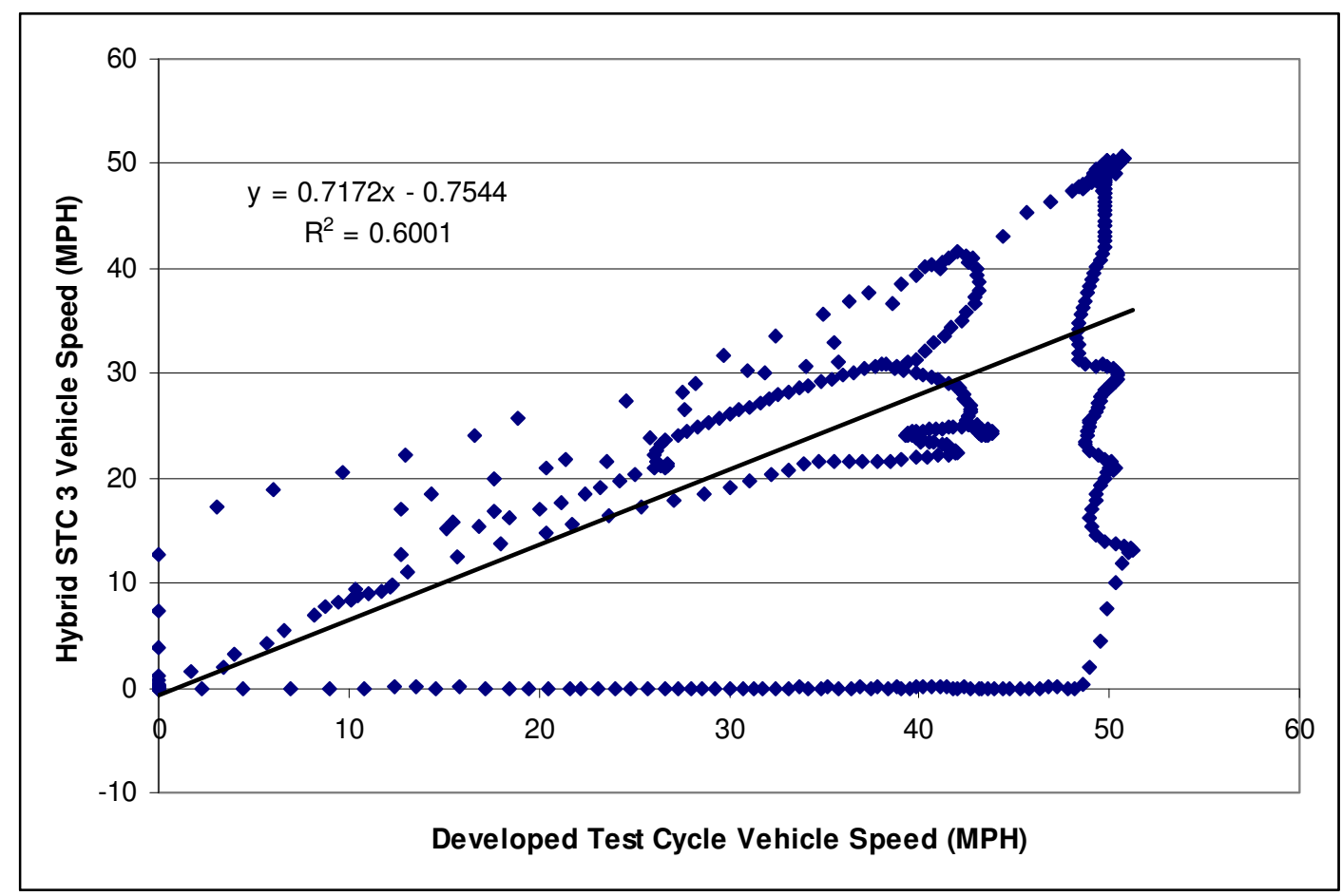

Figure 4.13: Hybrid STC 3 Run Compared to Developed Test Cycle.

The manufacturers may have further data allowing them to know what led to the immediate limitations on STC 1 and subsequent STC tests that prevented the hybrid vehicle from advancing beyond a top speed of $25 \mathrm{mph}$. The hybrid vehicle accelerated and decelerated on target for SPU but this was not the case for STC tests. This may have been a combination of control strategy and mechanical issues. STC 3 encountered a problem where the vehicle failed to engage the drivetrain which led to a delayed acceleration about 235 seconds into the test. It was resolved and the test continued. It should be noted that the hybrid vehicle did not successfully achieve the first ramp during any of its runs (see Figure 4.8). Possible factors attributing to this may have been insufficient initial state of charge or the rate of acceleration being too much for the vehicles system to achieve.

The hybrid vehicle's mileage was also compared to the developed test cycle for further insight to its performance and repeatability. Table 4.2 shows the hybrid vehicles mileage comparison of each test with the developed test cycles. Here one can see an average of 3.1\% difference in miles traveled over SPU tests while the difference over the STC tests vary greatly since the vehicle not following the developed cycle well. The 
vehicle travels slightly less than the mileage prescribed in the SPU test cycle but falls far short of traveling repeatable distances during the STC tests.

Table 4.2: Comparison of Hybrid Vehicle Mileage to the Developed Test Cycles.

\begin{tabular}{|c|c|c|c|}
\hline & Model & Hybrid & \\
\hline & Test Weight & $40,000 \mathrm{lb}$ & \% Difference \\
\hline & Developed SPU Test Mileage & 1.50 & \\
\hline \multirow{13}{*}{ 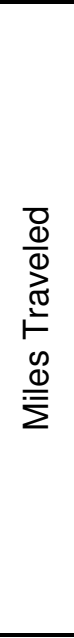 } & SPU 1 & 1.46 & -2.67 \\
\hline & SPU 2 & 1.45 & -3.33 \\
\hline & SPU 3 & 1.45 & -3.33 \\
\hline & Avg. SPU & 1.45 & -3.11 \\
\hline & Std. Dev. & 0.006 & \\
\hline & $\mathrm{CV}$ & 0.4 & \\
\hline & Developed STC Test Mileage & 5.0 & \\
\hline & STC 1 & 2.07 & -58.6 \\
\hline & STC 2 & 4.35 & -13.0 \\
\hline & STC 3 & 3.47 & -30.6 \\
\hline & Avg. STC & 3.30 & -34.1 \\
\hline & Std. Dev. & 1.1 & \\
\hline & $\mathrm{CV}$ & 35 & \\
\hline
\end{tabular}

In order to establish the effects of test weight reduction, the baselines results were compared at both $40,000 \mathrm{lb}$ and $56,000 \mathrm{lb}$ loads. Table 4.3 illustrates the fact that decreasing the load did little to alter the baseline vehicles ability to follow the test cycles.

Table 4.3: Mileage Comparison Between Baseline Tests.

\begin{tabular}{|c|c|c|c|c|}
\hline & Model & \multicolumn{2}{|c|}{ Baseline } & \\
\hline & Test Weight: & $40,000 \mathrm{lb}$ & $56,000 \mathrm{lb}$ & \% Difference \\
\hline \multirow{13}{*}{ 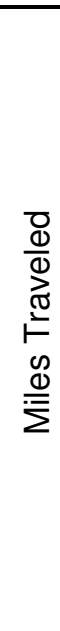 } & SPU 1 & 1.52 & 1.5 & 1.33 \\
\hline & SPU 2 & 1.51 & 1.51 & 0.00 \\
\hline & SPU 3 & 1.51 & 1.49 & 1.34 \\
\hline & Avg. SPU & 1.51 & 1.50 & 0.89 \\
\hline & Std. Dev. & 0.006 & 0.01 & \\
\hline & CV & 0.4 & 0.7 & \\
\hline & & & & \\
\hline & STC 1 & 4.99 & 4.96 & 0.60 \\
\hline & STC 2 & 5 & 4.96 & 0.81 \\
\hline & STC 3 & 5 & 4.97 & 0.60 \\
\hline & Avg. STC & 5 & 4.96 & 0.67 \\
\hline & Std. Dev. & 0.006 & 0.006 & \\
\hline & $\mathrm{CV}$ & 0.1 & 0.1 & \\
\hline
\end{tabular}




\subsection{Saginaw Pick Up (SPU)}

The SPU testing, with its frequent braking and acceleration, was more conducive for hybrid efficiency and this was where the greatest savings and benefits were predicted. Each vehicle was run through three SPU cycles where data were collected, averaged and compared in Table 4.4, Figure 4.14 and Figure 4.15 below for integrated $\mathrm{CO}_{2}$ and $\mathrm{NOx}$ emissions. The results that the hybrid produced more $\mathrm{CO}_{2}$, less $\mathrm{NOx}$ and decreased fuel economy.

Table 4.4: Saginaw Pick Up Cycle Results.

\begin{tabular}{|l|r|r|r|r|r|r|}
\cline { 2 - 7 } \multicolumn{1}{c|}{} & \multicolumn{3}{c|}{ Hybrid } & \multicolumn{3}{c|}{ baseline } \\
\cline { 2 - 7 } \multicolumn{1}{c|}{} & \multicolumn{1}{c|}{$\mathrm{CO}_{2}$} & $\mathrm{NOx}$ & Fuel Econ. & \multicolumn{1}{c|}{$\mathrm{CO}_{2}$} & \multicolumn{1}{c|}{$\mathrm{NOx}$} & Fuel Econ. \\
\hline SPU1 & 12000 & 47.1 & 1.22 & 9760 & 54.6 & 1.55 \\
\hline SPU2 & 12100 & 48.5 & 1.21 & 9670 & 53.7 & 1.56 \\
\hline SPU3 & 12000 & 47.5 & 1.21 & 9720 & 54.0 & 1.55 \\
\hline Avg. & 12033 & 47.7 & 1.21 & 9717 & 54.1 & 1.55 \\
\hline Std. Dev. & 57.735 & 0.721 & 0.006 & 45.092 & 0.458 & 0.006 \\
\hline CV & 0.480 & 1.512 & 0.476 & 0.464 & 0.847 & 0.372 \\
\hline
\end{tabular}




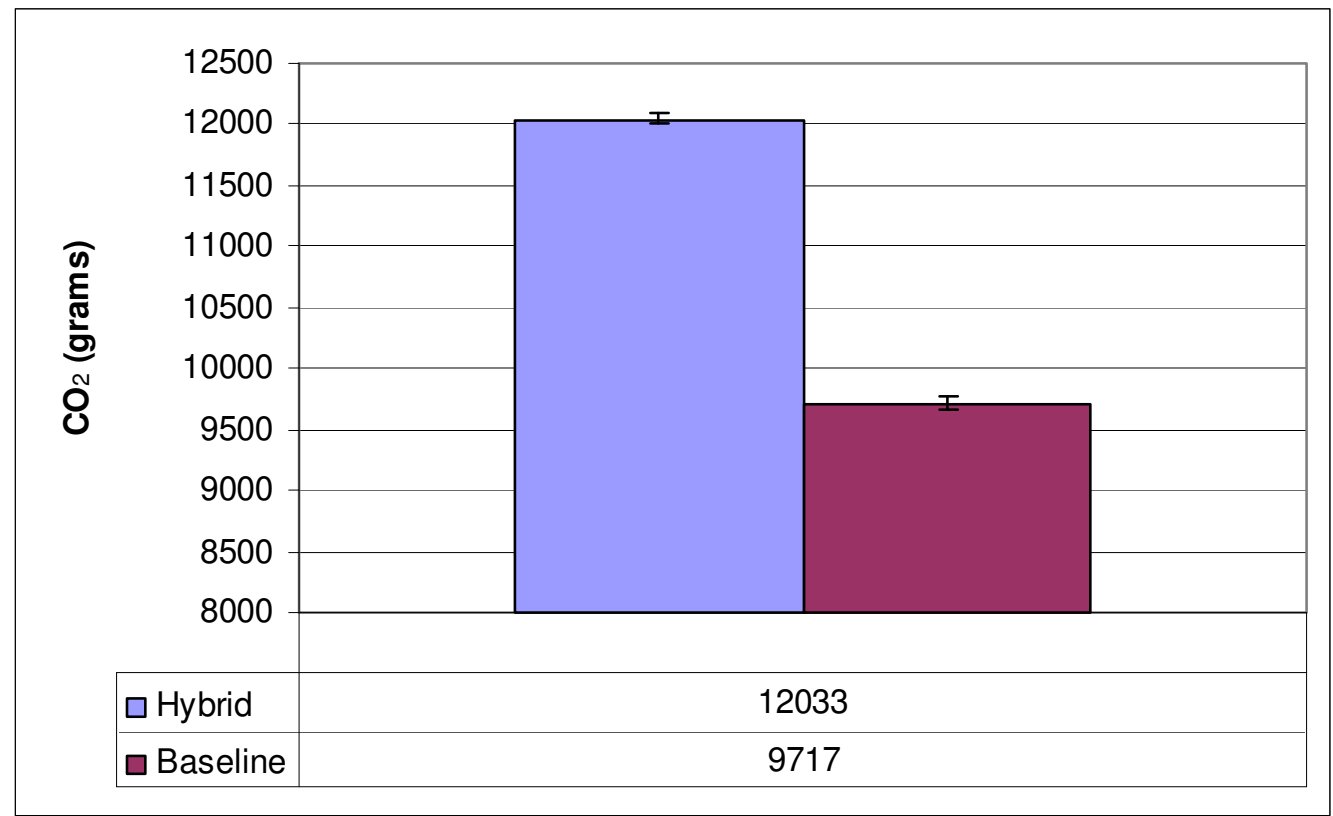

Figure 4.14: Average $\mathrm{SPU} \mathrm{CO}_{2}$ Comparison.

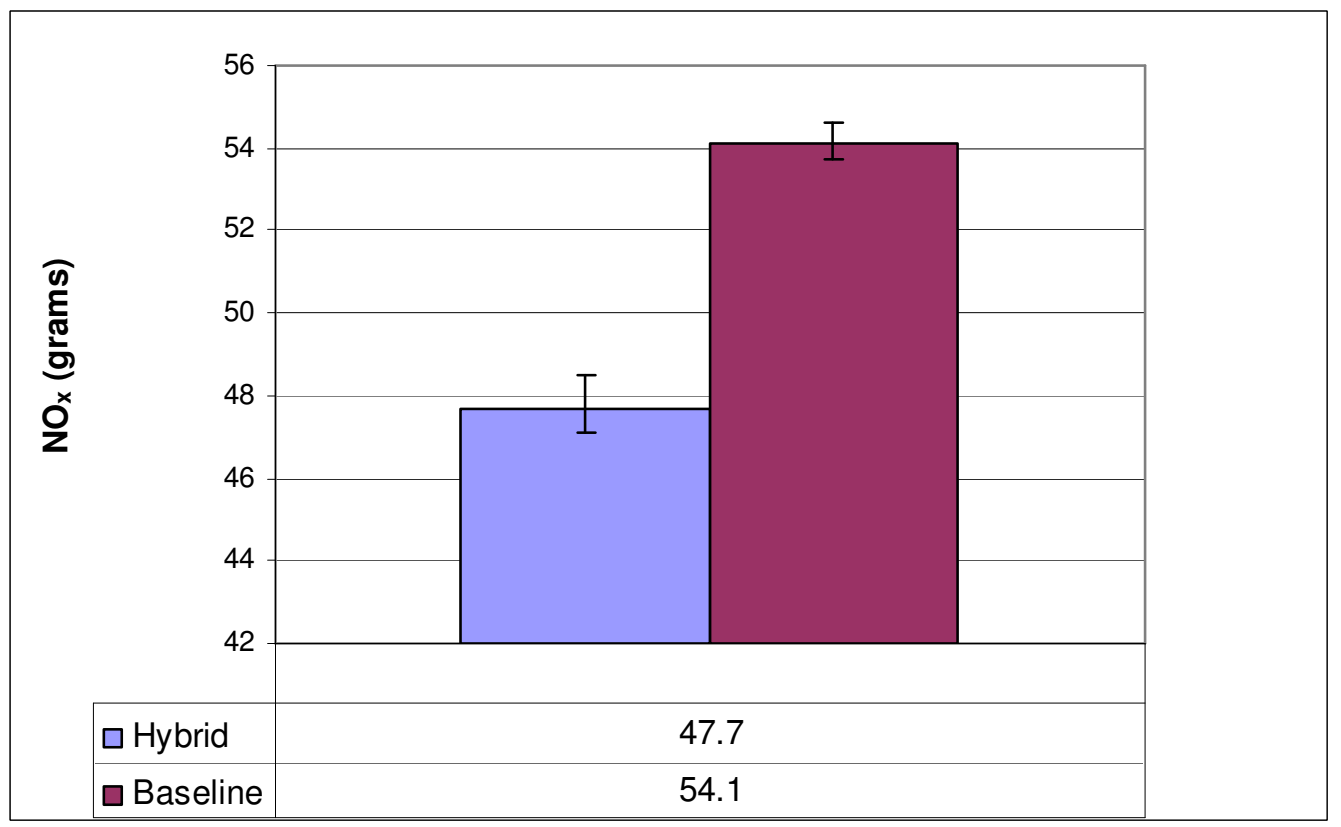

Figure 4.15: Average SPU NOx Comparison. 
Table 4.5: SPU Comparison of Hybrid to Baseline Vehicle.

\begin{tabular}{|l|r|r|r|}
\cline { 2 - 4 } \multicolumn{1}{c|}{} & \multicolumn{3}{c|}{ \% Difference } \\
\cline { 2 - 4 } \multicolumn{1}{c|}{$\mathrm{CO}_{2}$} & \multicolumn{1}{c|}{$\mathrm{NOx}$} & \multicolumn{1}{c|}{ Fuel Econ. } \\
\hline SPU 1 & 22.6 & -13.7 & -21.3 \\
\hline SPU 2 & 24.1 & -9.68 & -22.4 \\
\hline SPU 3 & 23.5 & -12.0 & -21.9 \\
\hline Average & 23.4 & -11.8 & -21.9 \\
\hline Std. Dev. & 0.75 & 2.0 & 0.55 \\
\hline
\end{tabular}

Table 4.5 shows that the hybrid vehicle had an average $23.4 \%$ increase in $\mathrm{CO}_{2}$ while reducing NOx emissions by roughly $11.8 \%$. The main goal of reducing fuel consumption was not achieved. The hybrid vehicle achieved, on average, 21.9\% lower fuel economy than the baseline vehicle. During hybrid vehicle testing, failure of the auxiliary gearbox required it to be replaced.

\subsection{Saginaw Transport Cycle (STC)}

The hybrid vehicle had difficulty following the high speed cycle as shown in Figure 4.8. This inability to maintain and follow the developed test cycle resulted in a data set that was difficult to use for any comparisons or evaluation. The test run that most readily resembled and followed the developed cycle was the second run, STC 2. STC 2 showed trends similar to that of the SPU runs in that there was a reduction in NOx (decrease of $5.85 \%$ ) but an increase in $\mathrm{CO}_{2}$ (increase of $8.27 \%$ ). Fuel economy showed no improvement despite the fact that test runs generally fell below the prescribed test cycle vehicle speed though engine speed was higher for the hybrid vehicle than the baseline (see Figure 4.18). 
Table 4.6: Saginaw Transport Cycle Results.

\begin{tabular}{|l|r|r|r|r|r|r|}
\cline { 2 - 7 } \multicolumn{1}{c|}{} & \multicolumn{3}{c|}{ Hybrid } & \multicolumn{3}{c|}{ baseline } \\
\cline { 2 - 7 } \multicolumn{1}{c|}{} & CO2 & NOx & Fuel Econ. & \multicolumn{1}{l|}{ CO2 } & NOx & Fuel Econ. \\
\hline STC1 & 10000 & 36.6 & 2.07 & 13700 & 67.600 & 3.66 \\
\hline STC2 & 14400 & 62.8 & 3.03 & 13300 & 66.700 & 3.76 \\
\hline STC3 & 11500 & 54.1 & 3.03 & 13200 & 66.100 & 3.79 \\
\hline Avg. & 11966.667 & 51.167 & 2.710 & 13400.000 & 66.800 & 3.737 \\
\hline Std. Dev. & 2236.813 & 13.344 & 0.554 & 264.575 & 0.755 & 0.068 \\
\hline CV & 18.692 & 26.080 & 20.452 & 1.974 & 1.130 & 1.822 \\
\hline
\end{tabular}

Table 4.7: STC Comparison of Hybrid to Baseline Vehicle.

\begin{tabular}{|l|r|r|r|}
\cline { 2 - 4 } \multicolumn{1}{c|}{} & \multicolumn{3}{c|}{ \% Difference } \\
\cline { 2 - 4 } \multicolumn{1}{c|}{} & \multicolumn{1}{c|}{ CO2 } & \multicolumn{1}{c|}{ NOx } & \multicolumn{1}{l|}{ Fuel Econ. } \\
\hline STC 1 & -27.0 & -45.6 & -43.4 \\
\hline STC 2 & 8.27 & -5.85 & -19.4 \\
\hline STC 3 & -12.9 & -18.2 & -20.1 \\
\hline Average & -10.5 & -23.2 & -27.6 \\
\hline Std. Dev. & 14.5 & 16.6 & 11.2 \\
\hline
\end{tabular}

\subsection{Steady State (SS)}

The steady state comparison showed that the baseline performed better than the hybrid. The very nature of the steady state test does not favor a vehicle that relies on regenerative braking, not encountered during steady state operation, for additional fuel saving and emission reduction. The hybrid vehicle was also hindered by having a smaller displacement engine and additional friction losses, stemming from the hydraulic setup in it's drivetrain. The standard steady state tests ranged from 30 to $50 \mathrm{mph}$ in $10 \mathrm{mph}$ increments. Due to the hybrid vehicle's inability to attain the higher speeds, the $50 \mathrm{mph}$ test was forgone, and the gradeability test was performed in its place. The data from the 30 and 40 mph tests can be seen in the Table 4.8 below. 
Table 4.8: Steady State Comparison.

\begin{tabular}{|c|c|c|r|r|r|}
\hline \multicolumn{3}{|c|}{$30 \mathrm{MPH}$} & \multicolumn{4}{c|}{$40 \mathrm{MPH}$} \\
\hline \multicolumn{2}{|c|}{ Integrated $\mathrm{CO}_{2}$ data (grams) } & \multicolumn{3}{c|}{ Integrated $\mathrm{CO}_{2}$ data (grams) } \\
\hline Hybrid & Baseline & $\%$ Difference & Hybrid & Baseline & $\%$ Difference \\
\hline 7790 & 4250 & 83.3 & 7300 & 6350 & 15.0 \\
\hline \multicolumn{3}{|c|}{ Integrated NOx data (grams) } & \multicolumn{3}{c|}{ Integrated NOx data (grams) } \\
\hline Hybrid & Baseline & $\%$ Difference & Hybrid & Baseline & $\%$ Difference \\
\hline 27.0 & 20.5 & 31.7 & 31.1 & 32.7 & -4.89 \\
\hline \multicolumn{3}{|c|}{ Fuel Economy (MPG) } & \multicolumn{4}{c|}{ Fuel Economy (MPG) } \\
\hline Hybrid & Baseline & $\%$ Difference & Hybrid & Baseline & $\%$ Difference \\
\hline 3.19 & 5.84 & -45.4 & 4.31 & 5.21 & -17.3 \\
\hline
\end{tabular}

Table 4.8 shows that the hybrid vehicle produced higher $\mathrm{CO}_{2}$ on both tests and had lower fuel economy for both tests. NOx was not consistent with the values of constituents previously seen in the previous sections. While the hybrid produced more NOx at 30 mph, it emitted less NOx than the baseline at $40 \mathrm{mph}$. This is might be due to the fact that $40 \mathrm{mph}$ lies in a zone where the diesel engine would be the main mode of propulsion and 30 lies near a transition zone between modes of propulsion.

\subsection{Gradeablility}

A gradeability test was performed instead of the hybrid vehicle's last steady state run. The test simulated the forces involved with accelerating on a certain road grade. The gradeability test consisted of exercising the vehicle through a series of accelerations and decelerations. The dynamometer's power absorbers were cycled on and off to simulate the inclined take-off. Although the vehicle may not have followed the intended acceleration curve it is apparent that the hybrid vehicle did have the ability to take-off on a slope. 


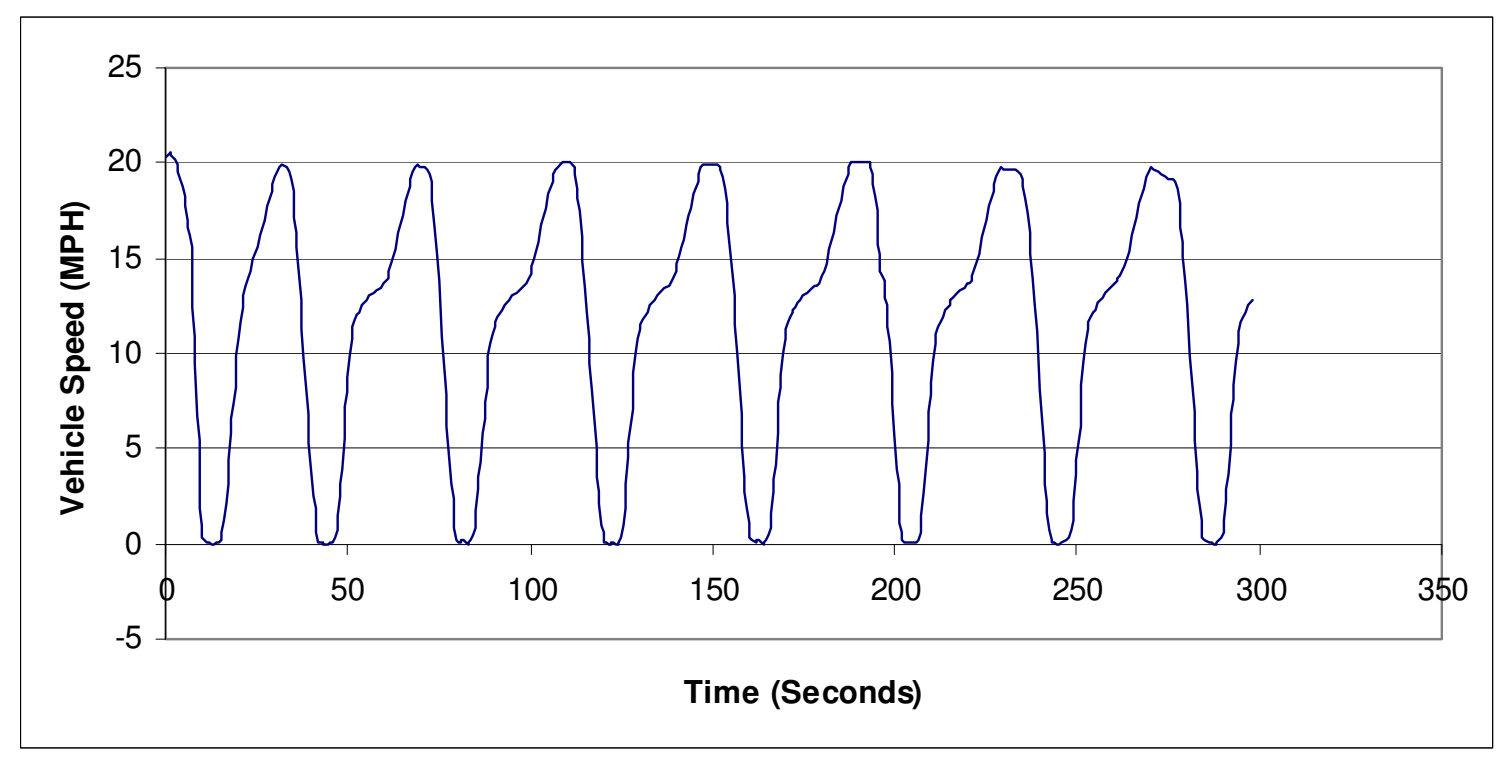

Figure 4.16: Hybrid Gradeability Test.

\subsection{Particulate Matter (PM)}

Once the filters from the various tests were weighed and logged, the different tests were compared. The hybrid vehicle emitted considerably more PM than the baseline vehicle during the SPU and STC test cycles.

Table 4.9: PM Comparison.

\begin{tabular}{|c|c|c|c|}
\hline \multicolumn{4}{|c|}{ Particulate Matter } \\
\hline Test & Hybrid & Baseline & $\%$ Difference \\
\hline SPU 1 & 2.31 & 0.73 & 216 \\
\hline SPU 2 & 2.25 & 0.73 & 208 \\
\hline SPU 3 & 2.22 & 0.73 & 204 \\
\hline Average & 2.26 & 0.73 & 210 \\
\hline St. Dev. & 0.04 & 0.00 & \\
\hline $\mathrm{CV}$ & 1.90 & 0.00 & \\
\hline STC 1 & 1.15 & 0.5 & 130 \\
\hline SCT 2 & 0.87 & 0.28 & 211 \\
\hline STC 3 & 0.63 & 0.27 & 133 \\
\hline Average & 0.89 & 0.35 & 154 \\
\hline St. Dev. & 0.26 & 0.13 & \\
\hline CV & 29 & 37 & \\
\hline
\end{tabular}


Referring back to Table 3.3 helps rule out the different engines being a major contender, assuming these certification values apply, in the hybrid vehicles large increase in PM since the engines were supposedly certified to the same PM levels. The increased fuel consumption was likely related to the numbers seen in the PM comparison.

\subsection{Fuel Economy Revisited}

Fuel economy is revisited since it was the main goal of this hybrid vehicle to increase fuel economy and help offset initial costs of the vehicle for potential customers. Even with the hydraulic assistance, this hybrid vehicle failed to improve upon the fuel economy of the baseline vehicle in any test performed and values can be seen in the Table 4.10. It should be noted that the hybrid failed to follow the test STC cycle effectively (as seen in Figure 4.2). The hybrid vehicle averaged $21.9 \%$ lower fuel economy than the baseline vehicle during the SPU test cycles and $19.4 \%$ lower fuel economy on STC 2.

Table 4.10: Fuel Economy Comparison.

\begin{tabular}{|l|r|r|r|}
\hline \multicolumn{4}{|c|}{ Fuel Economy (MPG) } \\
\hline & Hybrid & \multicolumn{1}{|c|}{ Baseline } & \% Difference \\
\hline SPU1 & 1.22 & 1.55 & -21.3 \\
\hline SPU2 & 1.21 & 1.56 & -22.4 \\
\hline SPU3 & 1.21 & 1.55 & -21.9 \\
\hline Average & 1.21 & 1.55 & -21.9 \\
\hline Standard Deviation & 0.01 & 0.01 & \\
\hline & & & -43.4 \\
\hline STC1 & 2.07 & 3.66 & -19.4 \\
\hline STC2 & 3.03 & 3.76 & -20.1 \\
\hline STC3 & 3.03 & 3.79 & -27.5 \\
\hline Average & 2.71 & 3.74 & \\
\hline Standard Deviation & 0.55 & 0.07 & \\
\hline
\end{tabular}




\subsection{Engine Parameters}

The hybrid vehicle's performance prompted review of how the hybrids engine behaved during the tests. This section will discuss the load following characteristics of the hybrid as well as its efficiency. Figure 4.17 compares the baseline and hybrid vehicles engine speeds. Here a section of the test has been isolated to increase the visibility of the traces. The figure reveals that the hybrid engine is following the same loading that baseline does while Figure 4.18 shows the same trend is seen during the SPU tests, the vehicle also operated at higher engine speeds during the steady state portions of the test. The hybrid vehicle was not expected to "load follow" as it's control strategy because the hybrid drivetrain should have alleviated the need for the engine to speed up during accelerations.

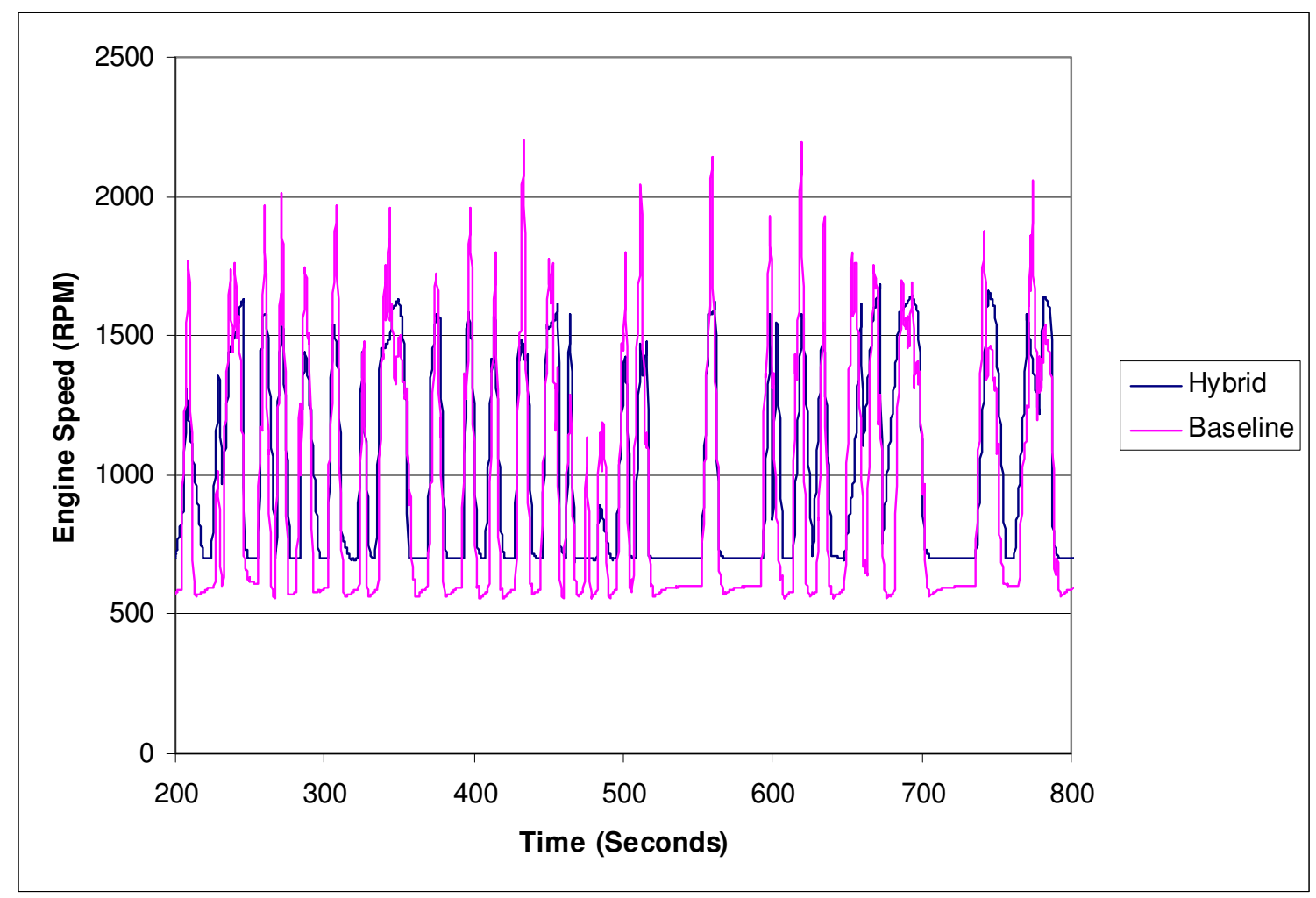

Figure 4.17: SPU 1 Engine Speeds. 


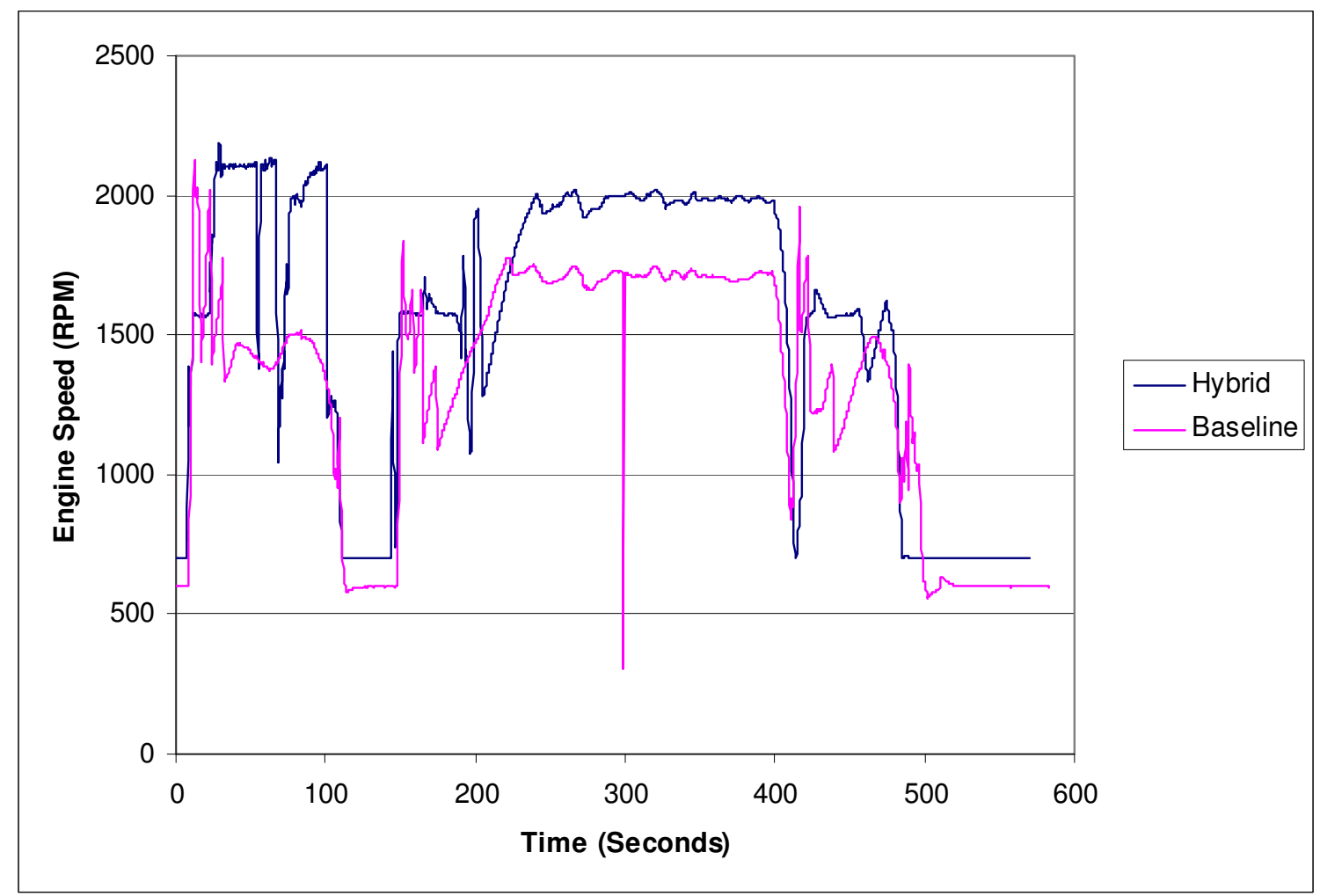

Figure 4.18: STC 2 Engine Speeds.

The increased fuel consumption and the behavior of STC 2, where the hybrid engine speed was higher than the baseline, raised questions on whether the engine was undersized. To gain additional insight into the engine performance of the two vehicles at hand, engine load was plotted against engine speed for a SPU run and STC 2. Figure 4.19 and Figure 4.20 compare the efficiencies of the two engines during an SPU (SPU 1) run. The data points in these figures correlate the percent load to engine speed seen throughout a test. 


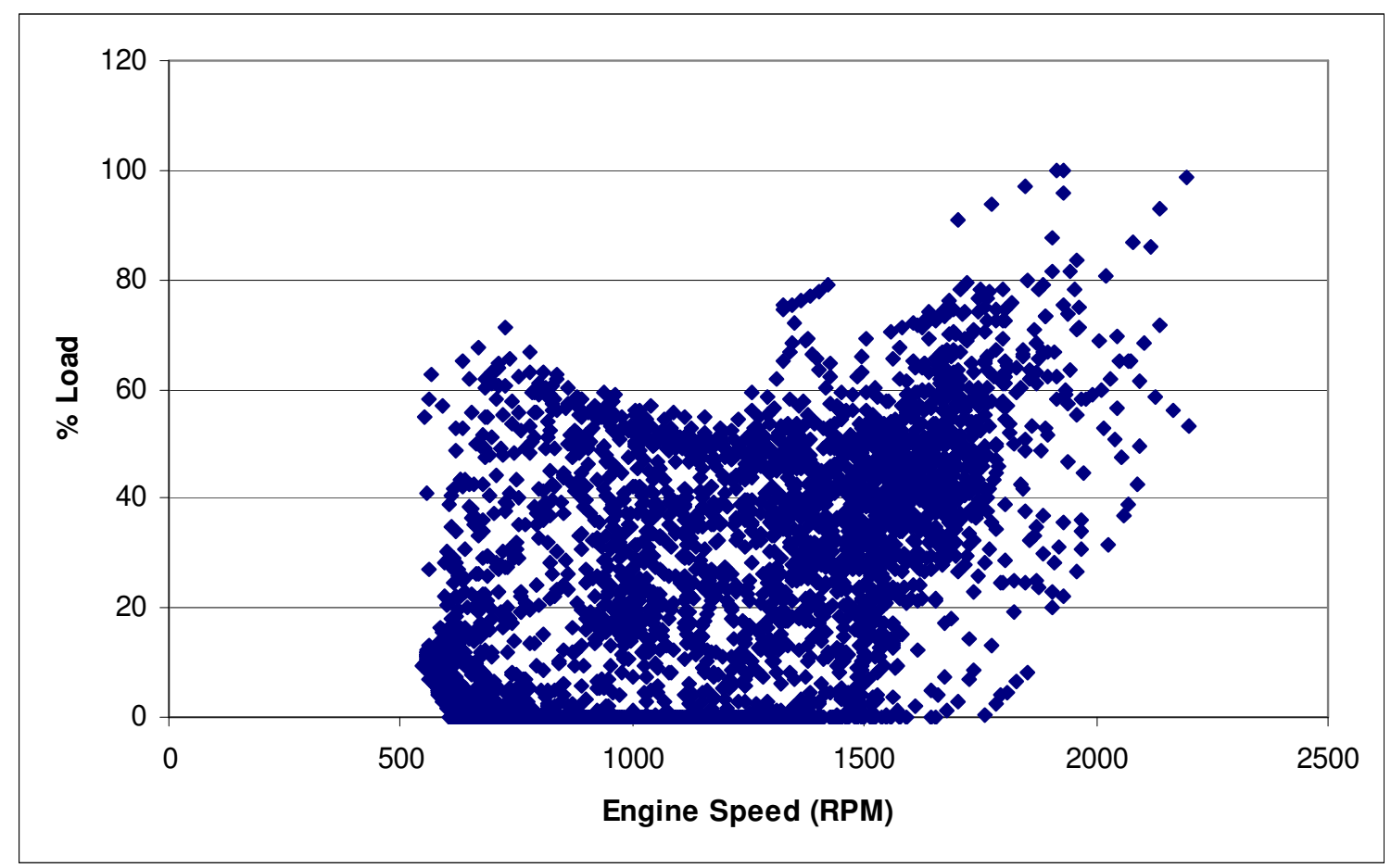

Figure 4.19: Baseline SPU Engine Efficiency

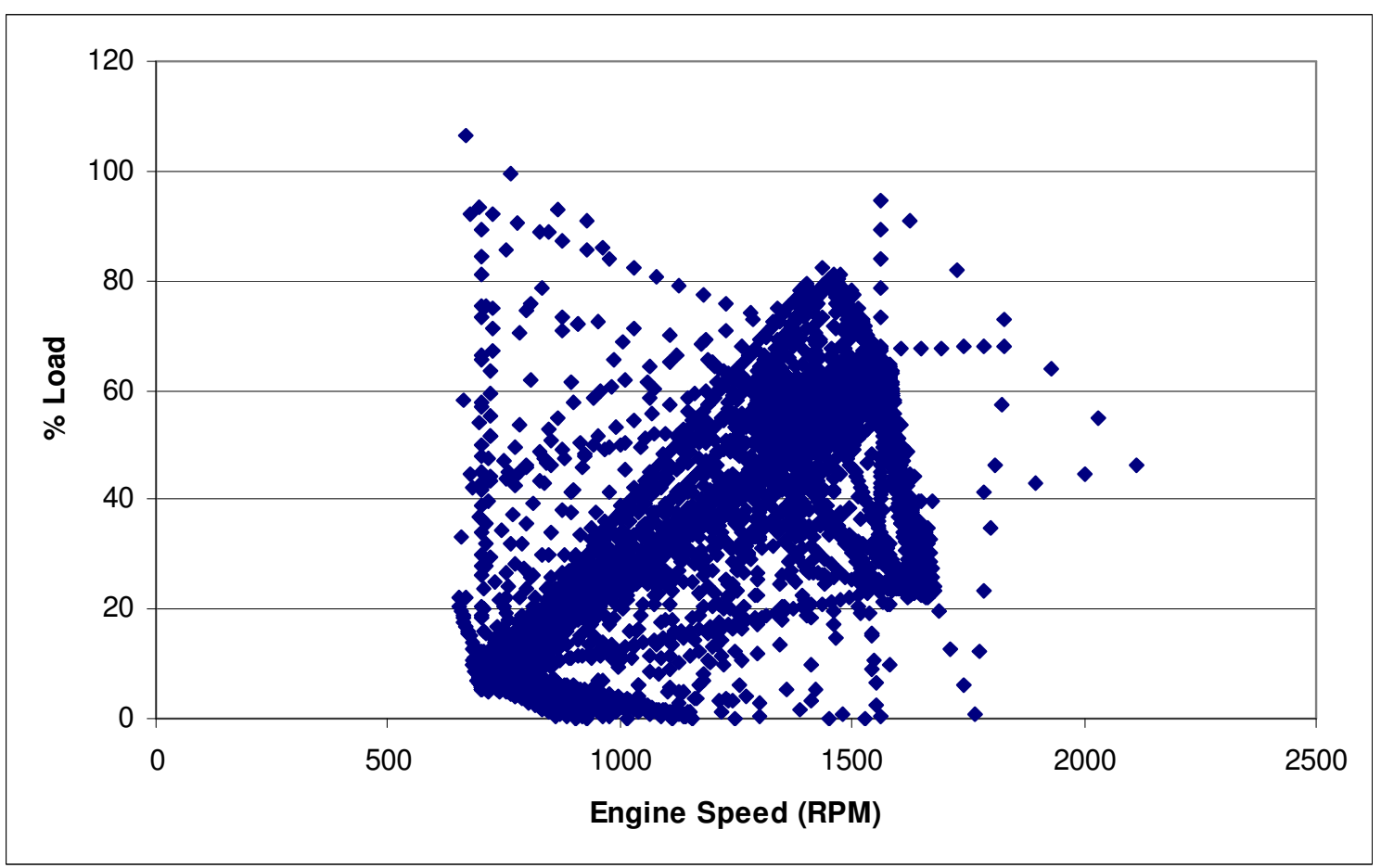

Figure 4.20: Hybrid SPU Engine Efficiency. 
The hybrid vehicle displays an interesting linearity (seen in Figure 4.20) which might be attributed to its control strategy and the hybrid vehicle is generally operating at higher engine speed and load than the baseline.

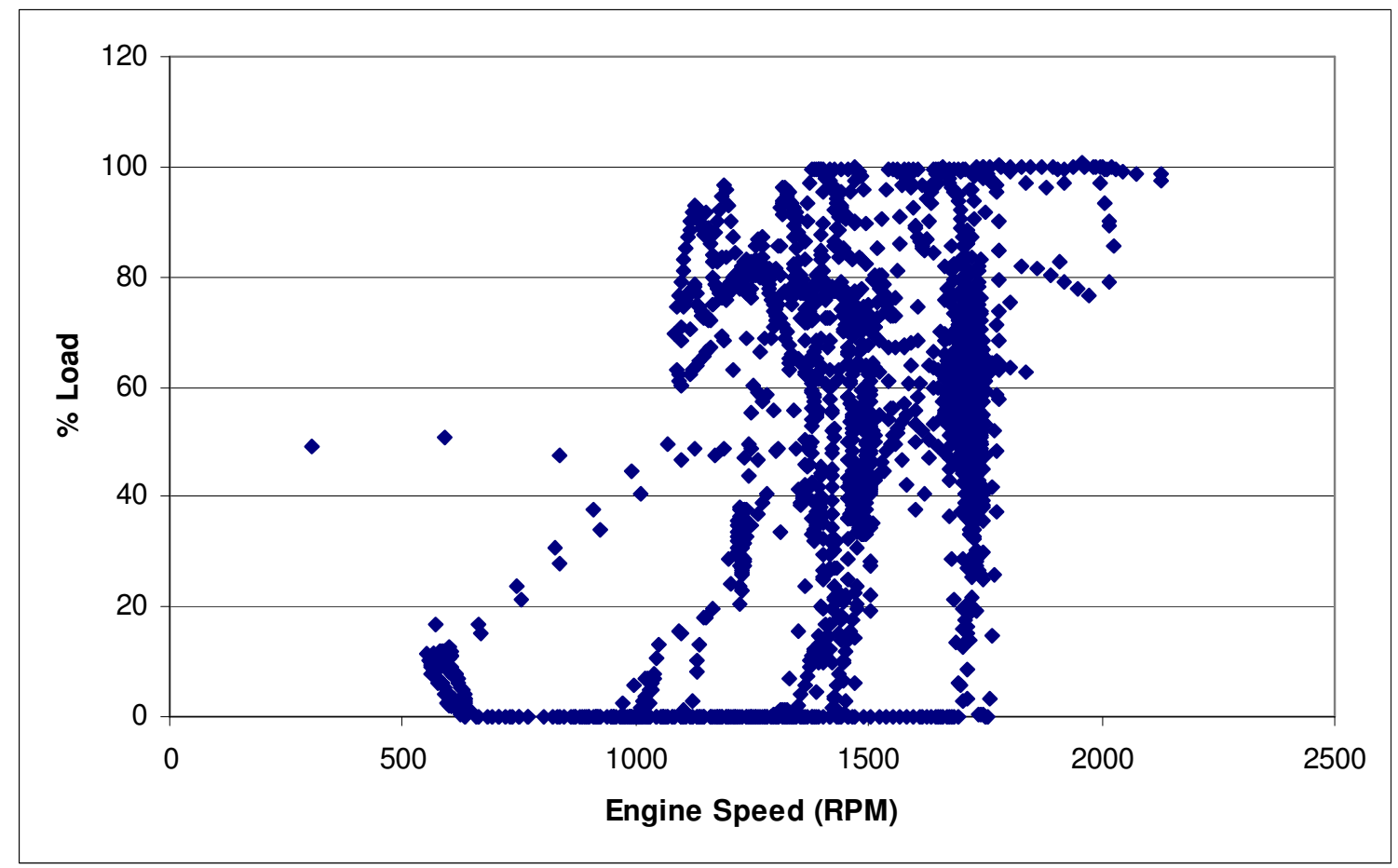

Figure 4.21: Baseline STC 2 Engine Efficiency. 


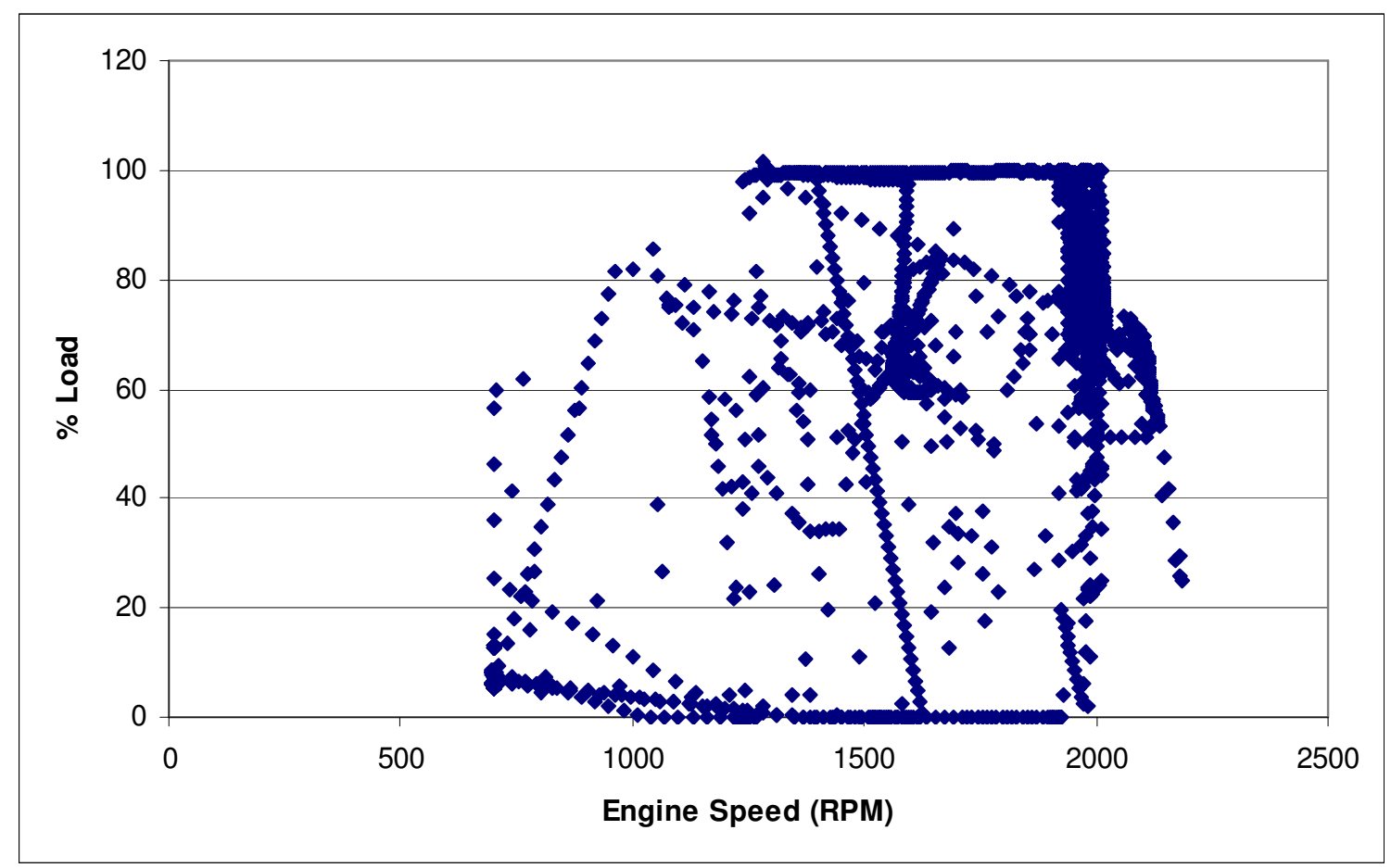

Figure 4.22: Hybrid STC 2 Engine Efficiency.

Figure 4.21 and Figure 4.22 represent the respective engine operation for STC 2. These figures more readily illustrate that the hybrid was running at higher engine speeds and higher engine loads than the baseline which operated at lower load and engine speeds and spent less time at or near $100 \%$ load. The hybrid vehicle did not seem to be fully receiving the benefit of the hybrid powertrain (as seen by load following characteristic in Figure 4.17 and Figure 4.18) and suggests that the engine may be undersized. 


\section{CONCLUSIONS AND RECOMMENDATIONS}

\subsection{Overview}

An experimental hybrid vehicle, incorporating new and traditional technologies, was developed and required testing for evaluation and insight into possible future development. The hybrid system was brought to the WVU for this evaluation and results were compared to the performance of a baseline vehicle. Some mechanical and possible control difficulties were encountered and the hybrid vehicle fell short of specified design goals of increased fuel economy and reduced emissions. The results of the testing revealed that although there is promise with this new technology, a great deal of engineering design and calculation must be considered before success is achieved.

\subsection{Conclusions}

The study showed that the hybrid vehicle had difficulty following the same test cycle that was successfully negotiated by the baseline vehicle. Good repeatability and adherence to the developed cycle was seen in the baseline testing and therefore the developed test cycle, representing a refuse truck's daily rigors, proved appropriate for this type of vehicle.

Both mechanical and control-strategy related problems were encountered and it is presumed that some of the control related limitations prevented the vehicle from negotiating the test cycles. Failure of the auxiliary transmission might have been due to the transmission being an "off the shelf" item that was unable to deal with the loads seen on the hybrid vehicles setup. The hybrid had shifting problems on STC runs. Other issues included solenoid control and overheating due to the fan that cooled the hydraulic fluid broke.

The emissions and fuel economy results revealed that this hybrid prototype was characterized by increased $\mathrm{CO}_{2}$ emissions in the range of $23.4 \%$, an average reduction of NOx by $11.8 \%$ on the SPU tests. The series of STC tests showed an increase again in $\mathrm{CO}_{2}$ of $8.27 \%$ and a decrease in NOx of $5.85 \%$. The results listed previously represent 
those from STC 2, the only test that came close to following the designed test cycle. Fuel economy of the hybrid vehicle decreased across the board when compared to the efficiency of the baseline model. The average fuel economy was $21.9 \%$ worse than the baseline during the SPU tests and $19.4 \%$ worse for STC 2. This could be due to the testing control strategy which kept the average engine speed at a higher level for the hybrid than for the baseline. This led to a decrease in fuel efficiency, when the intent was to increase the engine's efficiency. An increase in PM emissions was also seen throughout the tests.

The hybrid vehicles engine was seen to be following the load, similar to the baseline vehicle. This reveals another factor into the hybrid vehicles poor performance since the hybrid drivetrain should have alleviated the engines need to follow the load and primarily run in efficient modes when used to charging the accumulators. The hybrid vehicle followed the SPU test cycles but again there were indications that the engine was load following. These results indicate, when combined with the hybrids engine's operation over a high range of engine speed and engine load, that the engine was either undersized or not benefiting from the hybrid powertrain. While operation over this range may increase the volumetric and thermal efficiencies, it could have yielded the higher emissions seen due to greater fuel consumption.

The hybrid vehicle failed to meet its design goals. This vehicle was part of an iterative process in the quest achieving a successful hydraulic hybrid vehicle for use in refuse collection. The STC tests indicate more complicated problems that may stem from an inappropriate control strategy and failure to follow the vehicle speed trace through the first acceleration event of the test might be a sign that the vehicles accumulators were not fully charged before testing which could have resulted from the control strategy or insufficient idle time before testing. Some of the possible reasons for lower fuel economy could be linked to control strategy, undersized (or improper) components, and insufficient pressure in the accumulators prior to or during the test or a combination of them all. 


\subsection{Recommendations}

\subsubsection{Vehicle Recommendations}

The vehicle design was sound but the difficult control strategy was obviously not as appropriate as needed. Evaluation needs to be performed to isolate and improve the weak points of the hybrid system and it would be important to know where the engines used would fall in the EPA's engine certification in order to better compare the two setups to one another, or to compare the hybrid vehicle to a baseline outfitted with the same engine.

\subsubsection{Testing Recommendations}

The testing was performed on a tight schedule, leaving little room for error or troubleshooting. Vital time needed for testing was used up by fixing both the lab and several mechanical issues on the hybrid vehicle. Some possible changes to the testing, time permitting, could have aided in a better evaluation of the hybrid vehicles performance. State of charge information, not available for use in this evaluation, was needed to determine the performance of the accumulators and the systems potential and ability to provide energy saving properties.

Splitting the test into two portions (SPU and STC) may have changed the cycles to no longer be representative of the original cycle. The state of charge of the accumulators after a highly transient operation could be very different than with the developed short STC test. Therefore it would be recommended to increase the length of the STC to potentially compensate and allow for better evaluation of the vehicle through it's transition zones.

It is also recommended that the hybrid be run through more test cycles in order to attain a larger test matrix with repeatable results. Once this is achieved then it might be beneficial to vary the control strategy, while repeating the same test cycle. If the vehicle could not be tuned to achieve the test cycle, then perhaps a watered-down cycle that the hybrid could follow could be developed and then the baseline and hybrid run through this cycle, allowing for a better comparison of the hybrids performance and better insight on how to improve it. 


\section{REFERENCES}

1. "The Plain English Guide to The Clean Air Act," U.S. Environmental Protection Agency, http://www.epa.gov/air/caa/peg/understand.html [accessed: 7/9/07].

2. Riviera, A., "Hydraulic Accumulator Technology Boosts Transit Bus Fuel Economy," SAE Technical Paper No. 830648, 1983.

3. Sindler, P., "Study of an Error in Engine ECU Data Collected for In-Use Emissions Testing and Development and Evaluation of a Corrective Procedure," West Virginia University Department of Mechanical Engineering, Masters Thesis, 2007.

4. Jackey, R., Smith, P., Bloxham, S., "Physical System Model of a Hydraulic Energy Storage Device for Hybrid Powertrain Applications," SAE Technical Paper No. 2005-01-0810, 2005.

5. Chu, L., Wang, Q., Liu, M., Li, J., "Parametric Design of Series Hybrid Power-train for Transit Bus," SAE Technical Paper No. 2003-01-3371, 2003.

6. Andic, S., Sc., M., Eng., P., "Saving and Recovery of Braking Power," British Columbia Institute of Technology.

7. Matheson, P., Stecki, J., "Modeling and Simulation of a Fuzzy Logic Controller for a Hydraulic-Hybrid Powertrain for Use in Heavy Commercial Vehicles," SAE Technical Paper No. 2003-01-3275, 2003.

8. Clark, N., McKain, D., Messer, J., Lyons, D., "Chassis Test Cycles for Assessing Emissions from Heavy Duty Trucks," SAE Technical Paper No. 941946, 1994.

9. Clark, N., Gautam, M., Wayne, W., Nine, R., Thompson, G., Lyons, D., Maldonado, H., Carlock, M., Agrawal, A., "Creation and Evaluation of a Medium Heavy-Duty Truck Test Cycle," SAE Technical Paper No. 2003-01-3284, 2003.

10. Gautam, M. Clark, N., Riddle, W., Nine, R., Wayne, S., Maldonado, H., Agrawal, A., Carlock, M., "Development and Initial Use of a Heavy-Duty Diesel Truck Test Schedule for Emissions Characterization," SAE Technical Paper No. 2002-01-1753, 2002.

11. Buchwald, P., Christensen, G., Larsen, H., Pedersen, P., "Improvement of Citybus Fuel Economy Using a Hydraulic Hybrid Propulsion System - A Theoretical and Experimental Study,” SAE Technical Paper No. 790305, 1979.

12. Kepner, R., "Hydraulic Power Assist - A Demonstration of Hydraulic Hybrid Vehicle Regenerative Braking in a Road Vehicle Application," SAE Technical Paper No. 2002-01-3128, 2002.

13. Matheson, P., Stecki, J., "Development and Simulation of a Hydraulic Hybrid Powertrain for use in Commercial Heavy Vehicles," SAE Technical Paper No. 200301-3370, 2003.

14. Assanis, D., Filipi, Z., Lin, C., Peng, H., Wu, B., "Optimal Power Management fir a Hydraulic Hybrid Delivery Truck," Vehicle System Dynamics, 2004.

15. Anderson, S., Blohm, T., Lamberson, D., Turner, W., "Hybrid Route Vehicle Fuel Economy," SAE Technical Paper No. 2005-01-1164, 2005. 
16. "Hydraulic hybrids - the most efficient lowest cost hybrids," United States Environmental Protection Agency, http://www.epa.gov/oms/technology/420f0643 [accessed: 1/23/2007].

17. "World's First Full Hydraulic Hybrid in a Delivery Truck," United States Environmental Protection Agency, http://www.epa.gov/oms/technology/420f06054 [accessed: 1/23/2007].

18. "2005 Model Year Engine Family and Model \& Parts Information," U.S. Environmental Protection Agency, http://www.epa.gov/otaq/certdata.htm\#largeng [accessed: 7/10/07].

19. Parker-Hannifin/Autocar, technical information and reference materials received during testing, $12 / 17 / 2005$.

20. Beta, R., Clark, N., Gautam, M., Howell, A., Long, T., Loth, J., Lyons, D., Palmer, M., Rapp, B., Smith, J., Wang, W., "The First Transportable Heavy Duty Vehicle Emissions Testing Laboratory," SAE Technical Paper No. 912668, 1991.

21. Clark, N., Gautam, M., Beta, R., Wang, W., Loth, J., Palmer, M., Lyons, D., "Design and operation of a new transportable laboratory for emissions testing of heavy duty trucks and buses," Heavy Vehicle Systems Vol. 2, Nos 3/4, 1995.

22. Gautam, M. Clark, N., Lyons, D., Long, T., Howell, A., Loth, J., Palmer M., Wang, W., Beta, R., "Design Overview of a Heavy Duty Mobile Vehicle Emissions Testing Laboratory," Advanced Automotive Technologies, ASME, 1991.

23. SAE Truck and Bus Hybrid and Electric Vehicle Committee, "Recommended Practice for Measuring Fuel Economy and Emissions of Hybrid-Electric and Conventional Heavy-Duty Vehicles,” SAE J2711, 2002. 


\section{APPENDIX}

7.1 Appendix A: Hybrid Operation [19].

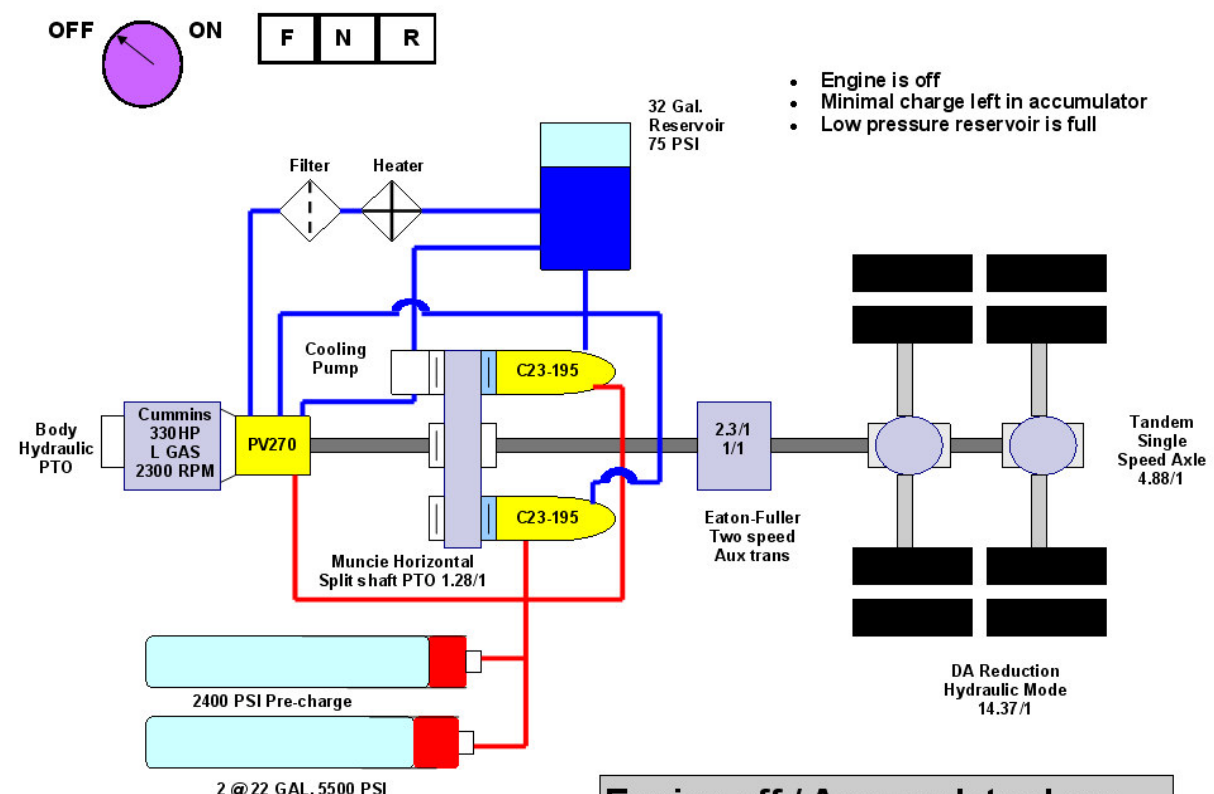

Engine off / Accumulator Low

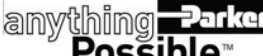

Figure 7.1: Hybrid Vehicle at Rest [19] 


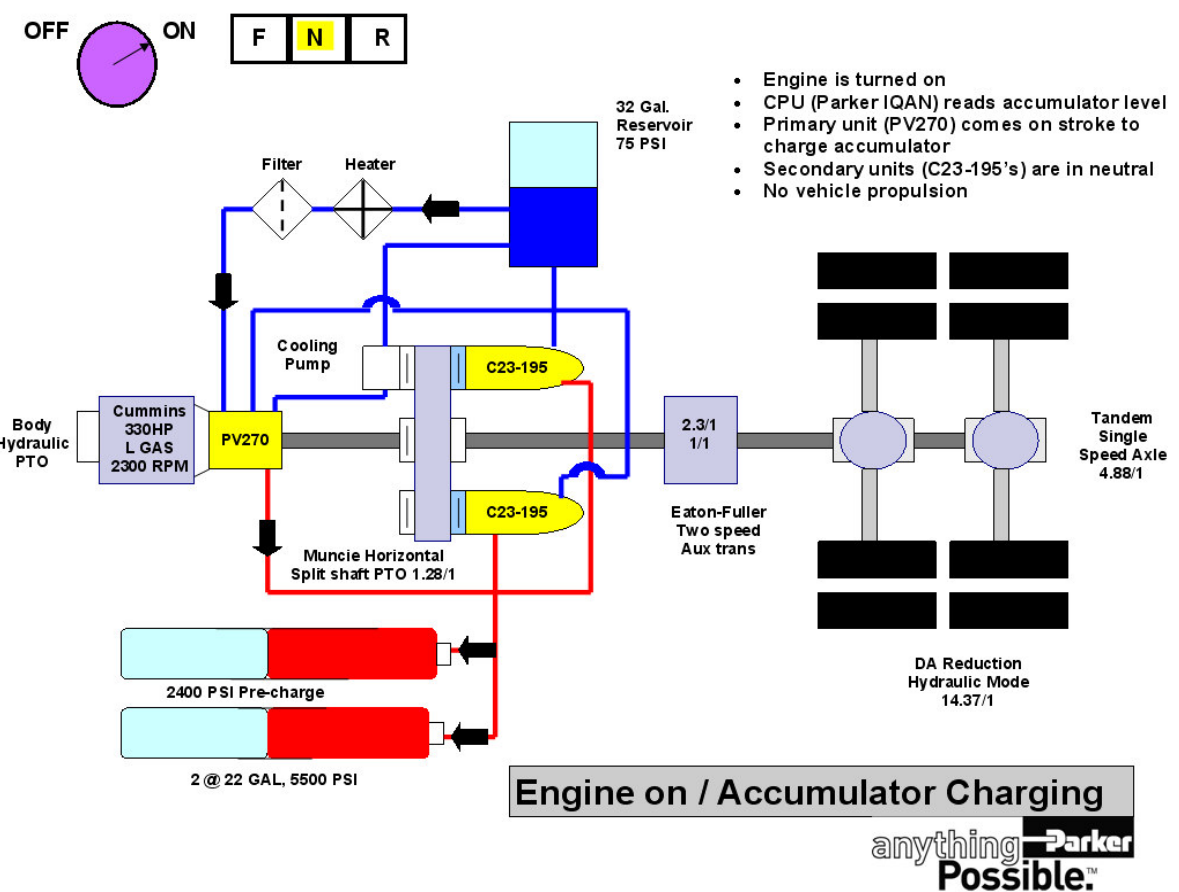

Figure 7.2: Initial Accumulator Charging [19]

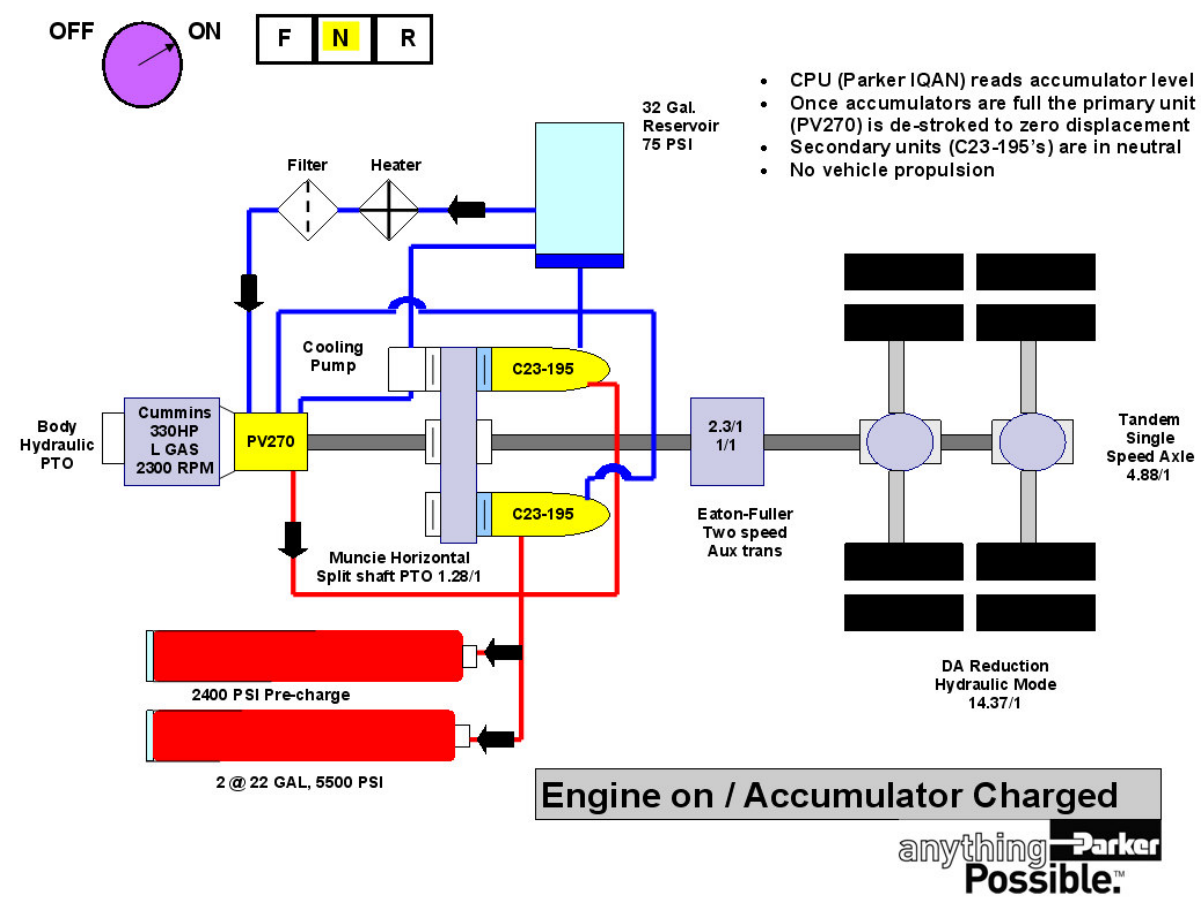

Figure 7.3: Accumulators Charged [19] 


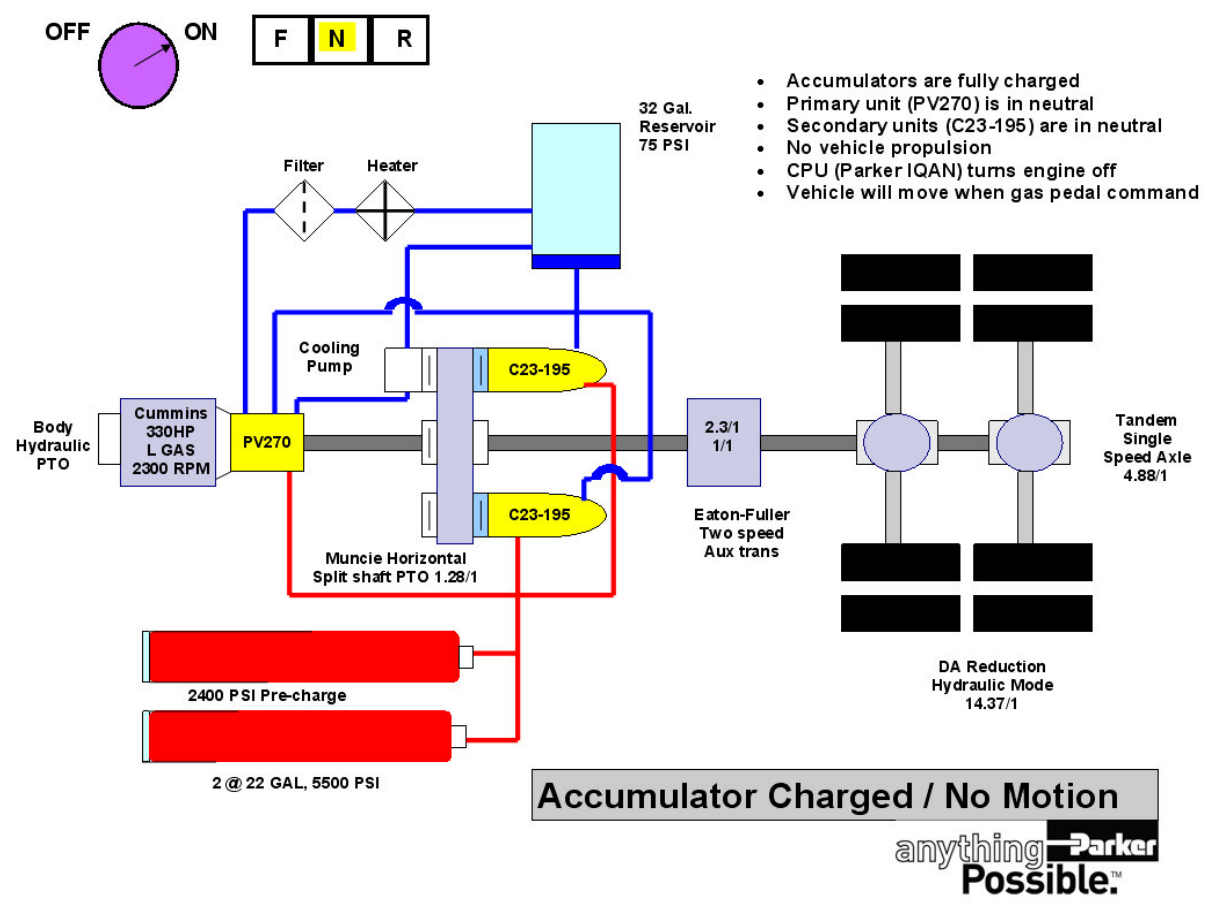

Figure 7.4: Accumulators Charged, Waiting For Command [19]

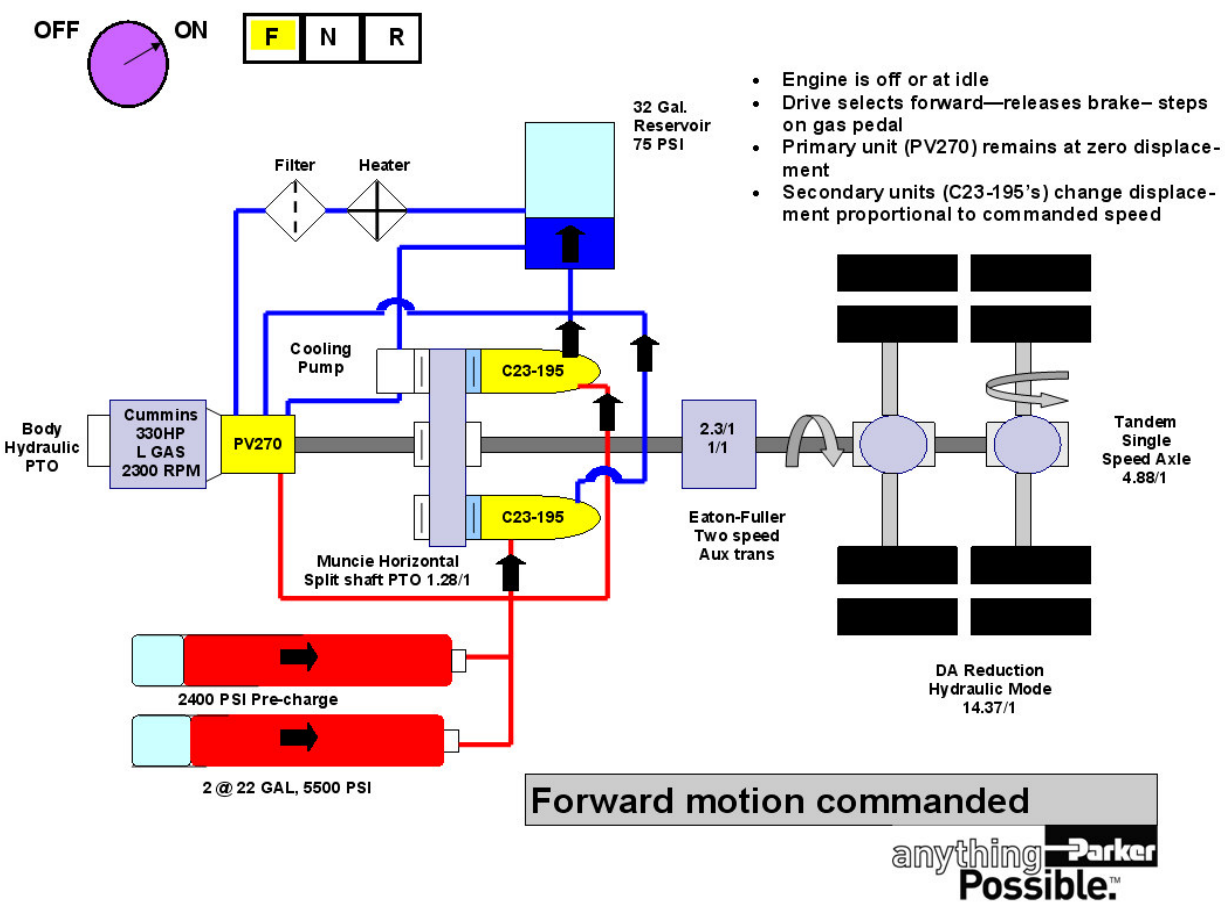

Figure 7.5: Acceleration Command Received, C23-195s Provide Propulsion [19] 


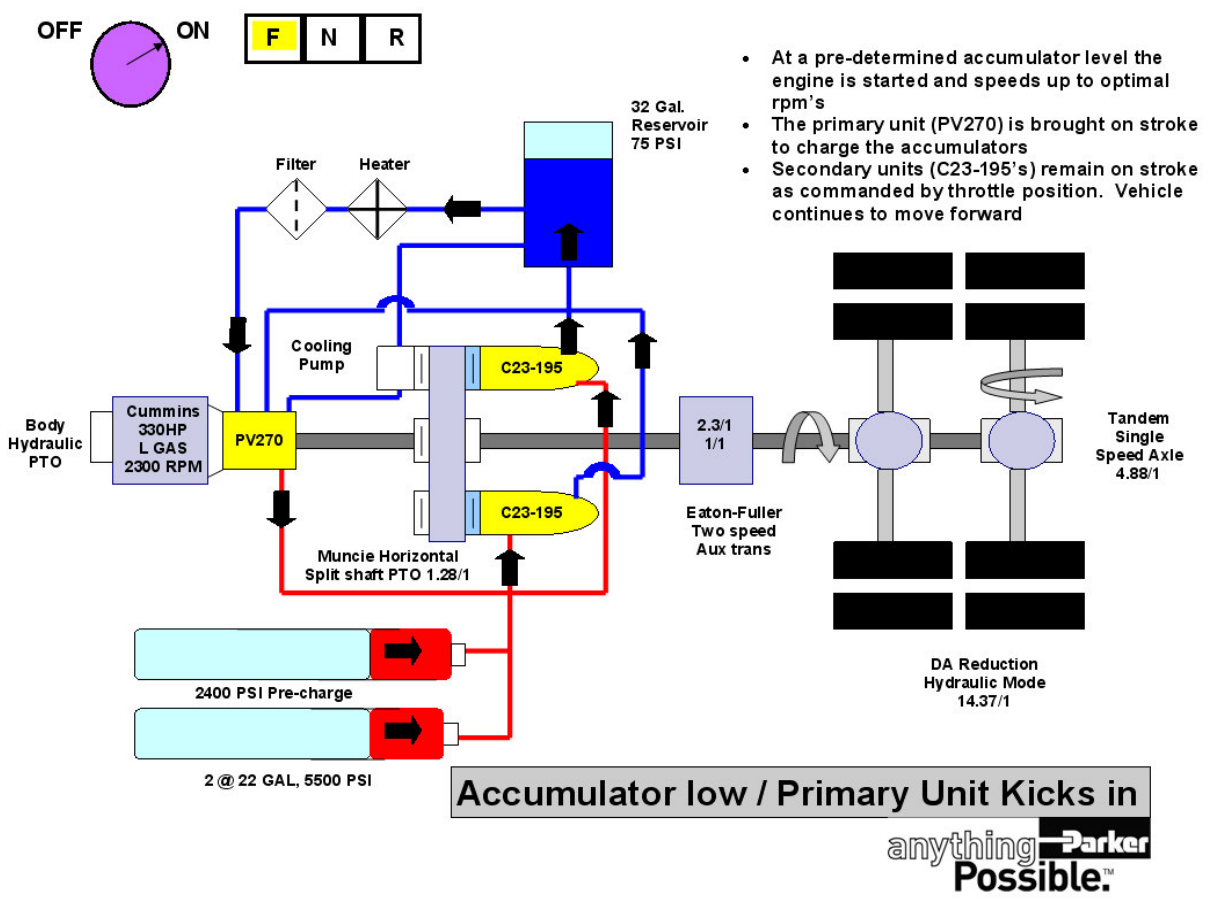

Figure 7.6: Accumulators Low, PV270 Brought On Line [19]

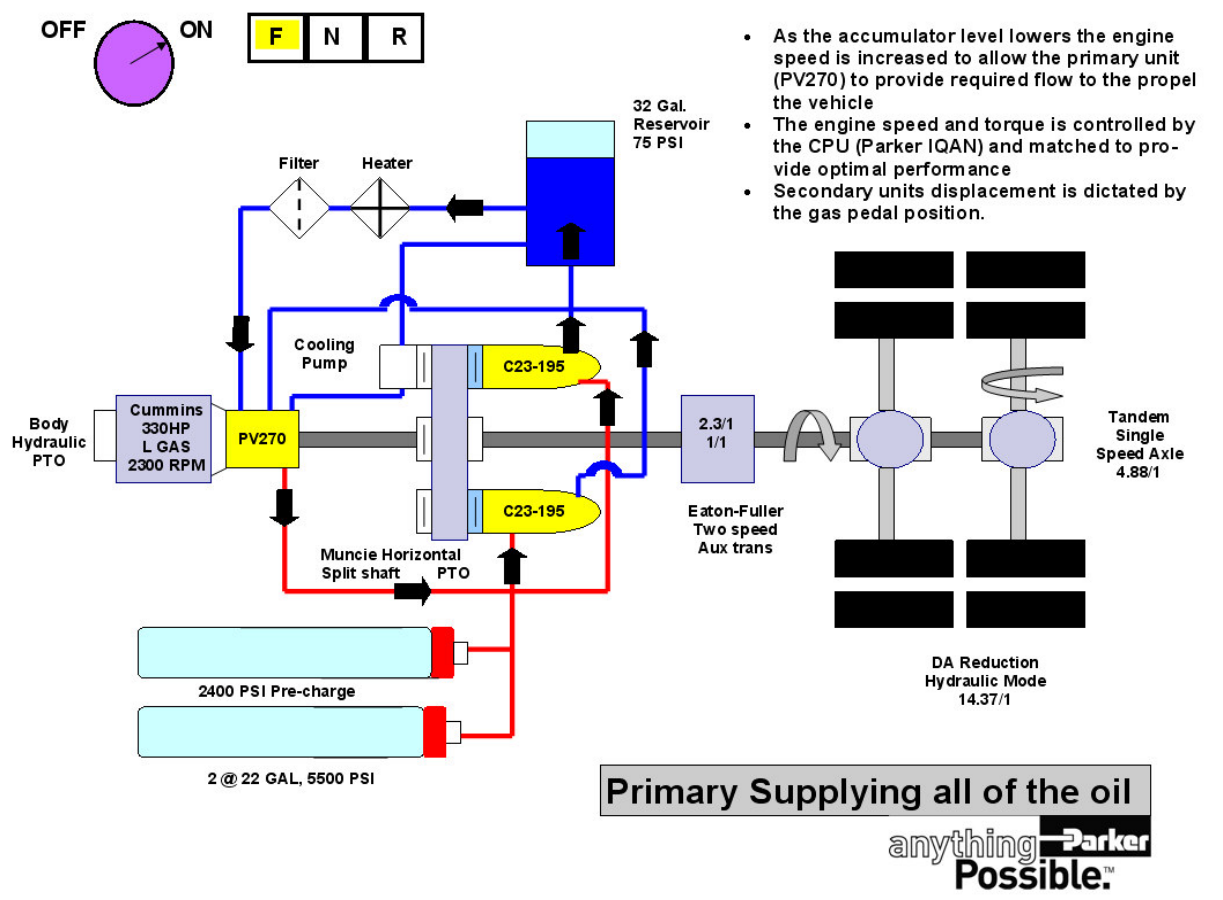

Figure 7.7: Accumulator Low, PV270 Providing Primary Propulsion [19] 


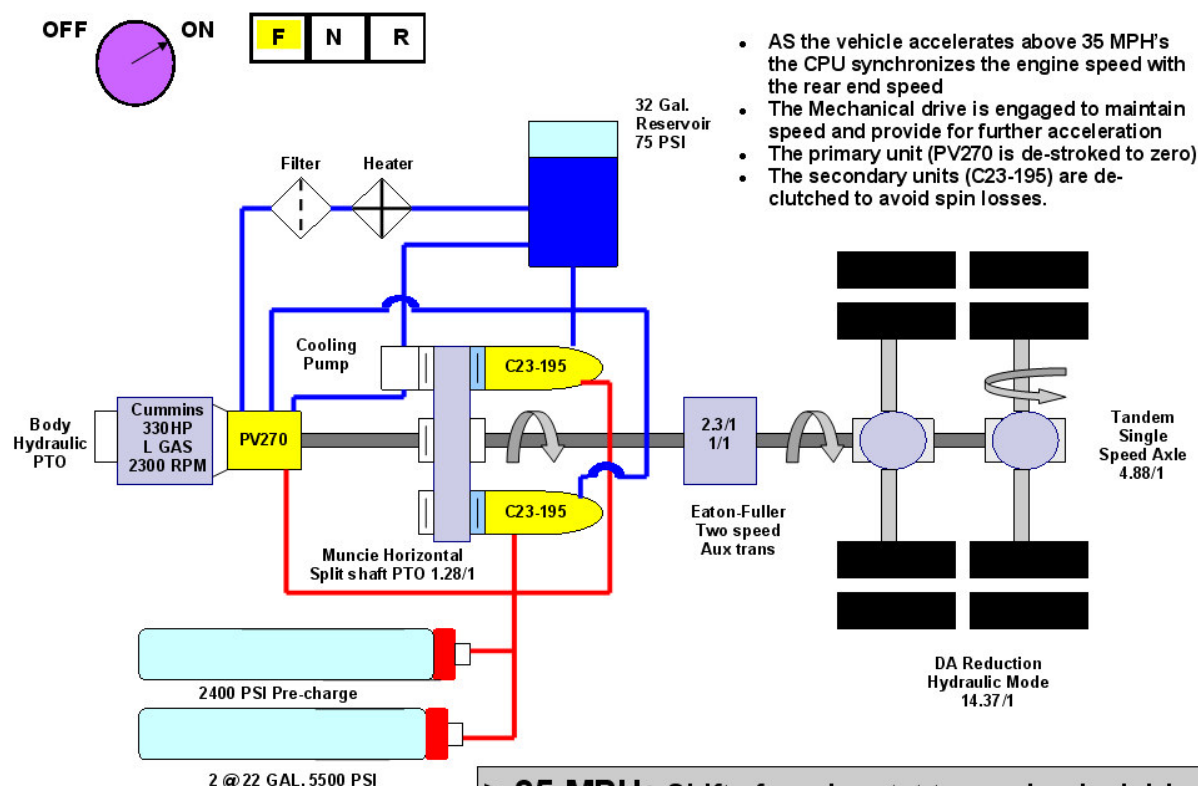

> 35 MPH: Shifts from hy-stat to mechanical drive

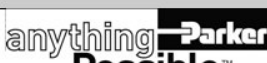

Possible."

Figure 7.8: Mechanical Drive [19]

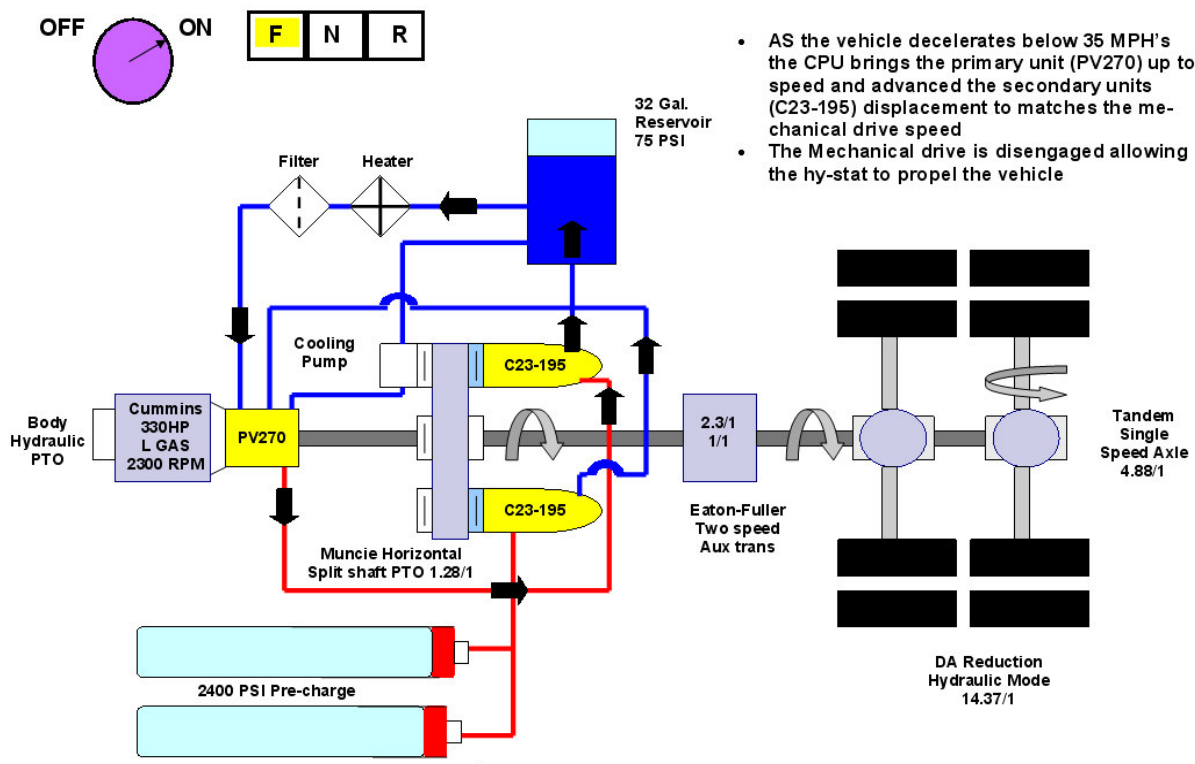

< 35 MPH: Shifts from mechanical drive to hy-stat

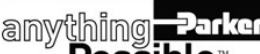

Possible.

Figure 7.9: PV270 Providing Primary Power Below 35 MPH [19] 


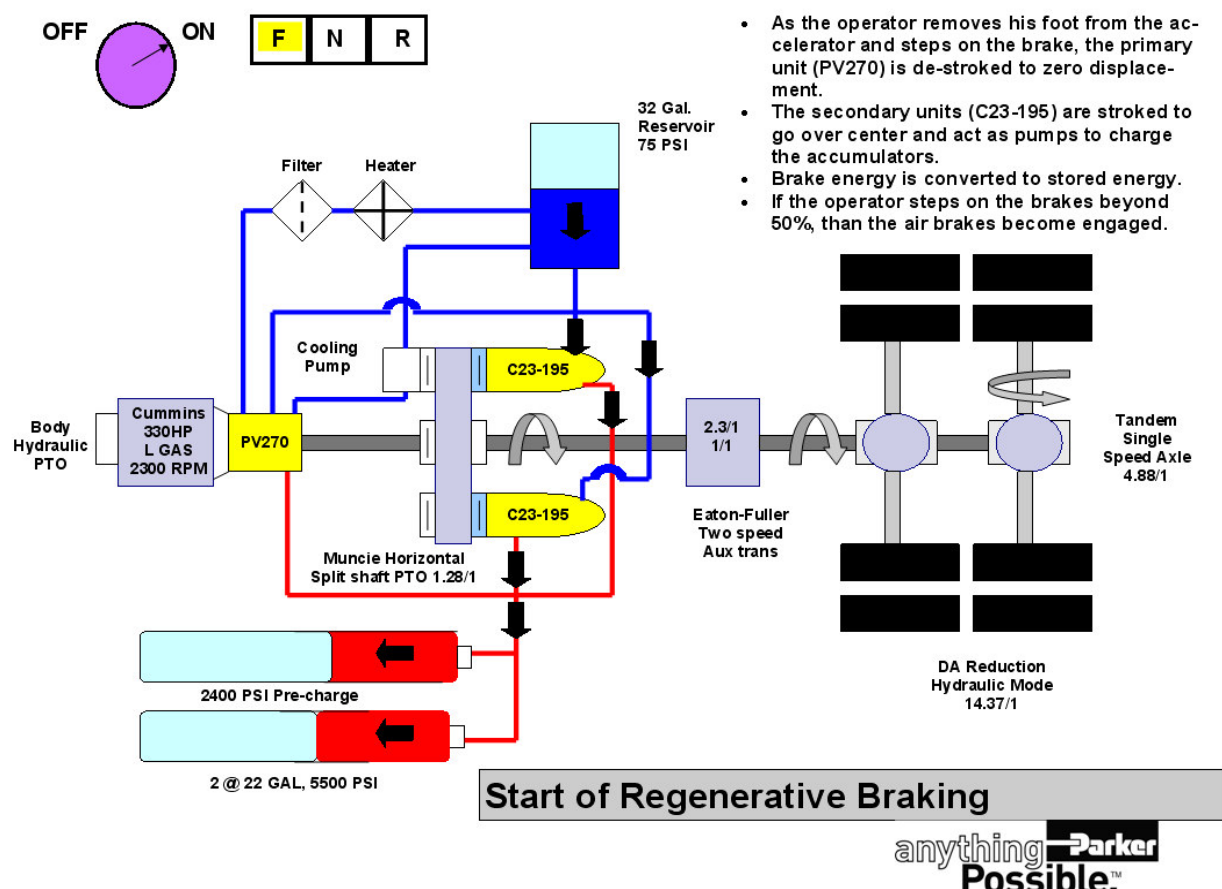

Figure 7.10: Regenerative Braking, Accumulators Charging [19]

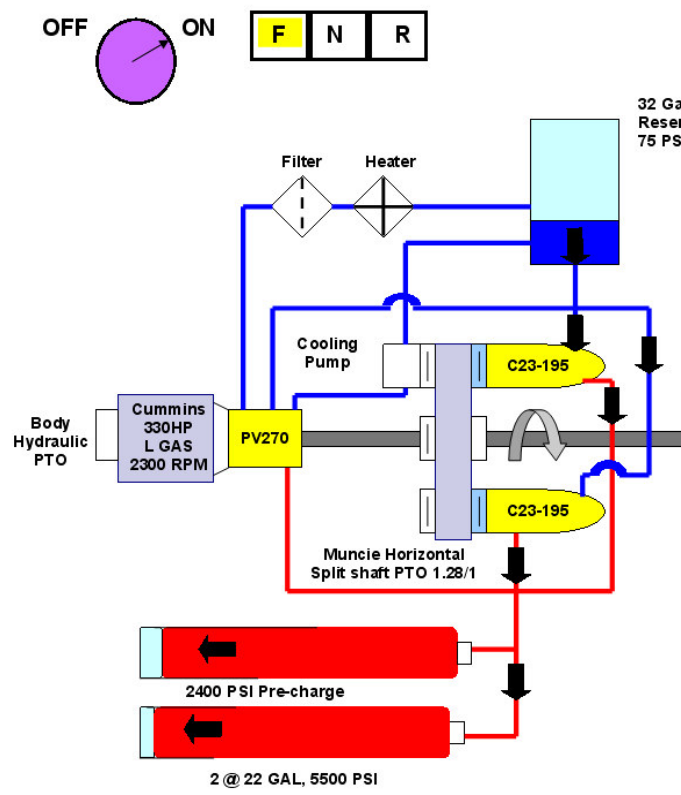

As the operator retains his foot on the brake the engine goes to idle or stops.

The primary unit (PV279) remains de-stroked. The primary unit (PV279) remains de-stroked. The secondary units (C23-195) are further
stroked over center and act as pumps to charge fully the accumulators.

Only if the operator steps on the brakes beyond $50 \%$, will the air brakes become engaged.

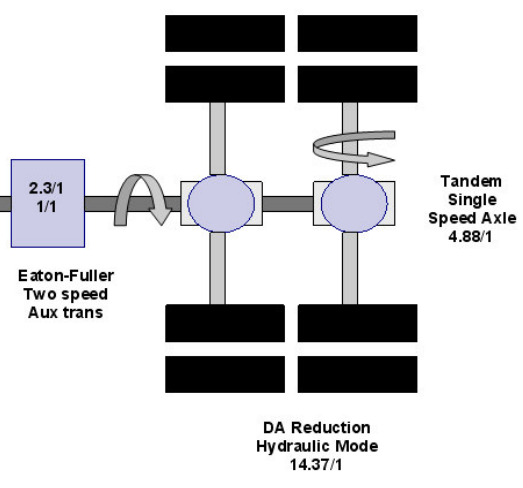

Regenerative Braking

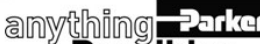

Possible.

Figure 7.11: Regenerative Braking, Friction Brakes On Command [19] 


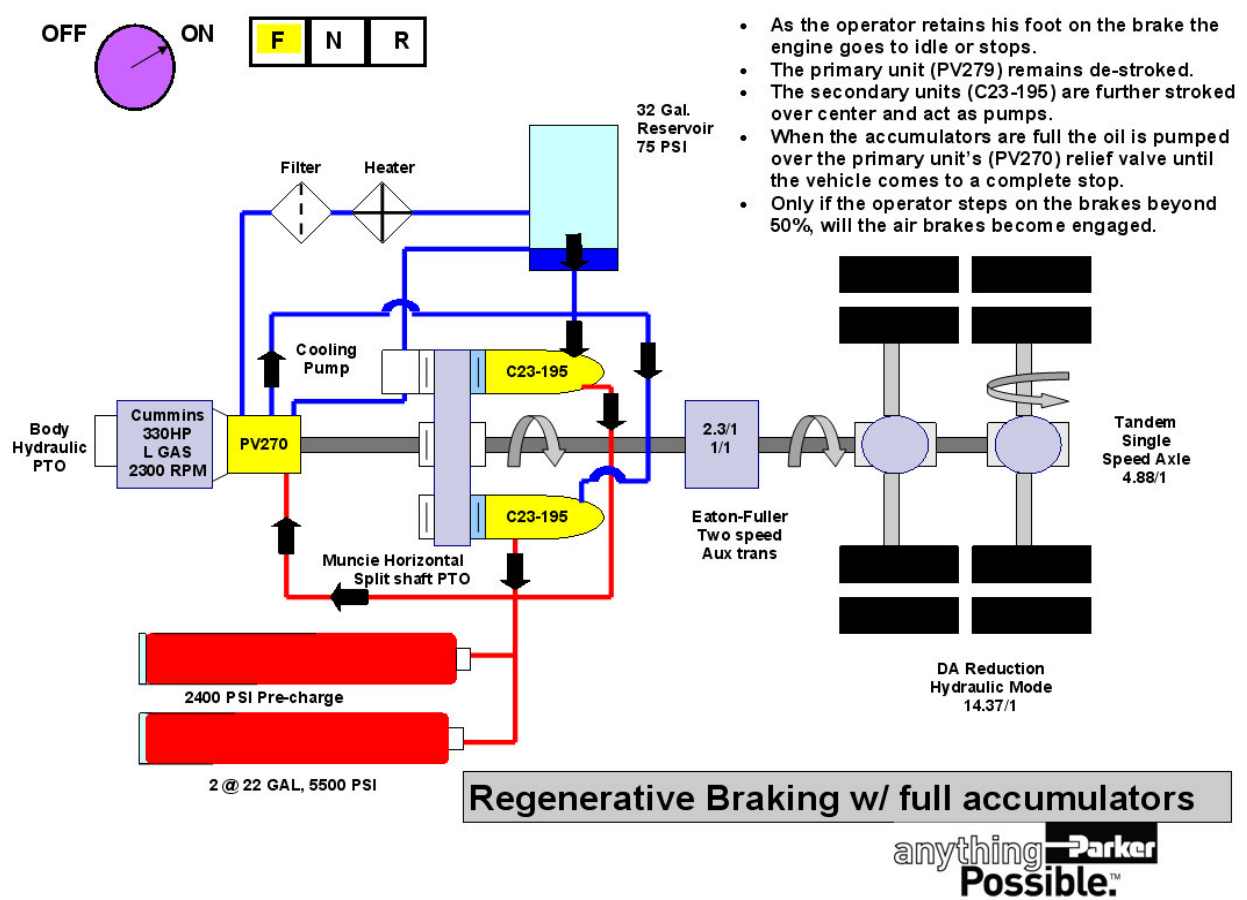

Figure 7.12: Regenerative Braking, Accumulators Full [19]

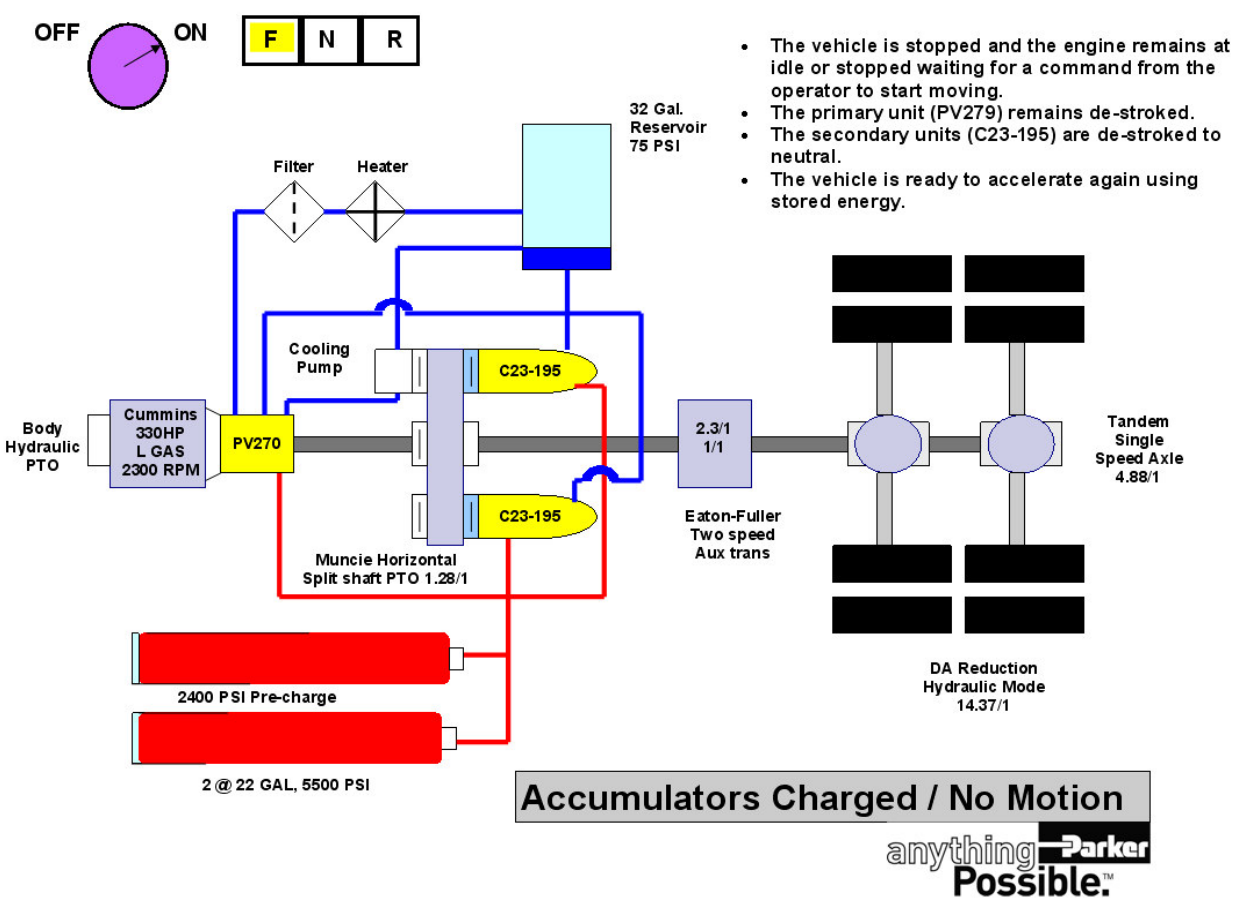

Figure 7.13: Accumulators Charged, Vehicle Stopped [19] 
7.2 Appendix B: Hybrid Transition Modes [19]. 


\section{Transition Modes - X-truck Alpha - Rev. 11.0}

\section{Transition from Low to High Range (2-speed gear box) - 28 MPH (All Modes)}

1.1. Two speed gear box shifts to high range @ 28 mph, C23s @ 3200RPM (note: picked because the PTO cooling)

1.2. De-energize service brake bypass solenoids

1.3. Must go to hydrostatic mode first - close accumulator valves (unless it is determined that we can control the C23's with the accumulator)

1.4. De-Stroke C23s to zero displacement

1.5. De-Stroke PV270 to zero displacement

1.6. Set engine at idle speed - 800 RPM

1.7. Shift the 2 speed gearbox to neutral

1.8. Ask for 25cc on ONE C23 (do not wait for displacement to be achieved)

1.9. Increase PV270 displacement to force C23 to rotate at synch speed PLUS 25 rpm (2 speed gearbox)

1.9.1. Low Gear $\mathrm{C} 23$ Target RPM $=(\mathrm{MPH} \times 118.286)+25$

1.9.2. High Gear C23 Target RPM $=(\mathrm{MPH} \times 51.429)+25$

1.10. Output signal to shift to high range (to air cylinder with limit switch digital feedback)

1.11. Verify input signal to verify high range

1.12. Open accumulator valves (unless hydrostatic mode is required)

1.13. Resume primary/secondary software control

1.14. Increase C23 to requested displacement

1.15. Energize service brake bypass solenoids

1.16. Calculations:

1.16.1. Synching will occur at $28 \mathrm{MPH}$.

1.16.2. Driveshaft will be at 1125 RPM.

1.16.3. C23 will need to rotate at $1440 \mathrm{RPM}(\mathrm{MPH} \times 51.429-\mathrm{PTO}$ to driveshaft -2 speed gearbox in high)

1.16.4. Engine speed can be set to programmer's discretion (800 RPM)

1.16.5. Set $\mathrm{C} 23$ to $25 \mathrm{cc}$ displacement

1.16.6. C23 will require approximately 10 GPM from the PV270:

Pump Displacement (Cu. In. / Rev.) = cc (displacement) $\times 0.06102$

$\mathrm{PD}$ (Cu. In.) $=25 \times 0.06102$

$\mathrm{PD}(\mathrm{Cu} . \ln )=$.

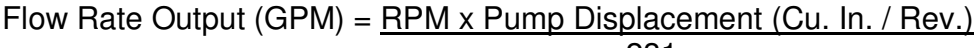

$\mathrm{GPM}=\underline{1440 \times 1.53}$

231

$\mathrm{GPM}=9.54$

1.16.7. PV270 will need to stroke (initially) to $90 \mathrm{cc}$ (2x required) and stroke back to $45 \mathrm{cc:}$

Flow Rate Output (GPM) = RPM x Pump Displacement (Cu. In. / Rev.)

GPM $\times 231=$ RPM $\times$ PD (Cu. In.)

231

$9.54 \times 231=800 \times \mathrm{PD}(\mathrm{Cu} . \mathrm{In}$.)

$2203.74 / 800=P D$

$2.75=\mathrm{PD}(\mathrm{Cu} . \mathrm{In}$.

Pump Displacement (Cu. In. / Rev. $)=c c$ (displacement) $\times 0.06102$

PD (Cu. In.) / $0.06102=$ PDcc

$2.75 / 0.06102=\mathrm{PDcc}$

$45 c c=$ PDcc

\section{Transition from High Range to Direct Drive: All Modes $\mathbf{- 4 0} \mathbf{~ m p h}$}

2.1. Note - allow some pressure to remain in accumulator to insure ability to complete process 
1.1.1. De-energize service brake bypass solenoids

1.1.2. Close accumulator valves

1.1.3. De-stroke C23s - engine adjusts rpm/load to compensate

1.1.4. De-energize the "drive" solenoids on C23s

1.1.5. De-stroke PV270

1.1.6. Adjust engine rpm to match driveshaft speed - approx. 1607 RPM (MPH x 40.18-2 speed gearbox in high)

1.1.7. Clutch in engine to drive shaft -1 digital output

1.1.8. Verify input signal to denote engine is clutched

1.1.9. De-clutch C23s - 1 output for each C23

1.1.10. Verify input signal to denote each C23 de-clutch

1.1.11. During braking, during direct drive mode, we can use the PV270 to collect brake energy accumulator valves must be opened

\section{Transition from Accumulator Mode to Hydrostatic Mode}

2.1. Close H.P. accumulator valve

2.2. Resume primary/secondary software control

2.2.1. Adjust engine RPM/Load to most efficient point for torque needed

2.2.2. Control the pv270 or C23s displacement to drive the vehicle

\section{Transition from Direct Drive to High Range Hydrostatic Mode - 35 mph}

3.1. Decrease PV270 displacement to zero

3.2. Close accumulator valve

3.3. Energize C23 drive solenoids

3.4. Ask for 25cc on both C23s (do not wait for displacement to be achieved)

3.5. Control PV270 to a displacement that SHOULD give C23s correct speed for engagement

3.5.1. Low Gear C23 Target RPM $=(\mathrm{MPH} \times 118.286)+25$

3.5.2. High Gear C23 Target RPM $=(\mathrm{MPH} \times 51.429)+25$

3.6. Wait for $\mathrm{C} 23 \mathrm{~s}$ to achieve 25cc

3.7. Adjust PV270 (C23?) displacement so that at least 1 C23 is synchronized, and then engage

3.8. Adjust PV270 (C23?) displacement so the other C23 is synchronized, and engage

3.9. De-clutch engine from drive shaft

3.10. Verify input to denote engine de-clutched

3.11. Resume primary/secondary software control

3.12. Energize service brake bypass solenoids

3.13. Calculations:

3.13.1. Synching will occur at $35 \mathrm{MPH}$.

3.13.2. Engine / driveshaft will be at $1400 \mathrm{RPM}$

3.13.3. C23s will need to rotate at $1800 \mathrm{RPM}(\mathrm{MPH} \times 51.429-1.28$ ratio $-\mathrm{PTO}$ to driveshaft -2 speed gearbox in high)

3.13.4. Set C23s to 25cc displacement

3.13.5. C23s will require approximately 24 GPM from the PV270:

Pump Displacement (Cu. In. / Rev.) = cc (displacement) x 0.06102

PD (Cu. In. $)=25 \times 0.06102$

$\operatorname{PD}(\mathrm{Cu} . \mathrm{In})=$.

Flow Rate Output (GPM) = RPM x Pump Displacement (Cu. In. / Rev.)

$\mathrm{GPM}=\frac{1800 \times 1.53}{231}$

231

GPM $=11.92(x 2$ for $2 \mathrm{C} 23 \mathrm{~s})=23.84$

3.13.6. PV270 will need to stroke (initially) to $129 \mathrm{cc}$ (2x required) and stroke back to 64cc:

Flow Rate Output (GPM) = RPM x Pump Displacement (Cu. In. / Rev.)

GPM $\times 231=$ RPM $\times$ PD (Cu. In.)

231

$23.84 \times 231=1400 \times$ PD (Cu. In.)

$5507.04 / 1400=P D$ 


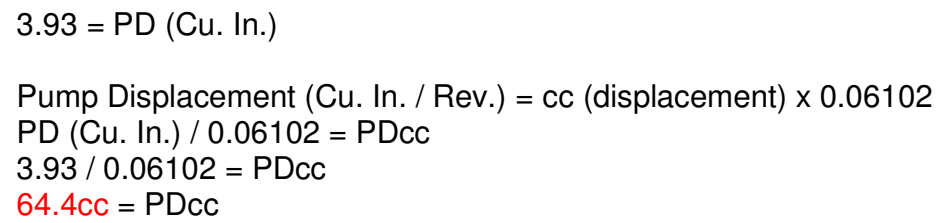

\section{Transition from Direct Drive to Accumulator Mode}

1.1. Go to high range hydrostatic mode and then to accumulator mode

1.1.1. Difficult to synch C23s with Accumulators

\section{Transition from High Range to Low Range : All Modes @ 20 MPH}

\subsection{Do not perform while braking.}

2.2. De-energize service brake bypass solenoids

2.3. Must go to hydrostatic mode first - close accumulator valves (unless it is determined that we can control the C23's with the accumulator)

2.4. De-Stroke C23s to zero displacement

2.5. De-Stroke PV270 to zero displacement

2.6. Shift the 2 speed gearbox to neutral

2.7. Ask for 25cc on ONE C23 (do not wait for displacement to be achieved)

2.8. Increase PV270 displacement to force C23's to rotate at synch speed PLUS 25 rpm (2 speed gearbox)

2.8.1. Low Gear $\mathrm{C} 23$ Target $\mathrm{RPM}=(\mathrm{MPH} \times 118.286)+25$

2.8.2. High Gear C23 Target RPM
2.9. Shift the 2 speed gearbox to low

2.10. Verify shift to low input

2.11. Energize service brake bypass solenoids

2.12. Resume primary/secondary software control

2.13. System Pressure increases to required hydrostatic mode pressure

2.13.1. If necessary to transition to accumulator mode :

2.13.2. Adjust C23s and PV270 displacements to equalize system and accumulator pressures(PV270 outlet pressure transducer and accumulator displacement transducer)

2.13.3. Open accumulator valves (unless hydrostatic mode is required)

2.14. Calculations:

2.14.1. Synching will occur at $20 \mathrm{MPH}$.

2.14.2. Driveshaft will be at 1848 RPM.

2.14.3. C23 will need to rotate at 2366 RPM (MPH x 118.286 - 1.28 ratio - PTO to driveshaft -2 speed gearbox in low)

2.14.4. Engine speed can be set to programmer's discretion (800 RPM)

2.14.5. Set C23 to 25cc displacement

2.14.6. C23 will require approximately 16 GPM from the PV270:

Pump Displacement (Cu. In. / Rev.) = cc (displacement) $\times 0.06102$

PD (Cu. In.) $=25 \times 0.06102$

PD (Cu. In.) = 1.53

Flow Rate Output (GPM) = $\underline{\text { RPM x Pump Displacement (Cu. In. / Rev.) }}$

$$
\begin{aligned}
\text { GPM } & =\frac{2366 \times 1.53}{231} \\
\text { GPM } & =15.67
\end{aligned}
$$

2.14.7. PV270 will need to stroke (initially) to $148 \mathrm{cc}$ (2x required) and stroke back to 74cc:

Flow Rate Output (GPM) = RPM x Pump Displacement (Cu. In. / Rev.)

GPM $\times 231=$ RPM $\times$ PD (Cu. In.)

$15.67 \times 231=800 \times \mathrm{PD}(\mathrm{Cu} . \mathrm{In}$.)

$3619.77 / 800=\mathrm{PD}$

4.52 = PD (Cu. In.)

Pump Displacement (Cu. In. / Rev. $)=$ cc (displacement) $\times 0.06102$ 
$\mathrm{PD}(\mathrm{Cu}$. In. $) / 0.06102=\mathrm{PDcc}$

$4.52 / 0.06102=\mathrm{PDcc}$

$74 \mathrm{CC}=\mathrm{PDCc}$

\section{Transition from Hydrostatic Mode to Accumulator Mode}

1.1. Open accumulator valves

1.2. Resume primary/secondary software control

1.2.1. Adjust C23s and PV270 displacements to equalize system and accumulator pressures(PV270 outlet pressure transducer and accumulator displacement transducer)

\section{Additional Strategies}

1. Engine control strategy to "top off accumulator"

1.1. H.P. limit is determined by current potential for braking energy recovery

1.2. L.P. limit is determined by ability to put out 320 H.P.

1.3. Develop curves

1.4. Determine most efficient engine speed

2. Reverse - accumulator mode (only) with C23's over center. Limit vehicle speed.

3. Loss of traction

3.1. ABS?

4. Cooling circuit operation

4.1. All modes?

4.2. Direct drive - PV270 spinning @ high speed

4.3. Hydro or accumulator mode - working flow can always flows through cooler

5. Fully document

5.1. What software perversion is on the vehicle on what dates

5.2. What hardware is on the truck on what dates

6. Diagnostics

7. Apply small hydraulic braking when accelerator pedal $=0$, above $5 \mathrm{mph}$ only

7.1. When truck at standstill, no accelerator pedal or brake pedal, will the truck roll away, especially with engine off.

7.2. No special mode for this condition as yet, will try to work within current modes to handle this condition.

\section{Braking (hard) in direct drive}

1. ABS condition

1.1. De-clutch engine so engine is not killed? 


\subsection{Appendix C: Original Cycle}

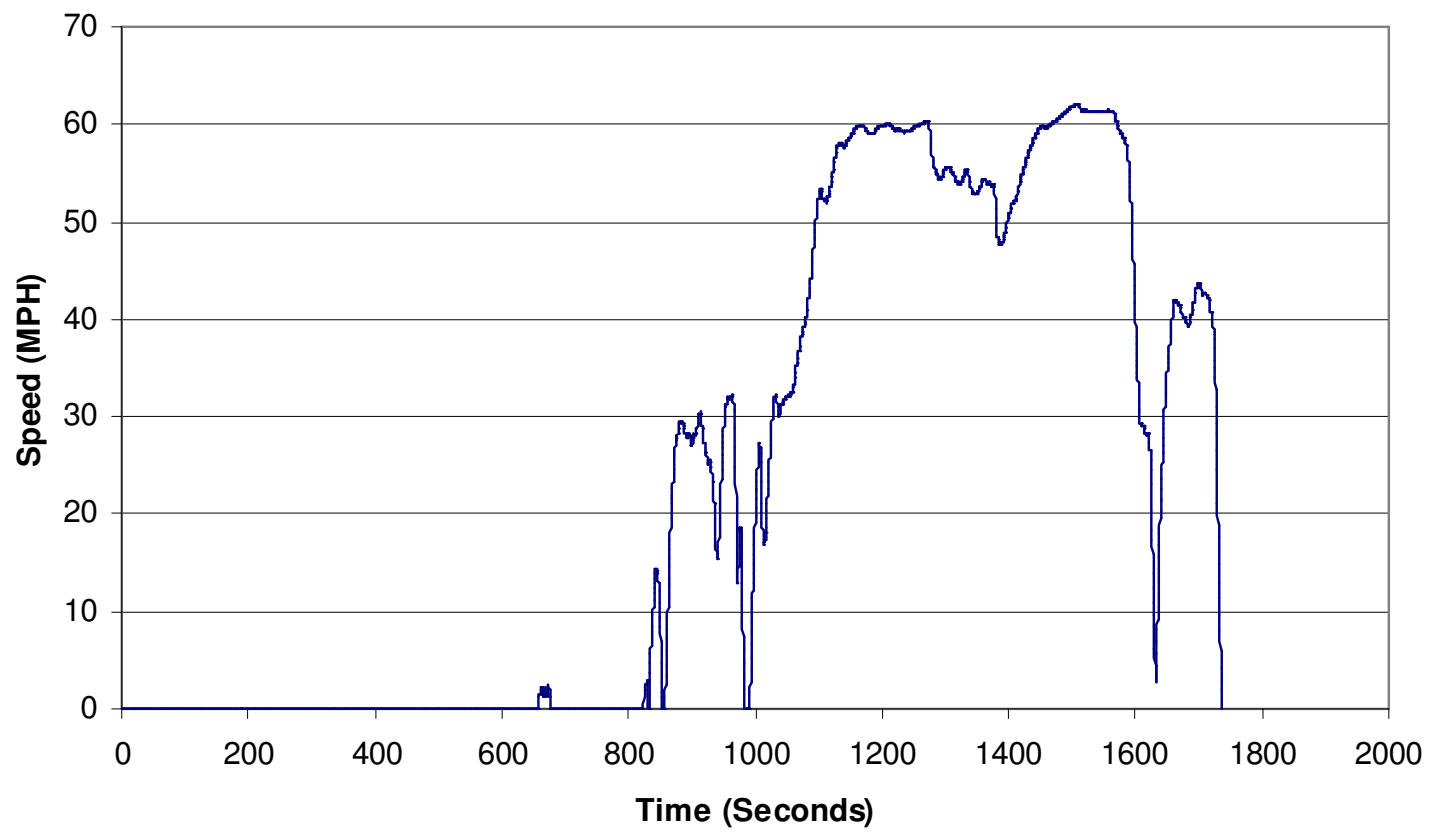

Figure 7.14: Original Recorded Saginaw Data (High Speed 1)

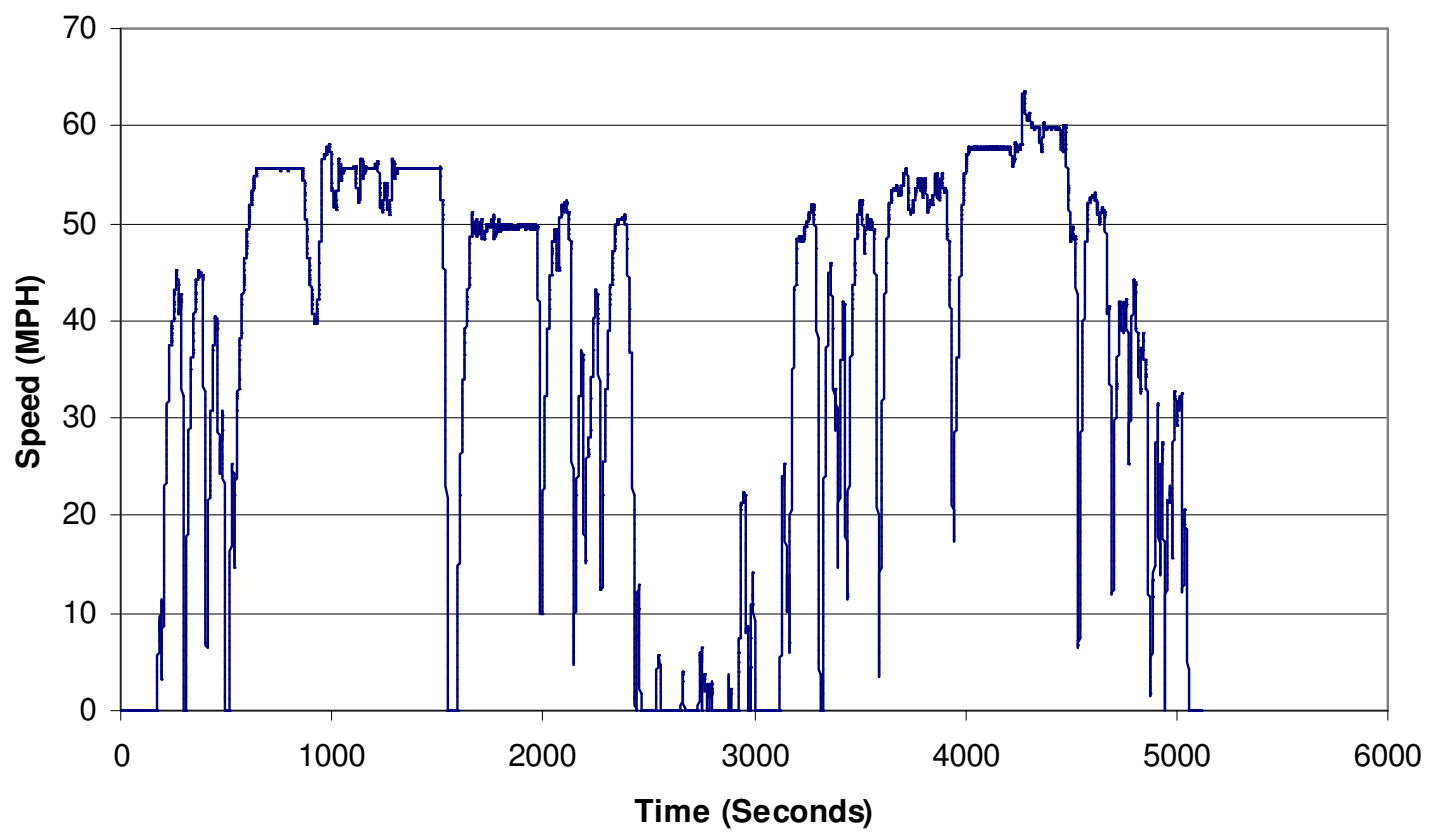

Figure 7.15: Original Recorded Saginaw Data (High Speed 2) 


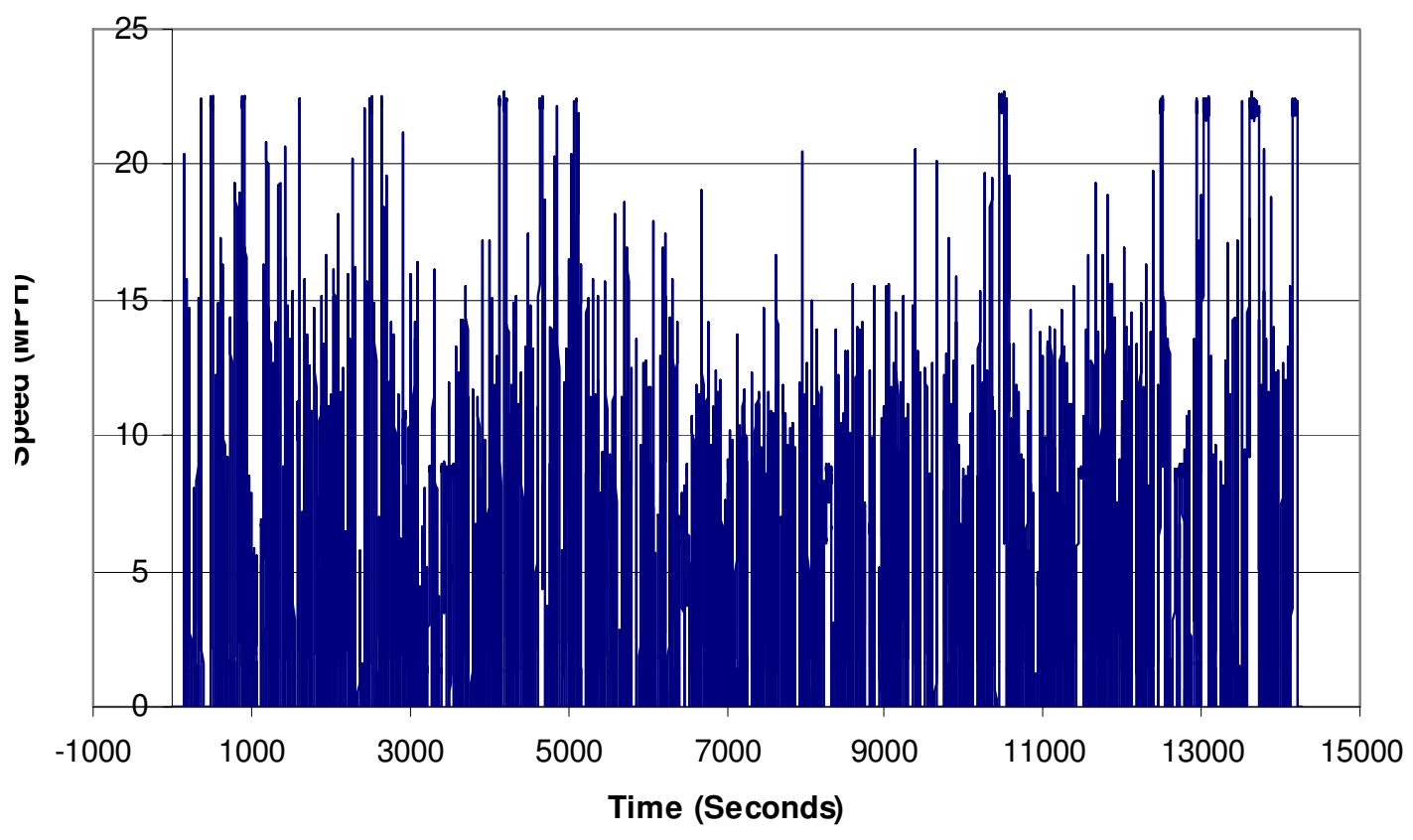

Figure 7.16: Original Recorded Saginaw Data (Low Speed) 


\subsection{Appendix D: Short Reports}

Table 7.1: Test Numbers Correlated to Test Cycles.

\begin{tabular}{|lc|}
\hline Baseline @ 56,000lb & Test \# \\
\hline SPU & $4561-3$ \\
SPU & $4561-4$ \\
SPU & $4561-5$ \\
STC & $4562-1$ \\
STC & $4562-2$ \\
STC & $4562-3$ \\
SS-30 & $4563-1$ \\
SS-40 & $4564-1$ \\
SS-50 & $4565-1$ \\
\hline Hybrid @ 40,000lb & Test \# \\
SPU & $4570-3$ \\
SPU & $4570-4$ \\
SPU & $4570-5$ \\
STC & $4571-1$ \\
\hline STC & $4571-2$ \\
STC & $4571-3$ \\
SS-30 & $4572-1$ \\
\hline SS-40 & $4573-1$ \\
SS-50* & $4574-1$ \\
\hline & \\
\hline Baseline @ 40,000lb & Test \# \\
SPU & $4576-3$ \\
\hline SPU & $4576-4$ \\
SPU & $4576-5$ \\
\hline STC & $4577-1$ \\
STC & $4577-2$ \\
\hline STC & $4577-3$ \\
\hline SS-30 & $4578-1$ \\
SS-40 & $4579-1$ \\
SS-50 & $4580-1$ \\
\hline & \\
\hline
\end{tabular}


Test Sequence Number: 4560

WVU Test Reference Number: PARKHANN-base-D2-SPU

Fleet Owner Full Name

Fleet Address

Fleet Address (City, State, Zip)

Vehicle Type

Vehicle ID Number (VIN)

Vehicle Manufacturer

Vehicle Model Year

Gross Vehicle Weight (GVW) (Ib.)

Vehicle Total Curb Weight (Ib.)

Vehicle Tested Weight (Ib.)

Odometer Reading (mile)

Transmission Type

Transmission Configuration

Number of Axles

Engine Type

Engine ID Number

Engine Model Year

Engine Displacement (Liter)

Number of Cylinders

Engine Rated Power (hp)

Primary Fuel

Test Cycle

Test Date

Engineer

Driver
Parker-Hannifin

8225 Hacks Cross

Olive Branch MI 38654

Garbage Truck

Base

Autocar

2006

66000

Not Available

56000

26

Auto

5 speed

3

Cummins ISL 330

46514906

2005

9

6

330

D2

SPU

12/12/05

Barnett, Ryan

England, Gary

Emissions Results (g/mile)

Fuel Economy

\begin{tabular}{|c|c|c|c|c|c|c|c|c|c|}
\hline Run Seq. No. & $\mathrm{CO}$ & $\mathrm{NO}^{1}$ & $\mathrm{NO}^{2}$ & FIDHC & PM & $\mathrm{CO}_{2}$ & Mile/gal & BTU/mile & Miles \\
\hline
\end{tabular}


Test Sequence Number: 4561

WVU Test Reference Number: PARKHANN-base-D2-SPU

Fleet Owner Full Name

Fleet Address

Fleet Address (City, State, Zip)

Vehicle Type

Vehicle ID Number (VIN)

Vehicle Manufacturer

Vehicle Model Year

Gross Vehicle Weight (GVW) (lb.)

Vehicle Total Curb Weight (lb.)

Vehicle Tested Weight (Ib.)

Odometer Reading (mile)

Transmission Type

Transmission Configuration

Number of Axles

Engine Type

Engine ID Number

Engine Model Year

Engine Displacement (Liter)

Number of Cylinders

Engine Rated Power (hp)

Primary Fuel

Test Cycle

Test Date

Engineer

Driver
Parker-Hannifin

8225 Hacks Cross

Olive Branch MI 38654

Garbage Truck

Base

Autocar

2006

66000

Not Available

56000

26

Auto

5 speed

3

Cummins ISL 330

46514906

2005

9

6

330

D2

SPU

12/13/05

Barnett, Ryan

England, Gary

Emissions Results (g/mile)

Fuel Economy

\begin{tabular}{|c|c|c|c|c|c|c||c|c|c|}
\hline Run Seq. No. & $\mathrm{CO}$ & $\mathrm{NO}_{\mathrm{x}}{ }^{1}$ & $\mathrm{NO}^{2}$ & $\mathrm{FIDHC}$ & $\mathrm{PM}$ & $\mathrm{CO}_{2}$ & $\mathrm{Mile} / \mathrm{gal}$ & $\mathrm{BTU} / \mathrm{mile}$ & $\mathrm{Miles}$ \\
\hline $4561-3$ & 10.9 & 43.3 & 42.4 & 0.56 & 0.93 & 8437 & 1.19 & 111111 & 1.50 \\
\hline $4561-4$ & 11.3 & 43.9 & 43.2 & 0.44 & 0.93 & 8197 & 1.22 & 107966 & 1.51 \\
\hline $4561-5$ & 11.8 & 44.0 & 43.2 & 0.53 & 0.90 & 8365 & 1.20 & 110181 & 1.49 \\
\hline & & & & & & & & & \\
\hline 4561 Average & 11.3 & 43.7 & 43.0 & 0.51 & 0.92 & 8333 & 1.20 & 109753 & 1.50 \\
\hline Std. Dev. & 0.5 & 0.4 & 0.4 & 0.06 & 0.02 & 123 & 0.02 & 1616 & 0.01 \\
\hline CV\% & 4.1 & 0.9 & & 12.2 & 2.0 & 1.5 & 1.5 & 1.5 & 0.9 \\
\hline
\end{tabular}

x-Not Reportable, a-Outlier, b-HC Not Reportable(Residual HC), c-missing component, d-Coefficient of Variation Too Large, e-below detectable limit 
Test Sequence Number: 4562

\section{WVU Test Reference Number: PARKHANN-base-D2-STC}

Fleet Owner Full Name

Fleet Address

Fleet Address (City, State, Zip)

Vehicle Type

Vehicle ID Number (VIN)

Vehicle Manufacturer

Vehicle Model Year

Gross Vehicle Weight (GVW) (lb.)

Vehicle Total Curb Weight (lb.)

Vehicle Tested Weight (Ib.)

Odometer Reading (mile)

Transmission Type

Transmission Configuration

Number of Axles

Engine Type

Engine ID Number

Engine Model Year

Engine Displacement (Liter)

Number of Cylinders

Engine Rated Power (hp)

Primary Fuel

Test Cycle

Test Date

Engineer

Driver
Parker-Hannifin

8225 Hacks Cross

Olive Branch MI 38654

Garbage Truck

Base

Autocar

2006

66000

Not Available

56000

30

Auto

5 speed

3

Cummins ISL 330

46514906

2005

9

6

330

D2

STC

12/13/05

Barnett, Ryan

England, Gary

Emissions Results (g/mile)

Fuel Economy

\begin{tabular}{|c|c|c|c|c|c|c||c|c|c|}
\hline Run Seq. No. & $\mathrm{CO}$ & $\mathrm{NO}_{\mathrm{x}}{ }^{1}$ & $\mathrm{NO}_{\mathrm{x}}{ }^{2}$ & $\mathrm{FIDHC}$ & $\mathrm{PM}$ & $\mathrm{CO}_{2}$ & Mile/gal & $\mathrm{BTU} / \mathrm{mile}$ & Miles \\
\hline $4562-1$ & 1.79 & 16.4 & 16.4 & 0.12 & 0.59 & 3127 & 3.20 & 41136 & 4.96 \\
\hline $4562-2$ & 1.40 & 16.2 & 16.1 & 0.11 & 0.40 & 3066 & 3.27 & 40327 & 4.96 \\
\hline $4562-3$ & 1.36 & 16.1 & 16.0 & 0.11 & 0.35 & 3042 & 3.29 & 40010 & 4.97 \\
\hline $4562-4$ & 1.34 & 16.4 & 16.2 & 0.11 & 0.33 & 2979 & 3.36 & 39180 & 4.97 \\
\hline & & & & & & & & & \\
\hline 4562 Average & 1.47 & 16.3 & 16.2 & 0.11 & 0.42 & 3054 & 3.28 & 40163 & 4.97 \\
\hline Std. Dev. & 0.21 & 0.2 & 0.2 & 0.01 & 0.12 & 61 & 0.07 & 809 & 0.01 \\
\hline CV\% & 14.3 & 1.0 & & 7.1 & 29.0 & 2.0 & 2.0 & 2.0 & 0.2 \\
\hline
\end{tabular}

x-Not Reportable, a-Outlier, b-HC Not Reportable(Residual HC), c-missing component, d-Coefficient of Variation Too Large, e-below detectable limit 


\section{Test Sequence Number: 4563}

\section{WVU Test Reference Number: PARKHANN-base-D2-HH30}

Fleet Owner Full Name

Fleet Address

Fleet Address (City, State, Zip)

Vehicle Type

Vehicle ID Number (VIN)

Vehicle Manufacturer

Vehicle Model Year

Gross Vehicle Weight (GVW) (Ib.)

Vehicle Total Curb Weight (lb.)

Vehicle Tested Weight (Ib.)

Odometer Reading (mile)

Transmission Type

Transmission Configuration

Number of Axles

Engine Type

Engine ID Number

Engine Model Year

Engine Displacement (Liter)

Number of Cylinders

Engine Rated Power (hp)

Primary Fuel

Test Cycle

Test Date

Engineer

Driver
Parker-Hannifin

8225 Hacks Cross

Olive Branch MI 38654

Garbage Truck

Base

Autocar

2006

66000

Not Available

56000

40

Auto

5 speed

3

Cummins ISL 330

46514906

2005

9

6

330

D2

$\mathrm{HH} 30$

12/13/05

Barnett, Ryan

England, Gary

Emissions Results (g/mile)

Fuel Economy

\begin{tabular}{|c|c|c|c|c|c|c|c|c|c|}
\hline Run Seq. No. & $\mathrm{CO}$ & $\mathrm{NO}{ }^{1}$ & $\mathrm{NO}_{\mathrm{x}}{ }^{2}$ & FIDHC & PM & $\mathrm{CO}_{2}$ & Mile/gal & BTU/mile & Miles \\
\hline 4563-1 & 0.76 & 9.5 & 9.5 & 0.072 & $\begin{array}{ll}- & \text { r }\end{array}$ & 1966 & 5.09 & 25859 & 2.40 \\
\hline
\end{tabular}


Test Sequence Number: 4564

WVU Test Reference Number: PARKHANN-base-D2-HH40

Fleet Owner Full Name

Fleet Address

Fleet Address (City, State, Zip)

Vehicle Type

Vehicle ID Number (VIN)

Vehicle Manufacturer

Vehicle Model Year

Gross Vehicle Weight (GVW) (Ib.)

Vehicle Total Curb Weight (Ib.)

Vehicle Tested Weight (Ib.)

Odometer Reading (mile)

Transmission Type

Transmission Configuration

Number of Axles

Engine Type

Engine ID Number

Engine Model Year

Engine Displacement (Liter)

Number of Cylinders

Engine Rated Power (hp)

Primary Fuel

Test Cycle

Test Date

Engineer

Driver
Parker-Hannifin

8225 Hacks Cross

Olive Branch MI 38654

Garbage Truck

Base

Autocar

2006

66000

Not Available

56000

43

Auto

5 speed

3

Cummins ISL 330

46514906

2005

9

6

330

D2

$\mathrm{HH} 40$

12/13/05

Barnett, Ryan

England, Gary

Emissions Results (g/mile)

Fuel Economy

\begin{tabular}{|c|c|c|c|c|c|c|c|c|c|}
\hline Run Seq. No. & $\mathrm{CO}$ & $\mathrm{NO}_{x}{ }^{1}$ & $\mathrm{NO}_{x}{ }^{2}$ & FIDHC & PM & $\mathrm{CO}_{2}$ & Mile/gal & BTU/mile & Miles \\
\hline $4564-1$ & 1.03 & 10.5 & 10.5 & 0.041 & - & 2204 & 4.54 & 28988 & 3.21 \\
\hline
\end{tabular}




\section{Test Sequence Number: 4565}

\section{WVU Test Reference Number: PARKHANN-base-D2-HH50}

Fleet Owner Full Name

Fleet Address

Fleet Address (City, State, Zip)

Vehicle Type

Vehicle ID Number (VIN)

Vehicle Manufacturer

Vehicle Model Year

Gross Vehicle Weight (GVW) (Ib.)

Vehicle Total Curb Weight (Ib.)

Vehicle Tested Weight (lb.)

Odometer Reading (mile)

Transmission Type

Transmission Configuration

Number of Axles

Engine Type

Engine ID Number

Engine Model Year

Engine Displacement (Liter)

Number of Cylinders

Engine Rated Power (hp)

Primary Fuel

Test Cycle

Test Date

Engineer

Driver
Parker-Hannifin

8225 Hacks Cross

Olive Branch MI 38654

Garbage Truck

Base

Autocar

2006

66000

Not Available

56000

46

Auto

5 speed

3

Cummins ISL 330

46514906

2005

9

6

330

D2

$\mathrm{HH} 50$

12/13/05

Barnett, Ryan

England, Gary

Emissions Results (g/mile)

Fuel Economy

\begin{tabular}{|c|c|c|c|c|c|c|c|c|c|}
\hline Run Seq. No. & $\mathrm{CO}$ & $\mathrm{NO}_{x}{ }^{1}$ & $\mathrm{NO}_{x}{ }^{2}$ & FIDHC & PM & $\mathrm{CO}_{2}$ & mile/gal & BTU/mile & Miles \\
\hline $4565-1$ & 1.70 & 11.4 & 11.4 & 0.092 & - & 2791 & 3.59 & 36708 & 4.00 \\
\hline
\end{tabular}


Test Sequence Number: 4566

WVU Test Reference Number: PARKHANN-base-D2-HH30

Fleet Owner Full Name

Fleet Address

Fleet Address (City, State, Zip)

Vehicle Type

Vehicle ID Number (VIN)

Vehicle Manufacturer

Vehicle Model Year

Gross Vehicle Weight (GVW) (Ib.)

Vehicle Total Curb Weight (Ib.)

Vehicle Tested Weight (Ib.)

Odometer Reading (mile)

Transmission Type

Transmission Configuration

Number of Axles

Engine Type

Engine ID Number

Engine Model Year

Engine Displacement (Liter)

Number of Cylinders

Engine Rated Power (hp)

Primary Fuel

Test Cycle

Test Date

Engineer

Driver
Parker-Hannifin

8225 Hacks Cross

Olive Branch MI 38654

Garbage Truck

Base

Autocar

2006

66000

Not Available

56000

50

Auto

5 speed

3

Cummins ISL 330

46514906

2005

9

6

330

D2

$\mathrm{HH} 30$

12/13/05

Barnett, Ryan

England, Gary

Emissions Results (g/mile)

Fuel Economy

\begin{tabular}{|c|c|c|c|c|c|c|c|c|c|}
\hline Run Seq. No. & $\mathrm{CO}$ & $\mathrm{NO}_{x}{ }^{1}$ & $\mathrm{NO}_{x}{ }^{2}$ & FIDHC & PM & $\mathrm{CO}_{2}$ & mile/gal & BTU/mile & Miles \\
\hline $4566-1$ & 3.71 & 42.6 & 42.6 & 0.28 & - & 7763 & 1.29 & 102092 & 0.41 \\
\hline
\end{tabular}


Test Sequence Number: 4567

WVU Test Reference Number: PARKHANN-base-D2-backgnd

Fleet Owner Full Name

Fleet Address

Fleet Address (City, State, Zip)

Vehicle Type

Vehicle ID Number (VIN)

Vehicle Manufacturer

Vehicle Model Year

Gross Vehicle Weight (GVW) (Ib.)

Vehicle Total Curb Weight (lb.)

Vehicle Tested Weight (lb.)

Odometer Reading (mile)

Transmission Type

Transmission Configuration

Number of Axles

Engine Type

Engine ID Number

Engine Model Year

Engine Displacement (Liter)

Number of Cylinders

Engine Rated Power (hp)

Primary Fuel

Test Cycle

Test Date

Engineer

Driver
Parker-Hannifin

8225 Hacks Cross

Olive Branch MI 38654

Garbage Truck

Base

Autocar

2006

66000

Not Available

56000

Auto

5 speed

3

Cummins ISL 330

46514906

2005

9

6

330

D2

backgnd

12/13/05

Barnett, Ryan

England, Gary

Emissions Results (Total grams)

Fuel Economy

\begin{tabular}{|c|c|c|c|c|c|c|c|c|c|}
\hline Run Seq. No. & $\mathrm{CO}$ & $\mathrm{NO}^{1}$ & $\mathrm{NO}_{x}{ }^{2}$ & FIDHC & PM & $\mathrm{CO}_{2}$ & mile/gal & Total BTU & Miles \\
\hline $4567-1$ & 0.14 & 1.2 & 1.3 & 0.49 & 0.0008 & 251 & 0.22 & 3320 & 0.01 \\
\hline
\end{tabular}


Test Sequence Number: 4568

WVU Test Reference Number: PARKHANN-hybrid-D2-SPU

Fleet Owner Full Name

Fleet Address

Fleet Address (City, State, Zip)

Vehicle Type

Vehicle ID Number (VIN)

Vehicle Manufacturer

Vehicle Model Year

Gross Vehicle Weight (GVW) (lb.)

Vehicle Total Curb Weight (lb.)

Vehicle Tested Weight (Ib.)

Odometer Reading (mile)

Transmission Type

Transmission Configuration

Number of Axles

Engine Type

Engine ID Number

Engine Model Year

Engine Displacement (Liter)

Number of Cylinders

Engine Rated Power (hp)

Primary Fuel

Test Cycle

Test Date

Engineer

Driver
Parker-Hannifin

8225 Hacks Cross

Olive Branch MI 38654

Garbage Truck

Q0000945

Autocar

2006

66000

Not Available

56000

Auto

2 speed

3

Cummins ISC 315

Missing Tag

2005

8

6

315

D2

SPU

12/14/05

Barnett, Ryan

England, Gary

Emissions Results (g/mile)

Fuel Economy

\begin{tabular}{|c|c|c|c|c|c|c||c|c|c|}
\hline Run Seq. No. & $\mathrm{CO}$ & $\mathrm{NO}_{\mathrm{x}}{ }^{1}$ & $\mathrm{NO}_{\mathrm{x}}{ }^{2}$ & $\mathrm{FIDHC}$ & $\mathrm{PM}$ & $\mathrm{CO}_{2}$ & $\mathrm{mile} / \mathrm{gal}$ & $\mathrm{BTU} / \mathrm{mile}$ & $\mathrm{Miles}$ \\
\hline $4568-1$ & 0.62 & 62.4 & 62.3 & 0.62 & - & 11889 & 0.84 & 156263 & 1.36 \\
\hline
\end{tabular}

x-Not Reportable, a-Outlier, b-HC Not Reportable(Residual HC), c-missing component, d-Coefficient of Variation Too Large, e-below detectable limit Test Purpose:

testing of Parker Hannifin hybrid 


\section{Test Sequence Number: 4569}

\section{WVU Test Reference Number: PARKHANN-hybrid-D2-SPU}

Fleet Owner Full Name

Fleet Address

Fleet Address (City, State, Zip)

Vehicle Type

Vehicle ID Number (VIN)

Vehicle Manufacturer

Vehicle Model Year

Gross Vehicle Weight (GVW) (Ib.)

Vehicle Total Curb Weight (lb.)

Vehicle Tested Weight (lb.)

Odometer Reading (mile)

Transmission Type

Transmission Configuration

Number of Axles

Engine Type

Engine ID Number

Engine Model Year

Engine Displacement (Liter)

Number of Cylinders

Engine Rated Power (hp)

Primary Fuel

Test Cycle

Test Date

Engineer

Driver
Parker-Hannifin

8225 Hacks Cross

Olive Branch MI 38654

Garbage Truck

Q0000945

Autocar

2006

66000

Not Available

56000

Auto

2 speed

3

Cummins ISC 315

Missing Tag

2005

8

6

315

D2

SPU

12/15/05

Barnett, Ryan

England, Gary

Emissions Results (g/mile)

Fuel Economy

\begin{tabular}{|c|c|c|c|c|c|c|c|c|c|}
\hline Run Seq. No. & $\mathrm{CO}$ & $\mathrm{NO}_{x}{ }^{1}$ & $\mathrm{NO}_{\mathrm{x}}{ }^{2}$ & FIDHC & PM & $\mathrm{CO}_{2}$ & mile/gal & BTU/mile & Miles \\
\hline $4569-1$ & $\begin{array}{ll}- & \text { r }\end{array}$ & 55.0 & 55.1 & 2.65 & - & - & - & - & 1.53 \\
\hline
\end{tabular}

Test Purpose:

testing of Parker Hannifin hybrid 


\section{Test Sequence Number: $\mathbf{4 5 7 0}$}

\section{WVU Test Reference Number: PARKHANN-hybrid-D2-SPU}

Fleet Owner Full Name

Fleet Address

Fleet Address (City, State, Zip)

Vehicle Type

Vehicle ID Number (VIN)

Vehicle Manufacturer

Vehicle Model Year

Gross Vehicle Weight (GVW) (lb.)

Vehicle Total Curb Weight (lb.)

Vehicle Tested Weight (Ib.)

Odometer Reading (mile)

Transmission Type

Transmission Configuration

Number of Axles

Engine Type

Engine ID Number

Engine Model Year

Engine Displacement (Liter)

Number of Cylinders

Engine Rated Power (hp)

Primary Fuel

Test Cycle

Test Date

Engineer

Driver
Parker-Hannifin

8225 Hacks Cross

Olive Branch MI 38654

Garbage Truck

Q0000945

Autocar

2006

66000

Not Available

40000

Auto

2 speed

3

Cummins ISC 315

Missing Tag

2005

8

6

315

D2

SPU

$12 / 16 / 05$

Barnett, Ryan

England, Gary

Emissions Results (g/mile)

Fuel Economy

\begin{tabular}{|c|c|c|c|c|c|c||c|c|c|}
\hline Run Seq. No. & $\mathrm{CO}$ & $\mathrm{NO}_{\mathrm{x}}{ }^{1}$ & $\mathrm{NO}_{\mathrm{x}}{ }^{2}$ & $\mathrm{FIDHC}$ & $\mathrm{PM}$ & $\mathrm{CO}_{2}$ & $\mathrm{mile} / \mathrm{gal}$ & $\mathrm{BTU} / \mathrm{mile}$ & $\mathrm{Miles}$ \\
\hline $4570-3$ & 1.27 & 32.3 & 32.6 & 0.14 & 2.31 & 8186 & 1.22 & 107595 & 1.46 \\
\hline $4570-4$ & 1.32 & 33.3 & 31.1 & 0.17 & 2.25 & 8289 & 1.21 & 108961 & 1.45 \\
\hline $4570-5$ & 1.35 & 32.8 & 30.7 & 0.41 & 2.22 & 8263 & 1.21 & 108622 & 1.45 \\
\hline & & & & & & & & & \\
\hline 4570 Average & 1.31 & 32.8 & 31.5 & 0.24 & 2.26 & 8246 & 1.22 & 108393 & 1.45 \\
\hline Std. Dev. & 0.04 & 0.5 & 1.0 & 0.15 & 0.04 & 54 & 0.01 & 711 & 0.00 \\
\hline CV\% & 3.0 & 1.6 & & 60.9 & 1.9 & 0.7 & 0.7 & 0.7 & 0.3 \\
\hline
\end{tabular}

x-Not Reportable, a-Outlier, b-HC Not Reportable(Residual HC), c-missing component, d-Coefficient of Variation Too Large, e-below detectable limit Test Purpose:

testing of Parker Hannifin hybrid

\section{Special Procedures:}

had trouble attaining a few ramps

Observations:

Run 3 in NOx mode, 4 and 5 NO/NOx split 
Test Sequence Number: 4571

WVU Test Reference Number: PARKHANN-hybrid-D2-STC

Fleet Owner Full Name

Fleet Address

Fleet Address (City, State, Zip)

Vehicle Type

Vehicle ID Number (VIN)

Vehicle Manufacturer

Vehicle Model Year

Gross Vehicle Weight (GVW) (lb.)

Vehicle Total Curb Weight (lb.)

Vehicle Tested Weight (lb.)

Odometer Reading (mile)

Transmission Type

Transmission Configuration

Number of Axles

Engine Type

Engine ID Number

Engine Model Year

Engine Displacement (Liter)

Number of Cylinders

Engine Rated Power (hp)

Primary Fuel

Test Cycle

Test Date

Engineer

Driver
Parker-Hannifin

8225 Hacks Cross

Olive Branch MI 38654

Garbage Truck

Q0000945

Autocar

2006

66000

Not Available

40000

Auto

2 speed

3

Cummins ISC 315

Missing Tag

2005

8

6

315

D2

STC

$12 / 16 / 05$

Barnett, Ryan

England, Gary

Emissions Results (g/mile)

\begin{tabular}{|c|c|c|c|c|c|c||c|c|c|}
\hline Run Seq. No. & $\mathrm{CO}$ & $\mathrm{NO}^{1}$ & $\mathrm{NO}^{2}$ & $\mathrm{FIDHC}$ & $\mathrm{PM}$ & $\mathrm{CO}_{2}$ & $\mathrm{mile} / \mathrm{gal}$ & $\mathrm{BTU} / \mathrm{mile}$ & $\mathrm{Miles}$ \\
\hline $4571-1$ & 1.38 & 17.6 & 17.6 & 0.43 & 1.15 & 4843 & 2.07 & 63688 & 2.07 \\
\hline $4571-2$ & 0.52 & 14.5 & 14.4 & 0.12 & 0.87 & 3305 & 3.03 & 43440 & 4.35 \\
\hline $4571-3$ & 0.34 & 15.6 & 14.0 & 0.09 & 0.63 & 3307 & 3.03 & 43467 & 3.47 \\
\hline & & & & & & & & & \\
\hline 4571 Average & 0.74 & 15.9 & 15.3 & 0.21 & 0.89 & 3818 & 2.71 & 50198 & 3.29 \\
\hline Std. Dev. & 0.56 & 1.6 & 2.0 & 0.18 & 0.26 & 888 & 0.56 & 11682 & 1.15 \\
\hline CV\% & 74.8 & 10.2 & & 86.8 & 29.4 & 23.2 & 20.5 & 23.3 & 34.9 \\
\hline
\end{tabular}

x-Not Reportable, a-Outlier, b-HC Not Reportable(Residual HC), c-missing component, d-Coefficient of Variation Too Large, e-below detectable limit Test Purpose:

testing of Parker Hannifin hybrid

Special Procedures:

truck had shifting problems and could not attain ramps 


\section{Test Sequence Number: 4572}

\section{WVU Test Reference Number: PARKHANN-hybrid-D2-HH30}

Fleet Owner Full Name

Fleet Address

Fleet Address (City, State, Zip)

Vehicle Type

Vehicle ID Number (VIN)

Vehicle Manufacturer

Vehicle Model Year

Gross Vehicle Weight (GVW) (lb.)

Vehicle Total Curb Weight (lb.)

Vehicle Tested Weight (Ib.)

Odometer Reading (mile)

Transmission Type

Transmission Configuration

Number of Axles

Engine Type

Engine ID Number

Engine Model Year

Engine Displacement (Liter)

Number of Cylinders

Engine Rated Power (hp)

Primary Fuel

Test Cycle

Test Date

Engineer

Driver
Parker-Hannifin

8225 Hacks Cross

Olive Branch MI 38654

Garbage Truck
Q0000945
Autocar
2006
66000
Not Available
40000
Auto
2 speed
3
Cummins ISC 315
Missing Tag
2005

8

6

315

D2

$\mathrm{HH} 30$

$12 / 16 / 05$

Barnett, Ryan

England, Gary

Emissions Results (g/mile)

Fuel Economy

\begin{tabular}{|c|c|c|c|c|c|c|c|c|c|}
\hline Run Seq. No. & $\mathrm{CO}$ & $\mathrm{NO}_{x}{ }^{1}$ & $\mathrm{NO}_{x}{ }^{2}$ & FIDHC & PM & $\mathrm{CO}_{2}$ & mile/gal & BTU/mile & Miles \\
\hline $4572-1$ & 0.20 & 10.8 & 9.9 & 0.041 & - & 3142 & 3.19 & 41299 & 2.41 \\
\hline
\end{tabular}

x-Not Reportable, a-Outlier, b-HC Not Reportable(Residual HC), c-missing component, d-Coefficient of Variation Too Large, e-below detectable limit Test Purpose:

testing of Parker Hannifin hybrid 


\section{Test Sequence Number: 4573}

\section{WVU Test Reference Number: PARKHANN-hybrid-D2-HH40}

Fleet Owner Full Name

Fleet Address

Fleet Address (City, State, Zip)

Vehicle Type

Vehicle ID Number (VIN)

Vehicle Manufacturer

Vehicle Model Year

Gross Vehicle Weight (GVW) (lb.)

Vehicle Total Curb Weight (lb.)

Vehicle Tested Weight (Ib.)

Odometer Reading (mile)

Transmission Type

Transmission Configuration

Number of Axles

Engine Type

Engine ID Number

Engine Model Year

Engine Displacement (Liter)

Number of Cylinders

Engine Rated Power (hp)

Primary Fuel

Test Cycle

Test Date

Engineer

Driver
Parker-Hannifin

8225 Hacks Cross

Olive Branch MI 38654

Garbage Truck

Q0000945

Autocar

2006

66000

Not Available

40000

Auto

2 speed

3

Cummins ISC 315

Missing Tag

2005

8

6

315

D2

$\mathrm{HH} 40$

$12 / 16 / 05$

Barnett, Ryan

England, Gary

Emissions Results (g/mile)

Fuel Economy

\begin{tabular}{|c|c|c|c|c|c|c||c|c|c|}
\hline Run Seq. No. & $\mathrm{CO}$ & $\mathrm{NO}^{1}$ & $\mathrm{NO}^{2}$ & $\mathrm{FIDHC}$ & $\mathrm{PM}$ & $\mathrm{CO}_{2}$ & $\mathrm{mile} / \mathrm{gal}$ & $\mathrm{BTU} / \mathrm{mile}$ & $\mathrm{Miles}$ \\
\hline $4573-1$ & 0.12 & 9.6 & 9.6 & 0.032 & - & 2325 & 4.31 & 30559 & 3.06 \\
\hline
\end{tabular}

x-Not Reportable, a-Outlier, b-HC Not Reportable(Residual HC), c-missing component, d-Coefficient of Variation Too Large, e-below detectable limit Test Purpose:

testing of Parker Hannifin hybrid 


\section{Test Sequence Number: 4574}

\section{WVU Test Reference Number: PARKHANN-hybrid-D2-HH50}

Fleet Owner Full Name

Fleet Address

Fleet Address (City, State, Zip)

Vehicle Type

Vehicle ID Number (VIN)

Vehicle Manufacturer

Vehicle Model Year

Gross Vehicle Weight (GVW) (Ib.)

Vehicle Total Curb Weight (lb.)

Vehicle Tested Weight (lb.)

Odometer Reading (mile)

Transmission Type

Transmission Configuration

Number of Axles

Engine Type

Engine ID Number

Engine Model Year

Engine Displacement (Liter)

Number of Cylinders

Engine Rated Power (hp)

Primary Fuel

Test Cycle

Test Date

Engineer

Driver
Parker-Hannifin

8225 Hacks Cross

Olive Branch MI 38654

Garbage Truck

Q0000945

Autocar

2006

66000

Not Available

40000

Auto

2 speed

3

Cummins ISC 315

Missing Tag

2005

8

6

315

D2

$\mathrm{HH} 50$

$12 / 16 / 05$

Barnett, Ryan

England, Gary

Emissions Results (g/mile)

Fuel Economy

\begin{tabular}{|c|c|c|c|c|c|c||c|c|c|}
\hline Run Seq. No. & $\mathrm{CO}$ & $\mathrm{NO}_{\mathrm{x}}{ }^{1}$ & $\mathrm{NO}_{\mathrm{x}}{ }^{2}$ & $\mathrm{FIDHC}$ & $\mathrm{PM}$ & $\mathrm{CO}_{2}$ & $\mathrm{mile} / \mathrm{gal}$ & $\mathrm{BTU} / \mathrm{mile}$ & Miles \\
\hline $4574-1$ & 0.18 & 21.2 & 21.2 & 0.074 & - & 4994 & 2.01 & 65625 & 0.91 \\
\hline
\end{tabular}

x-Not Reportable, a-Outlier, b-HC Not Reportable(Residual HC), c-missing component, d-Coefficient of Variation Too Large, e-below detectable limit Test Purpose:

testing of Parker Hannifin hybrid

\section{Special Procedures:}

gradeability performance test 


\section{Test Sequence Number: 4576}

\section{WVU Test Reference Number: PARKHANN-base-D2-SPU}

Fleet Owner Full Name

Fleet Address

Fleet Address (City, State, Zip)

Vehicle Type

Vehicle ID Number (VIN)

Vehicle Manufacturer

Vehicle Model Year

Gross Vehicle Weight (GVW) (lb.)

Vehicle Total Curb Weight (lb.)

Vehicle Tested Weight (lb.)

Odometer Reading (mile)

Transmission Type

Transmission Configuration

Number of Axles

Engine Type

Engine ID Number

Engine Model Year

Engine Displacement (Liter)

Number of Cylinders

Engine Rated Power (hp)

Primary Fuel

Test Cycle

Test Date

Engineer

Driver
Parker-Hannifin

8225 Hacks Cross

Olive Branch MI 38654

Garbage Truck

5VCHC6MF96H202523

Autocar

2006

66000

Not Available

40000

Auto

5 speed

3

Cummins ISL 330

46514906

2005

9

6

330

D2

SPU

$12 / 17 / 05$

Barnett, Ryan

England, Gary

Emissions Results (g/mile)

Fuel Economy

\begin{tabular}{|c|c|c|c|c|c|c||c|c|c|}
\hline Run Seq. No. & $\mathrm{CO}$ & $\mathrm{NO}_{\mathrm{x}}{ }^{1}$ & $\mathrm{NO}_{\mathrm{x}}{ }^{2}$ & $\mathrm{FIDHC}$ & $\mathrm{PM}$ & $\mathrm{CO}_{2}$ & $\mathrm{mile} / \mathrm{gal}$ & $\mathrm{BTU} / \mathrm{mile}$ & $\mathrm{Miles}$ \\
\hline $4576-1$ & 24.5 & 34.9 & 35.2 & 0.98 & - & 6352 & 1.57 & 84012 & 1.52 \\
\hline $4576-2$ & 23.3 & 35.7 & 35.5 & 0.98 & 1.07 & 6365 & 1.57 & 84158 & 1.50 \\
\hline $4576-3$ & 25.0 & 35.9 & 35.6 & 0.82 & 0.73 & 6417 & 1.55 & 84880 & 1.52 \\
\hline $4576-4$ & 23.9 & 35.5 & 35.1 & 0.85 & 0.73 & 6385 & 1.56 & 84433 & 1.51 \\
\hline $4576-5$ & 23.4 & 35.6 & 35.0 & 0.76 & 0.73 & 6430 & 1.55 & 85007 & 1.51 \\
\hline & & & & & & & & & \\
\hline 4576 Average & 24.0 & 35.5 & 35.3 & 0.88 & 0.65 & 6390 & 1.56 & 84498 & 1.51 \\
\hline Std. Dev. & 0.7 & 0.4 & 0.2 & 0.10 & 0.39 & 33 & 0.01 & 436 & 0.01 \\
\hline CV\% & 3.1 & 1.0 & & 11.3 & 60.2 & 0.5 & 0.5 & 0.5 & 0.5 \\
\hline
\end{tabular}

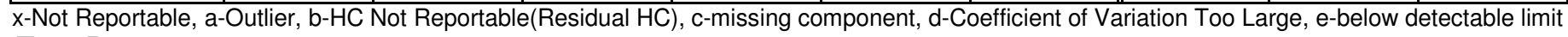
Test Purpose:

Restesting of Parker Hannifin baseline truck at $40000 \mathrm{lbs}$

\section{Special Procedures:}

runs 1 and 2 are warmups (we broke a through shaft), run 3 is NOx mode, runs 4 and 5 are NO/NOx split 
Test Sequence Number: 4577

\section{WVU Test Reference Number: PARKHANN-base-D2-STC}

Fleet Owner Full Name

Fleet Address

Fleet Address (City, State, Zip)

Vehicle Type

Vehicle ID Number (VIN)

Vehicle Manufacturer

Vehicle Model Year

Gross Vehicle Weight (GVW) (lb.)

Vehicle Total Curb Weight (lb.)

Vehicle Tested Weight (lb.)

Odometer Reading (mile)

Transmission Type

Transmission Configuration

Number of Axles

Engine Type

Engine ID Number

Engine Model Year

Engine Displacement (Liter)

Number of Cylinders

Engine Rated Power (hp)

Primary Fuel

Test Cycle

Test Date

Engineer

Driver
Parker-Hannifin

8225 Hacks Cross

Olive Branch MI 38654

Garbage Truck

5VCHC6MF96H202523

Autocar

2006

66000

Not Available

40000

Auto

5 speed

3

Cummins ISL 330

46514906

2005

9

6

330

D2

STC

12/17/05

Barnett, Ryan

England, Gary

Emissions Results (g/mile)

Fuel Economy

\begin{tabular}{|c|c|c|c|c|c|c||c|c|c|}
\hline Run Seq. No. & $\mathrm{CO}$ & $\mathrm{NO}^{1}$ & $\mathrm{NO}^{2}$ & $\mathrm{FIDHC}$ & $\mathrm{PM}$ & $\mathrm{CO}_{2}$ & $\mathrm{mile} / \mathrm{gal}$ & $\mathrm{BTU} / \mathrm{mile}$ & $\mathrm{Miles}$ \\
\hline $4577-1$ & 1.79 & 13.5 & 13.5 & 0.14 & 0.50 & 2740 & 3.66 & 36041 & 4.99 \\
\hline $4577-2$ & 1.46 & 13.3 & 13.2 & 0.11 & 0.28 & 2667 & 3.76 & 35077 & 5.00 \\
\hline $4577-3$ & 1.42 & 13.2 & 13.1 & 0.11 & 0.27 & 2642 & 3.79 & 34749 & 5.00 \\
\hline & & & & & & & & & \\
\hline 4577 Average & 1.56 & 13.3 & 13.3 & 0.12 & 0.35 & 2683 & 3.73 & 35289 & 4.99 \\
\hline Std. Dev. & 0.21 & 0.2 & 0.2 & 0.02 & 0.13 & 51 & 0.07 & 672 & 0.01 \\
\hline CV\% & 13.2 & 1.2 & & 14.5 & 36.7 & 1.9 & 1.9 & 1.9 & 0.1 \\
\hline
\end{tabular}

x-Not Reportable, a-Outlier, b-HC Not Reportable(Residual HC), c-missing component, d-Coefficient of Variation Too Large, e-below detectable limit Test Purpose:

Restesting of Parker Hannifin baseline truck at $40000 \mathrm{lbs}$

\section{Special Procedures:}

run 1 is NOx mode, runs 2 and 3 are NO/NOx split 


\section{Test Sequence Number: 4578}

WVU Test Reference Number: PARKHANN-base-D2-HH30

Fleet Owner Full Name

Fleet Address

Fleet Address (City, State, Zip)

Vehicle Type

Vehicle ID Number (VIN)

Vehicle Manufacturer

Vehicle Model Year

Gross Vehicle Weight (GVW) (lb.)

Vehicle Total Curb Weight (lb.)

Vehicle Tested Weight (lb.)

Odometer Reading (mile)

Transmission Type

Transmission Configuration

Number of Axles

Engine Type

Engine ID Number

Engine Model Year

Engine Displacement (Liter)

Number of Cylinders

Engine Rated Power (hp)

Primary Fuel

Test Cycle

Test Date

Engineer

Driver
Parker-Hannifin

8225 Hacks Cross

Olive Branch MI 38654

Garbage Truck

5VCHC6MF96H202523

Autocar

2006

66000

Not Available

40000

Auto

5 speed

3

Cummins ISL 330

46514906

2005

9

6

330

D2

$\mathrm{HH} 30$

$12 / 17 / 05$

Barnett, Ryan

England, Gary

Emissions Results (g/mile)

Fuel Economy

\begin{tabular}{|c|c|c|c|c|c|c|c|c|c|}
\hline Run Seq. No. & $\mathrm{CO}$ & $\mathrm{NO}_{x}{ }^{1}$ & $\mathrm{NO}_{x}{ }^{2}$ & FIDHC & PM & $\mathrm{CO}_{2}$ & mile/gal & BTU/mile & Miles \\
\hline $4578-1$ & 1.06 & 8.3 & 8.3 & 0.072 & - & 1714 & 5.84 & 22541 & 2.40 \\
\hline
\end{tabular}




\section{Test Sequence Number: 4579}

WVU Test Reference Number: PARKHANN-base-D2-HH40

Fleet Owner Full Name

Fleet Address

Fleet Address (City, State, Zip)

Vehicle Type

Vehicle ID Number (VIN)

Vehicle Manufacturer

Vehicle Model Year

Gross Vehicle Weight (GVW) (Ib.)

Vehicle Total Curb Weight (lb.)

Vehicle Tested Weight (lb.)

Odometer Reading (mile)

Transmission Type

Transmission Configuration

Number of Axles

Engine Type

Engine ID Number

Engine Model Year

Engine Displacement (Liter)

Number of Cylinders

Engine Rated Power (hp)

Primary Fuel

Test Cycle

Test Date

Engineer

Driver
Parker-Hannifin

8225 Hacks Cross

Olive Branch MI 38654

Garbage Truck

5VCHC6MF96H202523

Autocar

2006

66000

Not Available

40000

Auto

5 speed

3

Cummins ISL 330

46514906

2005

9

6

330

D2

$\mathrm{HH} 40$

$12 / 17 / 05$

Barnett, Ryan

England, Gary

Emissions Results (g/mile)

Fuel Economy

\begin{tabular}{|c|c|c|c|c|c|c|c|c|c|}
\hline Run Seq. No. & $\mathrm{CO}$ & $\mathrm{NO}_{x}{ }^{1}$ & $\mathrm{NO}_{x}{ }^{2}$ & FIDHC & PM & $\mathrm{CO}_{2}$ & mile/gal & BTU/mile & Miles \\
\hline $4579-1$ & 0.87 & 9.9 & 9.9 & 0.046 & - & 1922 & 5.21 & 25270 & 3.21 \\
\hline
\end{tabular}


Test Sequence Number: 4580

WVU Test Reference Number: PARKHANN-base-D2-HH50

Fleet Owner Full Name

Fleet Address

Fleet Address (City, State, Zip)

Vehicle Type

Vehicle ID Number (VIN)

Vehicle Manufacturer

Vehicle Model Year

Gross Vehicle Weight (GVW) (Ib.)

Vehicle Total Curb Weight (lb.)

Vehicle Tested Weight (lb.)

Odometer Reading (mile)

Transmission Type

Transmission Configuration

Number of Axles

Engine Type

Engine ID Number

Engine Model Year

Engine Displacement (Liter)

Number of Cylinders

Engine Rated Power (hp)

Primary Fuel

Test Cycle

Test Date

Engineer

Driver
Parker-Hannifin

8225 Hacks Cross

Olive Branch MI 38654

Garbage Truck

5VCHC6MF96H202523

Autocar

2006

66000

Not Available

40000

Auto

5 speed

3

Cummins ISL 330

46514906

2005

9

6

330

D2

$\mathrm{HH} 50$

$12 / 17 / 05$

Barnett, Ryan

England, Gary

Emissions Results (g/mile)

Fuel Economy

\begin{tabular}{|c|c|c|c|c|c|c|c|c|c|}
\hline Run Seq. No. & $\mathrm{CO}$ & $\mathrm{NO}_{x}{ }^{1}$ & $\mathrm{NO}_{x}{ }^{2}$ & FIDHC & PM & $\mathrm{CO}_{2}$ & mile/gal & BTU/mile & Miles \\
\hline $4580-1$ & 2.08 & 10.0 & 9.9 & 0.096 & - & 2529 & 3.96 & 33279 & 4.01 \\
\hline
\end{tabular}


